\title{
Fluid-Rock Interaction: A Reactive Transport Approach
}

\author{
${ }^{1}$ Carl I. Steefel and ${ }^{2}$ Kate Maher \\ ${ }^{1}$ Earth Sciences Division \\ Lawrence Berkeley National Laboratory \\ Berkeley, California 94720, USA \\ ${ }^{2}$ Dept. of Geological \& Environmental Sciences \\ School of Earth Sciences \\ Stanford University \\ Stanford, California 94305, USA
}

\section{INTRODUCTION}

Fluid-rock interaction (or water-rock interaction, as it was more commonly known) is a subject that has evolved considerably in its scope over the years. Initially its focus was primarily on interactions between subsurface fluids of various temperatures and mostly crystalline rocks, but the scope has broadened now to include fluid interaction with all forms of subsurface materials, whether they are unconsolidated or crystalline ("fluid-solid interaction" is perhaps less euphonious). Disciplines that previously carried their own distinct names, for example, basin diagenesis, early diagenesis, metamorphic petrology, reactive contaminant transport, chemical weathering, are now considered to fall under the broader rubric of fluid-rock interaction, although certainly some of the key research questions differ depending on the environment considered.

Beyond the broadening of the environments considered in the study of fluid-rock interaction, the discipline has evolved in perhaps an even more important way. The study of water-rock interaction began by focusing on geochemical interactions in the absence of transport processes, although a few notable exceptions exist (Thompson 1959; Weare et al. 1976). Moreover, these analyses began by adopting a primarily thermodynamic approach, with the implicit or explicit assumption of equilibrium between the fluid and rock. As a result, these early models were fundamentally static rather than dynamic in nature. This all changed with the seminal papers by Helgeson and his co-workers (Helgeson 1968; Helgeson et al. 1969) wherein the concept of an irreversible reaction path was formally introduced into the geochemical literature. In addition to treating the reaction network as a dynamically evolving system, the Helgeson studies introduced an approach that allowed for the consideration of a multicomponent geochemical system, with multiple minerals and species appearing as both reactants and products, at least one of which could be irreversible. Helgeson's pioneering approach was given a more formal kinetic basis (including the introduction of real time rather than reaction progress as the independent variable) in subsequent studies (Lasaga 1981; Aagaard and Helgeson 1982; Lasaga 1984). The reaction path approach can be used to describe chemical processes in a batch or closed system (e.g., a 
laboratory beaker), but such systems are of limited interest in the Earth sciences where the driving force for most reactions is transport. Lichtner (1988) clarified the application of the reaction path models to water-rock interaction involving transport by demonstrating that they could be used to describe pure advective transport through porous media. By adopting a reference frame which followed the fluid packet as it moved through the medium, the reaction progress variable could be thought of as travel time instead.

Multi-component reactive transport models that could treat any combination of transport and biogeochemical processes date back to the early 1980s. Berner and his students applied continuum reactive transport models to describe processes taking place during the early diagenesis of marine sediments (Berner 1980). Lichtner (1985) outlined much of the basic theory for a continuum model for multicomponent reactive transport. Yeh and Tripathi (1989) also presented the theoretical and numerical basis for the treatment of reactive contaminant transport. Steefel and Lasaga (1994) presented a reactive flow and transport model for nonisothermal, kinetically-controlled water-rock interaction and fracture sealing in hydrothermal systems based on simultaneous numerical solution of both reaction and transport

This chapter begins with a review of the important transport processes that affect or even control fluid-rock interaction. This is followed by a general introduction to the governing equations for reactive transport, which are broadly applicable to both qualitative and quantitative interpretations of fluid-rock interactions. This framework is expanded through a discussion of specific topics that are the focus of current research, or are either incompletely understood or not fully appreciated. At this point, the focus shifts to a brief discussion of the three major approaches to modeling multi-scale porous media 1) continuum models, 2) pore scale and pore network models, and 3) hybrid or multi-continuum models. From here, the chapter proceeds to investigate some case studies which illuminate the power of modern numerical reactive transport modeling in deciphering fluid-rock interaction.

\section{TRANSPORT PROCESSES}

Transport is a fundamental part of the fluid-rock interaction process for two reasons: 1) it provides the driving force for many of the reactions that take place by continuously introducing fluid out of equilibrium with respect to the reactive solid phase, and 2) it provides a characteristic time scale to be compared with the rates of reaction. In a batch system, the time scale of interest is the time over which equilibrium is achieved (where net reaction rates are, by definition, $=0$ ), or rates become so slow that the system effectively no longer changes. In an open system, a good laboratory analogue of which is the continuously stirred tank reactor (CSTR) or well-mixed flowthrough reactor, the continuous injection of solution that is out of equilibrium (either with itself, or with a solid phase inside the reactor) causes the solution composition coming out of the reactor to reach a steady-state. If the residence time in the CSTR is long enough, equilibrium between the solution and solid phase may be achieved - otherwise, the solution and solid phase may remain some distance from equilibrium at steady state. The steady state behavior is controlled by the ratio of the characteristic fluid residence time, $\tau_{\text {res }}$, to the characteristic reaction time, $\tau_{\text {react }}$

$$
\frac{\tau_{\text {res }}}{\tau_{\text {react }}}=\frac{k V}{Q} .
$$


where

$$
\begin{aligned}
& \mathrm{k}=\text { reaction rate constant }\left(\mathrm{s}^{-1}\right) \\
& \mathrm{Q}=\text { volumetric flow rate }\left(\mathrm{cm}^{3} \mathrm{~s}^{-1}\right) \\
& \mathrm{V}=\text { volume of reactor }\left(\mathrm{cm}^{3}\right)
\end{aligned}
$$

From this simple analysis, it should be clear that the approach to equilibrium has nothing to do with geologic time, but is controlled instead by the ratio of the characteristic residence (or transport) time and reaction time in the reactor. Similar concepts apply in the more complicated case of flow and transport through porous media, although the detailed transport processes require additional discussion.

The continuously stirred tank reactor provides perhaps the simplest example where rates of transport can be compared to rates of reaction. But in porous and/or fractured media, reactions can be driven by a variety of transport processes and changes in porosity, mineral saturation states and mineral abundances can be distributed along a flow path. The most important of these transport processes are advection, molecular diffusion, and mechanical dispersion. Although widely neglected, electrochemical migration is a flux created by the diffusion of charged species at differing rates which may be important in some cases. Below, these transport processes are defined mathematically in terms of fluxes, that is, the amount of solute passing through a unit area per unit time.

\section{Advection}

Advection involves the translation in space of dissolved or suspended material at the rate of movement of the bulk fluid phase. No modification of the shape of a front and no dilution occurs when transport is purely via advection - a sharp front remains so when undergoing purely advective transport. The advective flux, $J_{a d v}$, of a dissolved species in porous media can be described mathematically as

$$
J_{a d v}=\phi v C_{i},
$$

where $\phi$ is the porosity, $v$ is the average linear velocity in the media, and $C_{i}$ is the concentration of the $i$ th species. In most (but not all) examples of water-rock interaction, flow is through a porous medium and is described with Darcy's Law.

\section{Darcy's Law}

The fluid velocity in porous and fractured media is usually calculated from Darcy's Law, which states that the volumetric flux of water $\left(\mathrm{m}^{3}\right.$ fluid $\left./ \mathrm{m}^{2}{ }_{\text {medium }} / \mathrm{s}\right), \mathbf{q}$, is a vector proportional to the gradient in the hydraulic head, $h$

$$
\mathbf{q}=\phi \mathbf{v}=-\mathbf{K} \nabla h,
$$

where $\mathbf{K}$ is the hydraulic conductivity (here a second-order tensor) in units of $\mathrm{m} / \mathrm{s}$ (Darcy 1856). One can also write Darcy's Law in terms of fluid pressure by defining the hydraulic head as

$$
h=z+\frac{P}{\rho g},
$$

where $z$ is the depth, $P$ is the fluid pressure, $\rho$ is the fluid density, and $g$ is the acceleration due to gravity. The hydraulic conductivity is defined as 


$$
\mathbf{K}=\frac{\mathbf{\kappa} \rho g}{\mu},
$$

where $\boldsymbol{\kappa}$ is the permeability and $\mu$ is the dynamic viscosity. One can also write Darcy's Law explicitly in terms of the fluid pressure, permeability, and the viscosity

$$
\mathbf{q}=\phi \mathbf{v}=-\frac{\mathbf{\kappa}}{\mu}[\nabla P-\rho \mathbf{g}]
$$

Darcy's Law is applied where the porous medium can be treated as a continuum in which a representative elementary volume (REV) is significantly larger than the average grain size. In the case of flow at the pore scale, the averaging does not apply and Darcy's Law cannot be used. Representative values of the hydraulic conductivity (or permeability) are given in Table 1 for various subsurface materials.

\section{Molecular diffusion}

In water-rock interaction, we are often concerned with transport through low porosity and permeability material, in which case molecular diffusion needs to be included in addition to flow. The treatment of molecular diffusion has also suffered to some extent from the assumption that Fick's First Law (described below) is sufficient, but as shown below, this is true only in the case of diffusion of uncharged species in dilute solutions. A more general formulation relates the diffusive flux linearly to gradients in the chemical potential rather than concentration, but we begin with the simpler Fickian description of diffusion for the sake of simplicity.

Fick's First Law. Molecular diffusion is usually described in terms of Fick's First Law, which states that the diffusive flux (here shown for only a single coordinate direction $\mathrm{x}$ ) is proportional to the concentration gradient

$$
J_{i}=-D_{i} \frac{\partial C_{i}}{\partial x}
$$

$D_{i}$ is referred to as the diffusion coefficient and is specific to the chemical component considered as indicated by the subscript $i$. Fick's First Law is a phenomenological theory for diffusion that relates diffusion to the "driving force" provided by the concentration gradient, although it can also be derived atomistically (Lasaga 1998). In the case of diffusion in porous media, it is normally necessary to include a tortuosity correction as well (see discussion below). Values of diffusion coefficients for selected ion at infinite dilution in water at $25^{\circ} \mathrm{C}$ are given in Table 2 .

Fick's Second Law. Integrating the diffusive fluxes over a control volume leads to Fick's Second Law (Bear 1972; Lasaga 1998). By defining the fluxes at the faces of an elemental volume as in Figure 1 (here shown for only a single coordinate direction $\mathrm{x}$ ) a general form of the continuity equation can be derived by considering the change in concentration inside an elemental volume for a given time increment:

$$
\frac{d C}{\Delta t}=\frac{1}{\Delta x}\left[J_{x}-J_{x+\Delta x}\right]=-\frac{1}{\Delta x}\left[J_{x+\Delta x}-J_{x}\right] .
$$

Written as a partial derivative as $\Delta x$ and $\Delta t \rightarrow 0$, and substituting Fick's First Law in Equation (7), Equation (8) becomes 


$$
\frac{\partial C_{i}}{\partial t}=-\frac{\partial}{\partial x}\left[J_{i}\right]=\frac{\partial}{\partial x}\left[D_{i} \frac{\partial C_{i}}{\partial x}\right],
$$

which provides an expression for the change in concentration in terms of the divergence of the diffusive flux.

Integration of Equation (9) provides a solution for the time and space evolution of the concentration field. This equation is quite straightforward to integrate numerically, but analytical solutions are also available, with the general form

$$
C(x, t)=A+B \operatorname{erf}\left[\frac{x}{2 \sqrt{D t}}\right],
$$

where $A$ and $B$ are constants that depend on the initial and boundary conditions. For the case where the initial mass is located between $-h$ and $h$, with concentrations equal to zero elsewhere, the analytical solution is given by

$$
C(x, t)=\frac{1}{2} C_{0}\left[\operatorname{erf}\left(\frac{x+h}{2 \sqrt{D t}}\right)-\operatorname{erf}\left(\frac{x-h}{2 \sqrt{D t}}\right)\right],
$$

where erf is the error function and $\mathrm{C}_{0}$ is the initial concentration between $-\mathrm{h}$ and $h$ (Lasaga 1998). Figure 2 shows the evolution of such an initially narrow and sharp zone with time as a result of molecular diffusion.

\section{Electrochemical migration}

Fick's First Law is strictly applicable only in the case of an infinitely dilute solution with uncharged chemical species. In electrochemical systems or systems containing charged species, it is also necessary to consider an electrochemical migration term. While this could be considered as a separate flux on the same level as advection and diffusion, this effect is most commonly related to diffusion of charged species at different rates. The full expression for the migration of a charged species in an electric field (written again in terms of a single coordinate direction, $x$, for the sake of simplicity) is given by (Newman 1991)

$$
J_{i}^{m i g r}=-z_{i} u_{i} F C_{i} \frac{\partial \Phi}{\partial x},
$$

where $z_{i}$ is the charge of the species, $u_{i}$ is its mobility, $F$ is Faraday's constant $(=96,487$ Coulombs/equivalent), and $\Phi$ is the electrical potential. The mobility refers to the average velocity of a species in solution acted upon by a unit force, independent of the origin of the force. The flux of charged species in an electric field gives rise to a current, which can be expressed as

$$
i=F \sum_{i} z_{i} J_{i},
$$

where $i$ is the current density in units of amperes per $\mathrm{m}^{2}$. Expanding Equation (13) in terms of the migration term (Equation (12)) and the diffusive flux (Equation (7)), the current density can be written as

$$
i=-F^{2} \frac{\partial \Phi}{\partial x} \sum_{i} z_{i}^{2} u_{i} C_{i}-F \sum_{i} z_{i} D_{i} \frac{\partial C_{i}}{\partial x} .
$$


Where no concentration gradients are present, the current is given by the first term on the right hand side

$$
i=-\kappa_{e} \frac{\partial \Phi}{\partial x}
$$

where

$$
\kappa_{e}=F^{2} \sum_{i} z_{i}^{2} u_{i} C_{i}
$$

is the conductivity of the solution. Note that using Equation (16), it is possible to determine the mobility of an ion by measuring the conductivity of a solution. The mobility in turn can be used to determine the diffusion coefficient for an ion from the Nernst-Einstein equation (Newman 1991; Lasaga 1998)

$$
D_{i}=R T u_{i}
$$

where $R$ is the gas constant and $T$ is the temperature on the Kelvin scale. Rearranging Equation (14) to obtain an expression for the gradient in the electrical potential

$$
\frac{\partial \Phi}{\partial x}=-\frac{i}{\kappa_{e}}-\frac{F}{\kappa_{e}} \sum_{i} z_{i} D_{i} \frac{\partial C_{i}}{\partial x},
$$

it is apparent that even in the absence of an electrical current, $i$, it is possible to have a gradient in the electrical potential as a result of concentration gradients of charged species. The second term on the right hand side of Equation (18) is known as the diffusion potential, which vanishes when all of the diffusion coefficients for the charged species are the same. To proceed further, it is useful to define the fraction of the current carried by a species $j$ (or the transference number)

$$
t_{j}=\frac{z_{j}^{2} u_{j} C_{j}}{\sum_{i} z_{i}^{2} u_{i} C_{i}},
$$

which can be used along with the substitution of Equation (18) and Equation (16) into Equation (12) to obtain an expression for the migration flux

$$
J_{j}^{m i g r}=\frac{t_{j} i}{z_{j} F}+\frac{t_{j}}{z_{j}} \sum_{i} z_{i} D_{i} \frac{\partial C_{i}}{\partial x} .
$$

This equation (still only strictly applicable to relatively dilute solutions) can be used to describe the case where an electrical current is present (e.g., an electrochemical cell), although more commonly in fluid-rock interaction one encounters only the second term.

In the absence of a current and advection, the total flux (combining Fickian diffusion and electrochemical migration) is then given by

$$
J_{j}=-D_{j} \frac{\partial C_{j}}{\partial x}+\frac{t_{j}}{z_{j}} \sum_{i} z_{i} D_{i} \frac{\partial C_{i}}{\partial x} .
$$

As noted above, the second term vanishes when all of the diffusion coefficients for the charged species are the same, but since this is in general not the case, this term should normally be 
retained along with the first term. Note also that the effect of electrochemical migration may be important even in dilute systems.

Electrochemical migration has several important consequences. Inclusion of electrochemical migration prevents the unrealistic build up of charge in calculations using differing diffusivities for charged species. The typical way to avoid this problem in transport calculations is to use the same diffusion coefficient for all of the charged species, in which case the diffusion potential driving electrochemical migration disappears. However, this approach does not provide the same results as would a full treatment of electrochemical migration. An example from Steefel (2007) illustrates some of the potential effects. A fixed boundary condition on the left side is separated by $20 \mathrm{~mm}$ of $10 \%$ porosity material from a reacting feldspar (albite) grain (Figure 3). At $25^{\circ} \mathrm{C}$, the dissolution rate of feldspar is sufficiently slow that concentration gradients will not develop (Murphy et al. 1989). At higher temperatures where the rate of surface reaction is more rapid, however, it is possible to develop diffusionlimited dissolution (the rate of surface reactions is significantly faster than the rate at which ions can diffuse across the $20 \mathrm{~mm}$ distance, and thus a gradient develops). Comparison of the full multicomponent diffusion and electrochemical migration calculation (essentially the NernstPlanck equation) with one based on identical diffusion coefficients (no electrochemical migration) for all species indicates that conservative quantities like alkalinity need not have linear profiles where electrochemical migration is important. Comparing the two cases with identical albite dissolution rates, the concentrations of dissolved species next to the albite grain are not even the same. This is primarily due to the rapid diffusion of hydrogen ion, which results in a more nearly linear profile for $\mathrm{pH}$ in the multicomponent diffusion/electrochemical migration case as compared to the identical diffusion coefficient case.

\section{Diffusion in concentrated solutions}

Ficks's First Law runs into additional difficulties in concentrated aqueous solutions as discussed in Steefel (2007). A more rigorous and general expression is given by

$$
J_{j}^{\text {diff }}=-L_{j i} \frac{\partial \mu_{j}}{\partial x}
$$

where the $L_{j i}$ are the phenomenological coefficients introduced in the theory of irreversible thermodynamics (Onsager 1931; Prigogine 1967; Lasaga 1998) and $\mu_{j}$ is the chemical potential of the $j$ th species. Here, the fluxes are linearly related to gradients in the chemical potentials of the solutes rather than to their concentrations as in Fick's Law. The phenomenological coefficients, $L_{j i}$, can be linked back to measurable quantities by making use of the mobility again as the "velocity" of a particle acted upon by a force, with the force in this case provided by the chemical potential rather than the concentration

$$
J_{j}^{d i f f}=-u_{j} C_{j} \frac{\partial \mu_{j}}{\partial x} .
$$

In the case where a gradient in chemical potential rather than concentration is used, the migration flux (compare to Equation (20) in the absence of a current) becomes

$$
J_{j}^{m i g r}=\frac{t_{j}}{z_{j}} \sum_{i} z_{i} D_{i} \frac{\partial \mu_{i}}{\partial x} .
$$


By writing the chemical potential as (Denbigh 1981)

$$
\mu_{j}=\mu_{j}^{0}+R T \ln \left(\gamma_{j} C_{j}\right),
$$

where $\gamma_{j}$ is the activity coefficient for the species, and differentiating with respect to $x$, we obtain the following combined expression for the pure diffusive flux and electrochemical migration by making use again of the definition of the ion mobility (Equation (17))

$$
J_{j}=-D_{j} \frac{\partial C_{j}}{\partial x}-D_{j} C_{j} \frac{\partial \ln \gamma_{j}}{\partial x}+\frac{t_{j}}{z_{j}} \sum_{i} z_{i} D_{i} \frac{\partial C_{i}}{\partial x}+\frac{t_{j}}{z_{j}} \sum_{i} z_{i} D_{i} \frac{\partial \gamma_{i}}{\partial x} .
$$

This more general expression, which reduces to Equation (21) where gradients in activity coefficients are negligible (for example, for diffusion of a trace species in a strong electrolyte), makes clear that both the diffusive and electrochemical migration fluxes can depend on the activity coefficients for the species. If gradients in one or more activity coefficients are negative, it is possible for "uphill diffusion", in which a species diffuses up its own concentration gradient, to occur (Lasaga 1998).

\section{Tortuosity}

Since water-rock interaction commonly takes place in porous materials, it is important to account for the effect of tortuosity (Figure 4), which is defined as the ratio of the path length the solute would follow in water alone, $L$, relative to the tortuous path length it would follow in porous media, $L_{e}$ (Bear 1972)

$$
T_{L}=\left(L / L_{e}\right)^{2} .
$$

In this definition of tortuosity (sometimes the inverse of Equation (27) is used), its value is always $<1$ and the effective diffusion coefficient in porous media is obtained by multiplying the tortuosity by the diffusion coefficient for the solute in pure water. With this formulation, the diffusion coefficient in porous media is given by

$$
D_{i}^{*}=T_{L} D_{i} .
$$

The diffusive flux, then, is given by

$$
J_{j}^{d i f f}=-\phi D_{j} T_{L} \frac{\partial C_{j}}{\partial x}=-\phi D_{j}^{*} \frac{\partial C_{j}}{\partial x} .
$$

An alternative formulation for the coefficient for molecular diffusion in porous media is given by the formation factor, $F$, defined as (Bear 1972)

$$
F=\left(L_{e} / L\right)^{2} / \phi=1 / \phi T_{L},
$$

in which case the diffusive flux in porous media becomes

$$
J_{j}^{d i f f}=-\frac{D_{j}}{F} \frac{\partial C_{j}}{\partial x} .
$$


Various approaches for calculating formation factors (and thus, the diffusion coefficient in porous medium) are in use, with a formulation based on Archie's Law being the most common

$$
F=\frac{1}{a \phi^{m}}
$$

where $a$ is a fitted constant and $m$ is the cementation exponent. Values of $\mathrm{a}=0.71$ and $\mathrm{m}=1.57$ have been suggested for unfractured granite (Pharmamenko 1967), although values of $\mathrm{m}=2$ have been reported for many more porous and permeable subsurface materials (Oelkers 1996). Values for the formation factor in igneous intrusive rock in Sweden range from $10^{3}$ to $10^{7}$ (Skagius and Neretnieks 1986). In the case of low porosity materials, especially those with low pore connectivity, the formation factor may be quite large (and thus, the diffusion coefficient in porous media quite small).

\section{Hydrodynamic dispersion}

The phenomenon of hydrodynamic dispersion was noted as early as 1905 when Slichter reported that the concentration of an electrolyte monitored in an aquifer downstream of an injection point increased only gradually, with the plume shape becoming longer and wider as it advanced (Slichter 1905). The spreading of the solute mass as a result of dispersion is a diffusion-like process that has led to the use of Fick's First Law to describe the process in one dimension as

$$
J_{j}^{d i s p}=-D_{h} \frac{\partial C_{j}}{\partial x}
$$

where $D_{h}$ is the hydrodynamic dispersion coefficient. The coefficient of hydrodynamic dispersion is defined as the sum of molecular diffusion and mechanical dispersion, since these effects are not separable where flow is involved (Bear 1972)

$$
D_{h}=D^{*}+D .
$$

The representation of dispersion as a Fickian process, however, has been questioned extensively (Dagan 1988). As applied to reactive transport problems, the main problem is that dispersion does not involve mixing in the same way that molecular diffusion does (Cirpka 2002). This is discussed further below in the section on macrodispersion.

Mechanical dispersion Mechanical dispersion is a result of the fact that variations in the flow velocities exist, even where an average flow rate (as in Darcy's Law) can be defined for a particular representative elementary volume (REV). If all the detailed flow paths could be captured, then there would be no need for inclusion of a dispersion coefficient.

Mechanical dispersion was first clearly discussed for the case of laminar flow and transport within a cylindrical tube (Taylor 1953). In the case where a non-reactive tracer is instantaneously released at the inlet of the tube and complete mixing does not occur, the tracer pulse will arrive first where the flow is fastest, later where the flow is slower. At any one time, the bulk concentration of the fluid leaving the tube represents a flux-weighted average of the concentration in the fast and slow moving flow paths, so the breakthrough of the tracer will appear as disperse or gradual rather than sharp. This effect is referred to as Taylor dispersion (Taylor 1953; Aris 1956). Assuming Poiseuille's equation for flow in a cylinder holds, the 
steady-state parabolic velocity distribution as a function of radius $r$ can be calculated from (Daugherty and Franzini 1965)

$$
u(r)=\frac{2 Q}{\pi R^{2}}\left[1-\left(\frac{r}{R}\right)^{2}\right]=2 U\left[1-\left(\frac{r}{R}\right)^{2}\right],
$$

where $u(r)$ is the local fluid velocity within the cylinder, $Q$ is the volumetric flow rate, $R$ is the radius of the cylinder, and $U$ is the average velocity (Figure 5A). Using Equation (35), Taylor derived an analytical expression for the dispersion in the case of Poiseuille flow

$$
D_{h}=D+\frac{U R^{2}}{D},
$$

where $D_{h}$ is the dispersion coefficient, and $D$ is the molecular diffusion coefficient. Note that the dispersion coefficient depends on the molecular diffusion coefficient for its contribution to longitudinal spreading (the first term on the right hand side of Equation (36)), but also inversely on the molecular diffusion coefficient in the second term on the right hand side because radial diffusion acts to eliminate the gradients in concentration developed by the non-uniform velocity profile (Figure 5A). A comparison of the breakthrough curve for a non-reactive tracer calculated with the Taylor-Aris dispersion coefficient given in Equation (36) and a full two-dimensional axisymmetric cylindrical Poiseuille flow calculation in which dispersion is represented only through the variation in flow velocities and through molecular diffusion (i.e., no explicit dispersion coefficient is included) is given in Figure 5B (Steefel 2007).

A similar effect occurs within porous media (which are often conceptualized as bundles of capillary tubes), since the velocity adjacent to a solid grain is slower than the velocities in the center of the pore. Even in the case of a perfectly homogeneous porous medium (e.g., glass beads all of the same size), therefore, spreading of a solute plume will occur. Additional effects in porous media are related to the tortuosity of flow paths (Figure 4) and to differences in pore size, since velocities will be higher in those pores with wider apertures (Bear 1972).

Dispersion needs to be quantified at much larger scales in porous media, however, so some averaging of these dispersion mechanisms is usually required. Dispersion in porous media is typically defined as the product of the fluid velocity and a dispersivity, $\alpha$, with longitudinal and transverse components

$$
\begin{aligned}
& D_{L}=\alpha_{L} V_{i}, \\
& D_{T}=\alpha_{T} V_{i}
\end{aligned}
$$

where $V_{i}$ refers to the average velocity in the principal direction of flow, and the subscripts $L$ (longitudinal) and $T$ (transverse) refer to the dispersion coefficient parallel and perpendicular to the principal direction of flow respectively (Bear 1972).

Macrodispersion The treatment of hydrodynamic dispersion as a Fickian process (that is, one in which the flux is linearly proportional to the concentration gradient) has been widely criticized (Gelhar and Axness 1983; Gelhar 1986; Dagan 1988; Gelhar et al. 1992). As pointed out by a number of investigators, dispersion is scale-dependent, with larger dispersivities observed for larger observation scales. At the column scale, a typical dispersivity may be on the order of a centimeter, but at the field scale, apparent dispersivities of 10 to 100 meters or more 
are common. Gelhar (1986) showed that the dispersivity increased with scale of observation, although even at a single observation scale, dispersivities could range over 2-3 orders of magnitude due to differing degrees of aquifer heterogeneity at the different sites (Gelhar 1986; Gelhar et al. 1992). The increase with dispersivity as a function of the scale of measurement is related to the hierarchical nature of natural porous medium and is often referred to as macrodispersion. At the pore-scale, variations in flow velocity and direction are related to porescale heterogeneities like the variation in grain size and pore apertures, but at the field scale, additional heterogeneity features (sedimentary features, fractures, faults) are encountered which add to the spreading of the solute plume. As in the case of Taylor dispersion, the spreading of a solute plume is fundamentally related to the variations in flow velocity, with fast-flowing pathways leading to earlier breakthrough than slow flow pathways. In the case of Poiseuille flow in a tube, the effect is predictable and rigorously quantifiable because of the well-defined physics of the system, but in natural porous media where multi-scale heterogeneities typically occur, the problem of determining dispersivities is much more difficult and usually requires a stochastic treatment.

The effect of macrodispersion can be illustrated with a simple example as considered in Steefel (2007). Consider a permeability field with approximately six orders of magnitude variability in permeability (Figure 6A). The heterogeneous distribution of and strong contrast in permeability results in preferred flow paths that lead to fingering of a non-reactive tracer plume as it moves with the flow from left to right (Figure 6B). The two-dimensional numerical simulation was conducted without including a Fickian treatment of hydrodynamic dispersion and using an accurate Total Variation Diminishing (TVD) scheme that minimizes numerical dispersion (Steefel and MacQuarrie 1996). When a flux-weighted average of the solute concentration is calculated over the entire length of the capture plane on the right hand side, perpendicular to the flow direction (similar conceptually to what occurs where flow converges into a pumping well), one observes a gradual, disperse breakthrough as a result of the mixing of the early and late arriving fluid packets (Figure 7). To match the disperse breakthrough curve in the heterogeneous flow field with a one-dimensional simulation of flow in a homogeneous permeability field, it is necessary to use a dispersivity, $\alpha$, of about 50 centimeters.

Stochastic descriptions of dispersion There is much interest now in more rigorous descriptions of macrodispersion in particular. One approach has been to treat the parameters controlling transport (primarily the hydraulic conductivity or permeability, but also potentially such parameters as mineral volume fractions and/or reactive surface area) as stochastic rather than deterministic parameters, since the exact distribution of these parameters in the subsurface is typically poorly known (Gelhar 1986; Dagan 1989; Gelhar 1993). This is a particularly useful approach when the primary data available are breakthrough curves for tracers at an observation point. The shape of the curve can be used to deconvolve a stochastic distribution of hydraulic conductivities in the aquifer, implying that while we do not know the exact path a particular solute particle followed, we do have a statistical representation of the ensemble of solute travel times that could have produced the observed tracer concentrations at the observation point. Tracer breakthrough data, therefore, is often used to generate probability density functions for hydraulic conductivities and travel times, although this concept need not be strictly stochastic. 


\section{Reaction-induced changes in transport properties}

One of the most difficult problems in reactive transport today is the treatment of cases in which the physical properties of the porous medium evolve as a result of chemical reactions. The most commonly identified coupling involves the porosity and permeability as affected by chemical reactions (dissolution or precipitation), but other properties like the reactive surface area may evolve as well. A number of experimental studies have been conducted in which reaction-induced permeability change was identified (Dobson et al. 2003). Modeling studies have also been carried out in which flow and reaction have been explicitly coupled and allowed to evolve (Ortoleva et al. 1987; Steefel and Lasaga 1990; Steefel and Lasaga 1994; Steefel and Lichtner 1994; Steefel and Lichtner 1998b; Dobson et al. 2003; Steefel 2007; Cochepin et al. 2008). A smaller set of studies have combined experimental and/or characterization studies with reactive transport modeling (Dobson et al. 2003; Navarre-Sitchler et al. 2009).

Porosity is typically the first order parameter that is predicted from reactive transport simulations, since it is directly related to the sum of the mineral volumes precipitated or dissolved. It is possible to predict the evolution of the total porosity, therefore, with some degree of confidence. More difficult is to predict the transport parameters, especially permeability and diffusivity, since they depend on the detailed pore geometry. To make progress in this area, it will be necessary to combine the modeling with microscopic characterization of the porous medium as mineral dissolution or precipitation occur. A first attempt at this has been carried out by Navarre-Sitchler et al. (2009) who studied the evolution of the porosity, pore connectivity, pore geometry, and diffusivity as a function of the extent of chemical weathering. This study showed that as the chemical weathering process advanced within the approximately $1 \mathrm{~mm}$ wide weathering interface developed within a basalt clast, porosity increased as the primary minerals dissolved (as one would expect), but that pore connectivity increased as well once a critical porosity of $\sim 9 \%$ was achieved. The porosity and pore connectivity as a function of weathering were imaged with Xray microtomography at the Advanced Light Source (Figure 8). The 3D data was also used to construct a pore network model that was used for tracer diffusion calculations (Navarre-Sitchler et al. 2009). A comparison of unweathered and weathered basalt using both $\mu$ Xray fluorescence (Panel A) and 3D tracer diffusion simulations using the pore network model constructed from the microtomography (Panel B) indicates that the weathering process substantially increased the diffusivity as a result of weathering (Figure 9).

\section{REACTIVE TRANSPORT BASICS}

We are now ready to combine the transport processes outlined above with expressions for kinetically-controlled geochemical and biogeochemical reactions. A comprehensive and modern treatment requires the use of a sophisticated numerical simulator capable of handling variations in system properties (hydraulic conductivity, porosity, tortuosity, etc.) in both space and time, along with rigorous treatments of multicomponent diffusion and advection. In addition, the modern numerical simulators are capable of considering multicomponent reactions along with nonlinear rate laws, features that are well beyond what is possible with analytical solutions. Analytical solutions, while exact by definition for the particular equation and boundary and initial conditions considered, often force the would-be user into approximations (physical or chemical) that may or may not be warranted. Our interest here initially, however, is in exploring the first-order dynamics when reaction and transport are coupled, and for this purpose a simplified version of the advection-dispersion-reaction equation is adequate. 
For a system with transport of a non-reactive tracer, an expression for the conservation of solute mass can be derived by accounting for the flux of solute across the faces of a volume element. For a one-dimensional system (fluxes in the $\mathrm{Y}$ and $\mathrm{Z}$ directions $=0$ ), the net flux is obtained from

$$
\frac{\partial J_{i}}{\partial x}=\lim _{\Delta x \rightarrow 0} \frac{\left.J_{i}\right|_{x+\Delta x}-\left.J_{i}\right|_{x}}{\Delta x} .
$$

In a multidimensional system involving porous media, the accumulation of solute mass is given by the difference (that is, the divergence) of the fluxes summed over all of the faces of the element

$$
\frac{\partial\left(\phi C_{i}\right)}{\partial t}=-\nabla \cdot \mathbf{J}_{i}=-\left(\frac{\partial J_{i}}{\partial x}+\frac{\partial J_{i}}{\partial y}+\frac{\partial J_{i}}{\partial z}\right),
$$

where $\boldsymbol{J}_{\boldsymbol{i}}$ is the flux vector. Substitution of Equations (2) and (7) into Equation (39) (neglecting electrochemical migration for simplicity) yields

$$
\frac{\partial\left(\phi C_{i}\right)}{\partial t}=-\nabla \llbracket\left(\phi \mathbf{v} C_{i}\right)+\nabla \llbracket\left(\phi D_{i}^{*} \nabla C_{i}\right) .
$$

To include reactions, it is more instructive to use the one-dimensional version of the advectiondispersion equation, particularly since non-dimensionalization of the equation is more straightforward in this case. For a constant porosity, tortuosity, and flow system characterized by a first-order precipitation and dissolution reaction that can be described in terms of a single chemical component (e.g., $\mathrm{SiO}_{[\mathrm{aq}]}$ reacting with the single mineral quartz), the advectiondispersion-reaction equation becomes

$$
\phi \frac{\partial C}{\partial t}=-\phi v \frac{\partial C}{\partial x}+\phi D^{*} \frac{\partial^{2} C}{\partial x^{2}}+A k\left(1-\frac{C}{C_{e q}}\right),
$$

where $k$ is the rate constant in units of moles $\mathrm{m}^{-2} \mathrm{~s}^{-1}, A$ is the reactive surface area of the mineral in units of $\mathrm{m}^{2} \mathrm{~m}^{-3}$, and $C_{e q}$ is the solubility of the mineral in moles $\mathrm{m}^{-3}$.

\section{Important non-dimensional parameters}

By converting a partial differential equation to its non-dimensional form, it is possible to define a series of parameters that describe the relative importance of dynamic processes like chemical reaction, advection, and hydrodynamic dispersion. The first step is to define a length scale, $l$, which may be a characteristic length scale defined by the geology or hydrology (e.g., the flow length through an aquifer or weathering profile), or more commonly a length scale which reflects the spatial distribution of observations. Using this length scale, a non-dimensional or fractional distance can be defined as

$$
x^{\prime}=\frac{x}{l} .
$$

In addition, this allows us to define a characteristic time for dispersive transport

$$
t_{D}=\frac{l^{2}}{D^{*}}
$$


and advective transport

$$
t_{A}=\frac{l}{v} .
$$

When combined with a characteristic time for reaction

$$
t_{R}=\frac{\phi C_{e q}}{A k},
$$

it is possible to define a series of non-dimensional parameters that control the behavior of a water-rock interaction system involving transport: the Damköhler number for advective, $D a_{I}$, and diffusive (or dispersive), $D a_{I I}$, systems respectively

$$
\begin{gathered}
D a_{I}=\frac{t_{A}}{t_{R}}=\frac{A k l}{\phi v C_{e q}} \\
D a_{I I}=\frac{t_{D}}{t_{R}}=\frac{A k l^{2}}{\phi D^{*} C_{e q}} .
\end{gathered}
$$

In addition, the relative importance of advective versus diffusive (or dispersive) transport is compared in the Péclet number

$$
P e=\frac{t_{D}}{t_{A}}=\frac{v l}{D^{*}} .
$$

Note that each of these numbers depends on the characteristic length scale considered.

After introducing a non-dimensional form of the concentration

$$
C^{\prime}=\frac{C-C_{e q}}{C_{0}-C_{e q}},
$$

where $C_{0}$ is the concentration of the fluid injected into the system (Lichtner 1998) and a dimensionless time

$$
t_{D}^{\prime}=\frac{D^{*} t}{l^{2}},
$$

Equation (41) becomes

$$
\frac{\partial C^{\prime}}{\partial t_{D}^{\prime}}=\frac{\partial^{2} C^{\prime}}{\partial x^{\prime 2}}-P e \frac{\partial C^{\prime}}{\partial x^{\prime}}-D a_{I I} C^{\prime},
$$

which makes clear how the Péclet and Damköhler numbers control the behavior of the advection-dispersion-reaction equation.

At high Péclet numbers $(\mathrm{Pe}>>1)$, advective transport dominates and dispersive and diffusive transport are negligible, with the result that the concentration front is relatively sharp (Figure 10). Similarly, for Damköhler numbers $>>1$, reaction times are much faster than transport times for a given length scale. Where this is the case, local equilibrium is achieved for a reaction of the form given in Equation (41) over a length scale, $l$ (Bahr and Rubin 1987). In addition, reaction fronts 
are relatively sharp where the Damköhler number is large, since the approach to equilibrium requires a small amount of time relative to the time needed for a solute to traverse a distance.

\section{Transport versus surface reaction control}

Under the steady-state conditions considered here, there is always some theoretical length scale over which local equilibrium could be attained (assuming such an equilibrium state exists), although this length scale may not be realized in a particular geological environment (Steefel 2007). Where the concentration in the aqueous phase increases or decreases to the point where equilibrium or near-equilibrium is achieved, the overall rate of reaction within the spatial domain defined by the length scale $l$ becomes transport-controlled. This implies that the rate-limiting process in the overall reaction evaluated over the length scale $l$ is transport, rather than the rate of attachment and detachment of ions from the mineral surface. Transport control has often been discussed in the geochemical literature, but usually with regard to experimental studies where transport involved diffusion across a boundary layer next to a reacting mineral (Berner 1980). For example, numerous studies have shown that the dissolution of calcite is diffusion rather than surface-reaction controlled at $\mathrm{pH}$ values $<4$. This can be verified in rotating disk reactors by increasing the speed of rotation - in the case of a diffusion control on the rate of dissolution, the faster rate of spinning reduces the size of the diffusion boundary layer adjacent to the crystal, thus increasing the overall rate of dissolution (Pokrovsky et al. 2005).

While the rotating disk experiment involving calcite is a particularly good example of a transport-controlled system, the concept is much more general and may be applied at any scale. Consider a flow path through a granite undergoing weathering. If a fluid percolating through the granite approaches equilibrium over a flow distance of about 25 meters, but we collect water samples issuing from the profile 50 meters from the start of flow path, then we are collecting waters close to or at equilibrium that will express a transport control on the overall rate. Operationally, this means that the flow rate through the weathering profile (due, for example, to an increase in rainfall) controls the weathering flux, $J_{\text {weather, }}$ in the advection-dominant case over the 50 meters according to

$$
J_{\text {weather }}=q C_{e q} \text {, }
$$

where $q$ is the flow rate and $C_{e q}$ is the equilibrium concentration. If the scale of observation, $l$, is $>>$ than the equilibration length scale $\lambda$, then the weathering rate will not depend on the reaction kinetics. This is a general result that applies to all water-rock interaction systems (Lichtner 1993). A direct comparison of laboratory-determined rates of reaction, which are carried out in most cases under far from equilibrium conditions and thus under surface reaction control, and natural weathering rates evaluated at length scales greater than the equilibration length scale, will be meaningless in this case, since the rate control is not the same (Schnoor 1990). By definition, the field rate when transport-controlled will be slower than the surface reaction-controlled rate. But, as stressed above, the control on rates is scale-dependent, so data collected at a length scale $<<$ than the equilibration length scale may show evidence for a surface reaction control on rates and far from equilibrium conditions. Thus, observations of etch pitting in primary minerals, generally taken as good evidence of far from equilibrium conditions (White and Brantley 2003), may be fully compatible with an overall transport control on weathering rates, depending on how the scales of observations compare to the equilibration length scale. 


\section{Rates of fluid-rock interaction in heterogeneous systems}

Most studies of the kinetics of fluid-rock interaction carried out to date have assumed flow and reaction through a homogeneous, well-mixed system, as would be the case with a single continuously stirred flowthrough reactor (Haggerty et al. 1998; Snodgrass and Kitanidis 1998; White and Brantley 2003; Zhu 2005). This is perhaps somewhat strange given the enormous number of studies on macrodispersion in the hydrologic literature indicating that travel times, and thus residence times, in the subsurface are not all the same. Fortunately, the roles of both physical and chemical heterogeneities and their role in water-rock interaction are now beginning to be discussed (Malmström et al. 2000; Li et al. 2006; Meile and Tuncay 2006; Li et al. 2007b; Li et al. 2007a; Li et al. 2008). The role of physical heterogeneties can be clarified by returning to the heterogeneous permeability field shown in Figure 6. If we now include reactions along with the flow and transport, in this case the dissolution of plagioclase according to the kinetic scheme proposed by Oelkers et al. (1994), we see that the numerical modeling of the reactive transport predicts a steady-state fingering of the pore water $\mathrm{pH}$ that follows the high permeability zones (Figure 12A). Similarly, a contour plot of the logarithm of the mineral saturation states (the distance the pore water is from equilibrium with respect to plagioclase) shows a similar strong spatial variability - a transect in the $\mathrm{Y}$ direction at $\mathrm{X}=10$ centimeters would encounter up to 10 orders of magnitude variability, ranging from far from equilibrium to relatively close to equilibrium pore waters (Figure 12B). Therefore, a single transect could encounter both surfacereaction and at least partly transport-controlled rates. While this is a model result, it should be broadly representative of what would be expected for any reactive system with seven orders of magnitude variation in the local permeability.

Residence time distributions. The concept of macrodispersion has important implications for the kinetics of water-rock interaction. One can also think of these variations in flow velocity and/or flow length as leading to a distribution of residence times for aqueous species migrating through reactive material (Steefel 2007). A sample collected from a stream draining a catchment, for example, typically includes waters that have moved through a myriad of flow paths and distances. Some water may have moved through relatively shallow portions of the soil profile - these flow paths would typically involve relatively short residence times, with less exposure to primary reactive phases forming the bedrock. In contrast, other water may have moved along deeper, slower flow paths, encountering a greater abundance of reactive primary minerals along the way. The residence time of reactive water in contact with rock, therefore, can vary substantially in a natural system. Locally, the system may be far from equilibrium, elsewhere close to equilibrium. Conceptually, one might think of the overall system as an ensemble of flow-through reactors, some with short residence times and/or small amounts of reactive material, others with much longer residence times. In some cases, the residence time will have been long enough that the fluid actually equilibrates within the reactor, leading to a rate that is transport rather than surface reaction-controlled. If the effluent of this ensemble of flowthrough reactors were to converge into a single sampling tube (the experimental analogue of a stream gauging station at the catchment scale or a pumping well drawing water from a heterogeneous aquifer), then the total extent of reaction (i.e., the upscaled, volume-averaged reaction rate) would reflect the full distribution of residence times and reactive mineral mass.

Many examples of reactive flow through permeable rocks or sediment exist where strong contrasts in porosity and permeability result in regions characterized by very different transport regimes. This is often referred to as multi-region transport (Harvey and Gorelick 2000). The 
most common example is a dual permeability (or porosity) system, where a portion of the system is sufficiently permeable that macroscopic flow occurs within it, another portion is so impermeable that flow is negligible and transport is by molecular diffusion. Perhaps the best example of a dual permeability system is provided by fractured rock, where the permeability of the fractures is typically many orders of magnitude higher than the permeability of the rock matrix (Steefel and Lichtner 1998a).

Much of the evidence that multi-region transport systems exist in the subsurface comes from measurements of hydraulic conductivities on small laboratory-scale samples. Another source of evidence is provided by groundwater ages determined with various methods (Plummer et al. 2001). Although these groundwater ages are often interpreted as the result of mixing between two end members (old and young water), what we have learned about the distribution of hydraulic conductivities, and thus residence times, in heterogeneous 3D subsurface media argues against this (Varni and Carrera 1998; Tompson et al. 1999; Bethke and Johnson 2002; Weissmann et al. 2002). For example, Figure 13 shows groundwater ages determined using the chlorofluorocarbon (CFC) technique compared to $\mathrm{CFC}$ ages based on high resolution groundwater flow simulation of a heterogeneous alluvial fan aquifer in California (Weissmann et al. 2002). The high resolution flow modeling argues that the individual CFC ages are real, and not simply the result of mixing of old and young waters.

Evidence also comes from non-reactive tracer concentration profiles (or "breakthrough curves") determined in subsurface wells. Tracer concentration profiles at an observation well (or at the end of a laboratory column) characterized by multi-region effects typically show an early, usually sharp breakthrough, followed by a long gradual approach to a maximum value in the case of a constant injection. In the case of a transient pulse of a tracer followed by another fluid (a common case in contaminant hydrology), the tracer is eluted only very slowly from the column or aquifer. This behavior occurs because it requires some time for the tracer to be transported into the low permeability material, and once elution begins, then to be flushed from this zone.

Tracer breakthrough curves can be used to estimate a residence time distribution. With release of a non-reactive tracer pulse, fast pathways will deliver tracer first. Lower permeability regions within the flow domain will flush the tracer more slowly, providing information on the longer residence times. Using the first derivative of the concentration in the breakthrough curve in Figure 7, the formal probability density function for residence can be determined (Figure 14).

Upscaling reaction rates in heterogeneous media. Mineral reaction rates are typically measured in well-stirred laboratory systems where the intent is to eliminate gradients in concentration within the solution. An individual crystal is expected to experience the same chemical environment as its neighbor. To the extent that a diffusion boundary layer can be eliminated via stirring, the rate of the mineral reaction is surface reaction-controlled - this is potentially a problem with a rapidly reacting mineral like calcite at low $\mathrm{pH}$ (Pokrovsky et al. 2005). In porous media where water-rock interaction takes place, however, physical, chemical, and microbiological heterogeneities can lead to the development of gradients in concentration, and thus to a spatially variable reaction rates.

Perhaps the clearest example of where rates are not the same at all scales is provided by the case where a reacting phase is distributed heterogeneously-obviously, in this case the reaction rate in the microenvironment next to the mineral is greater than what is determined over a larger volume average. If the system is well-mixed via either molecular diffusion or dispersion, 
however, then the rate should be scale-independent if the reactive surface area is calculated correctly over the larger volume. At fairly high flow rates in single pores, it may even be possible to develop diffusion boundary layers along the reacting mineral surfaces, which results in gradients in concentration and reaction rate at this scale (Li et al. 2008). However, the Li et al (2008) study showed that given the typical flow rates encountered in the subsurface, the efficiency of molecular diffusion is high enough that complete mixing occurs at the scale of a single pore ( $\mathrm{Li}$ et al. 2008). However, in the case where incomplete mixing at the larger pore network scale occurs, significant spatial variations in concentration, mineral saturation state, and reaction rates are likely to occur and thus result in rates that are scale dependent (Li et al. 2006).

A similar scaling effect may occur at larger scales characterized by slow transfer between low permeability zones (often referred to as "immobile") and higher permeability ("mobile") zones. In these cases, disequilibrium between these zones may prevail, creating gradients in concentration and thus a spatial variability in reaction rates (Harvey and Gorelick 2000).

From the preceding discussion, it should be clear that upscaling reaction rates is not as simple as normalizing the rates to the total reactive surface area in the water-rock system. Rates in natural heterogeneous porous media will always be scale-dependent where incomplete mixing occurs.

\section{A REACTIVE TRANSPORT APPROACH TO MODELING FLUID- ROCK INTERACTION}

The chapter began with an overview of the transport processes that are important in fluidrock interaction and was followed with a very basic introduction to the essential equations that describe fluid-rock interaction concisely. We have relied so far primarily on analytical expressions, although some examples have been provided that make use of numerical models. The analytical solutions for reactive transport discussed in Section 5 are extremely useful for several reasons: 1) they have a pedagogical value in that fundamental system behavior can often be captured with relatively simple expressions or with non-dimensional parameters, 2) in most cases they are easier to solve than are the corresponding numerical representations, and 3) they are exact, and therefore offer a reliable comparison for other methods (chiefly numerical) where errors of various kinds can arise. There are some significant limitations, however, to relying strictly or even mostly to analytical solutions for the reactive transport problem. Perhaps most important is the fact that multicomponent, nonlinear reaction rate laws and reaction networks can rarely be handled with analytical approaches. Another potential danger in an over-reliance on analytical solutions is that they often lead to approximations that may or may not be justifiable. Examples abound, but to mention a few: 1) it is common to take the nonlinear reaction kinetics found in most experimental studies and treat these as linear for the purposes of including them in an analytical expression, significantly changing in some cases the system behavior, 2) the treatment of contaminant retardation is often carried out with the use of linear distribution coefficients, or $\mathrm{K}_{\mathrm{d}}$ values, despite the fact that nonlinear expressions for sorption (multicomponent ion exchange or surface complexation methods) typically provide far better descriptions of the processes involved, especially under chemically variable conditions (Steefel et al. 2005), and 3) assumptions of constant and/or uniform physical or chemical properties can lead to completely erroneous predictions of system behavior. 
Modern numerical software for reactive transport simulations provides some powerful additional capabilities that make it the ideal tool to analyze and interpret fluid-rock interaction. The potential pitfalls of numerical reactive transport modeling are many and should not be discounted (see Steefel and MacQuarrie (1996) for a discussion of many of the errors that can arise when numerical methods are used). Other problems have to do with the extensive thermodynamic and kinetic databases that need to be used with this approach - each of these is subject to its own errors and these can propagate through to the dynamic system behavior in ways that may or may not be intuitively obvious. That said, the features to be found in these software packages are constantly evolving in response to the development of new conceptual models, but even now they can handle a variety of coupled biogeochemical and transport processes that are beyond the capabilities of an analytical model. Perhaps their key strength for the geochemist and mineralogist is their ability to handle multicomponent systems of arbitrary complexity. For the mulicomponent case, the governing advection-dispersion-reaction equation becomes

$$
\frac{\partial\left(\phi C_{i}\right)}{\partial t}=\nabla \cdot\left(\phi D_{i} \nabla C_{i}\right)-\nabla \cdot\left(\phi \mathbf{u} C_{i}\right)-\sum_{r=1}^{N r} v_{i r} R_{r}-\sum_{m=1}^{N_{m}} v_{i m} R_{m}
$$

where we now have a set of coupled partial differential equations for the chemical components, $i$, in the system. These solutes may be affected by both the rates of the $N_{r}$ aqueous (homogeneous) reactions, $R_{r}$, and the rates of the $N_{m}$ solid phase (mineral) reactions, $R_{m}$, each reacting according to the stoichiometry given in the coefficients $v_{i r}$ and $v_{i m}$, respectively. The numerical software also has no problem handling both parallel and sequential kinetic pathways, which are common in microbially-mediated reaction networks.

Equally important is the ability to handle variable physical and chemical properties when a numerical approach is used. For some problems (e.g., the wormholing example shown in Figure 15 below), this is essential for describing the dynamics of fluid-rock interaction.

\section{Approaches to modeling multi-scale porous media}

Depending on the scale of interest, three different types of models are used to describe reactive transport in porous media today, 1) continuum models, 2) pore scale models, and 3) multiple continua or hybrid models involving a combination of scales (Steefel et al. 2005). Flow, transport, and reaction are conventionally described by macroscale models based on a continuum formulation of the underlying microscale equations (Lichtner 1985; Lichtner 1996). The continuum approach is the most advanced in terms of its treatment of multicomponent chemical processes. The continuum equations are often derived intuitively by averaging over a representative elementary volume (REV) or control volume resulting in effective macroscale parameters. Pore scale models include pore network and lattice Boltzmann models, but few efforts in reactive transport have been attempted. Multiple continuum models have been in use for some time (Pruess and Narisimhan 1985)-hybrid models which combine pore scale and continuum scale behavior are only now beginning to be considered seriously (Lichtner and Kang 2007). These different approaches are considered in more detail in what follows.

Continuum models. Subsurface reactive flow and transport models are most commonly based on the continuum representation of porous media. This approach depends on averaging system properties over a macroscopic length (control volume or REV) containing many solid grains (Lichtner 1996; Steefel et al. 2005). Because of this averaging of properties, however, the 
continuum approach is not valid for length scales on the order of a single pore dimension. Since many of the physical, chemical, and biological processes actually take place at the pore scale, developing averaging approaches for these coupled processes at larger scales is essential.

Solid properties may be either fixed (frozen) or evolving. The latter is much more difficult to simulate and involves using various phenomenological approaches for describing changes in such macroscale parameters as porosity, permeability, capillarity, tortuosity, and reactive surface area. The formation of wormholes, which takes place in carbonate rocks due the infiltration of fluids undersaturated with respect to the carbonate minerals, is an extreme example of evolving heterogeneity that can still be modeled at the continuum scale (Figure 15).

The wormholes form as a result of a reactive infiltration instability in which the enhancement of permeability resulting from mineral dissolution causes the wormholes to capture progressively increasing amounts of flow, thus accelerating their propagation (Ortoleva et al. 1987; Steefel and Lasaga 1990; Spiegelman et al. 2001; Spiegelman and Kelemen 2003; Steefel et al. 2005; Steefel 2007). Wormholes are observed in ideally homogeneous materials, such as plaster of Paris (gypsum), indicating that only slight variations in pore size are needed to form wormholes given the presence of high flow velocities and fast reaction kinetics.

Basic assumptions invoked in the continuum formulation are (Steefel et al. 2005) 1) solid, liquid, and gaseous phases all coexist at a single point (control volume) in space; 2) heterogeneous reactions involving two separate phases which interact across a common interface are treated as if they were homogeneous reactions uniformly distributed throughout a control volume. Interfacial surface area is represented as a uniform surface area concentration; 3) flow is described in terms of Darcy's law with velocity proportional to the pressure gradient. The proportionality coefficients are the permeability divided by the fluid viscosity; 4) the fluid, solid, and gas phases are well-mixed and therefore without concentration gradients, thus resulting in uniform reaction rates within the control volume.

The continuum description breaks down at the pore scale where the Navier-Stokes equations derived from fluid mechanics are required and where it may be necessary to capture microscopic-scale gradients in concentration resulting from transport and a non-uniform distribution of reactive material.

Pore-scale models. Pore scale models have been considered for some time in hydrology and petroleum engineering, but only very recently have such models included coupled reactive transport processes. Network models aim to capture pore scale behavior through a set of rules governing mass transport and chemical/biological reactions within and between individual pores. While they don't capture sub-pore scale gradients and processes that might be present, they offer the advantage of being able to treat processes like wormholing described above with only modest computational expense( $\mathrm{Li}$ et al. 2006). Li and co-workers used this approach to investigate various upscaling procedures for reactive transport processes controlled by a combination of transport and reaction kinetics at the pore scale. They demonstrated that continuum or volume averaging approaches often introduce significant errors, in some cases not even capturing the correct reaction direction. A more rigorous approach because of its ability to capture intra-pore gradients and geometries is offered by lattice Boltzmann methods (LBM) (Kang et al. 2006; Kang et al. 2007; Lichtner and Kang 2007), but these are limited with present day computational facilities to relatively small scale problems on the order of millimeters. In addition, there is some question how far up in scale the approach can be extended due to the computational difficulties 
associated with resolving enough pores to describe the equivalent of a representative elementary volume. The approach is potentially very powerful for developing formulations for use in hybrid models where pore scale processes such as biofilms, diffusion, and fracture or pore sealing can occur.

Multiple continuum or hybrid models. Fractured porous media, and more generally hierarchical media involving multiple length scales, play an important role in subsurface flow and transport processes. Fracture-dominated flow systems are involved in numerous subsurface geochemical processes, including contaminant migration, ore deposition, weathering, enhanced oil recovery, geothermal energy, degradation of concrete, and subsurface carbon sequestration. A description based on a single continuum formulation is unable to capture the unique features of a fractured system, and more generally, a hierarchical system involving multiple characteristic length scales, and can lead to serious error (Lichtner and Kang 2007).

If it were possible to model subsurface reactive flow problems at the micro scale over any desired macro length scale, there would be no need to consider other approaches. However, this is obviously not the case even with access to the world's fastest computers. Consequently, the problem must be simplified and approximations made in such a way that at least the first order effects of multi-scale processes are accommodated. One mathematical formulation of this problem is through a hierarchical set of continua, with each characteristic length scale represented by a different continuum that is coupled to the next continuum in the hierarchy (Lichtner and Kang 2007).

\section{Approaches and constraints for determining rates}

Rates of reaction can be determined in water-rock interaction systems affected by transport using several approaches. In general, however, intrinsic rates of reaction (e.g., moles $/ \mathrm{m}^{2} / \mathrm{s}$ ) cannot be determined uniquely without independently determining transport rates. An exception is the case where one process or the other (surface reaction or transport) is clearly the slowest and therefore rate-limiting step in the overall process. Unfortunately, a surface reaction or transport control is often assumed to apply in advance of a rigorous analysis that demonstrates this control.

Using aqueous concentration profiles From Equation (41), it is clear that rates of reaction can be determined from a concentration profile if the rates of transport are known. One can determine rates of water-rock interaction even where non-steady state conditions prevail, but the steady state case is much simpler to deal with. In the case of a steady state system, the rates of reaction in a pure diffusion system will be given by the curvature or second derivative of the concentration

$$
R=\phi D^{*} \frac{\partial^{2} C}{\partial x^{2}}
$$

while in a pure advective system, the rate is given by the first derivative or slope of the concentration

$$
R=-\phi v \frac{\partial C}{\partial x}
$$

Equations (54) and (55) can be used with finite differencing of discrete data to determine local reaction rates, respectively 


$$
\begin{gathered}
R_{j}=\left[\left(\phi D^{*}\right)_{j+1 / 2} \frac{C_{j+1}-C_{j}}{x_{j+1}-x_{j}}-\left(\phi D^{*}\right)_{j-1 / 2} \frac{C_{j}-C_{j-1}}{x_{j}-x_{j-1}}\right] \\
R_{j-1 / 2}=-(\phi v)_{j-1 / 2}\left[\frac{C_{j}-C_{j-1}}{x_{j}-x_{j-1}}\right],
\end{gathered}
$$

where $\mathrm{j}$ refers to the discrete data points and $\mathrm{x}_{\mathrm{j}}$ is the location of the data in space. In this form, the finite difference equations are written without assuming equally spaced data (implicitly assumed in Equation (54) and (55)). Alternatively, the rates can be fit using the analytical or numerical solution to the governing reactive transport equation, taking into account the appropriate boundary and initial conditions as necessary. If a species is affected by more than one reaction, then all of the relevant reactions need to be factored into the analysis and this is generally best accomplished with modern numerical reactive transport software. An example in which rates were determined using pore water solute data from marine sediments and the numerical software CrunchFlow is shown in Figure 16 (Maher et al. 2006).

Using mineral profiles Determining rates from mineral profiles is generally more difficult, both because the mineral profiles reflect integrated rates, but also because the movement of the reaction fronts can introduce additional difficulties of interpretation. Determining intrinsic rates (per unit surface area mineral) can be difficult because the spatial variation of reactive surface area across the reaction front needs to be factored in. An example involving the Santa Cruz Chronosequences is shown in Figure 17 and is discussed in more detail in the Case Studies section below (Maher et al. 2009).

\section{CASE STUDIES}

To make clear the power and flexibility of a reactive transport approach in fluid-rock interaction, it is perhaps most instructive at this point to consider some specific case studies. Several topics are considered, including 1) estimation of rates at the field scale, with examples coming from the field of biogeochemical cycling (Dale et al. 2008), chemical weathering (Maher et al. 2009), and contaminant remediation (Mayer et al. 2006). We conclude this section with a discussion of the ways in which isotopic studies can be integrated with multicomponent reactive transport modeling to improve our understanding and quantification of individual pathways within the overall fluid-rock interaction process.

\section{Rates of anaerobic methane oxidation in marine sediments}

The first example involves the use of reactive transport modeling to estimate the rate of anaerobic oxidation of methane (AOM) in marine sediments and is based on the study of Dale et al. (2008). The study was sufficiently detailed that, in addition to providing estimates of fieldscale rates of reaction, it yielded important new insights in to the form of the rate law for AOM, with consideration of both thermodynamic and kinetic effects. Specifically, the dataset and the modeling allowed the authors to explore the bioenergetic limitations on AOM by comparing observed and simulated in situ catabolic energy yields.

The Skagerrak study area is a sequence of marine sediments located in the Norwegian Trench parallel to the southern coast of Norway, with a maximum depth of $700 \mathrm{~m}$ (Knab et al. 2008). The reactive transport modeling framework is validated with two gravity cores from the 
site that show a zone of anaerobic oxidation of methane 0.5 meter thick at 1 meter depth. Dale et al. (2008) developed a one-dimensional diffusion-reaction model for these marine sediments following the general approach outlined in Berner (1980) and Boudreau (1997), writing a set of coupled partial differential equations for the depth profile of solutes and solids. While tortuosity-corrected molecular diffusion is the dominant transport process considered, they also included a bioirrigation term to capture the non-local transport of solutes (especially sulfate) at the top of the profile.

The reaction network considered in the model includes a complex suite of organic carbon degradation pathways (Table 3 and Figure 18). Labile and refractory organic carbon undergo extracellular hydrolysis to low molecular weight dissolved organic compounds (LMW-DOC), defined as glucose for the purposes of the mass balance and Gibbs energy calculations, described with reactions $R_{1}$ and $R_{2}$ respectively (Table 3 ). The LMW-DOC then undergoes fermentation to produce acetate and $\mathrm{H}_{2}\left(\mathrm{R}_{3}\right.$, ferm), which then provide the electrons and Gibbs energy for hydrogenotrophic ( $\mathrm{R}_{4}$, hySR) and acetotrophic $\left(\mathrm{R}_{5}\right.$, acSR) sulfate reduction and for hydrogenotrophic $\left(\mathrm{R}_{6}\right.$, hyME) and acetotrophic $\left(\mathrm{R}_{7}\right.$, acME) methanogenesis. Additionally, the $\mathrm{H}_{2}$ and acetate drive acetogenesis $\left(\mathrm{R}_{9}\right.$, acet) and acetotrophy $\left(\mathrm{R}_{10}\right.$, actr) respectively. The remaining microbial reaction is $A O M$, which produces $\mathrm{H}_{2}\left(\mathrm{R}_{8}, \mathrm{AOM}\right)$. These electron donor reactions represent catabolic pathways in which energy is generated. Anabolic pathways that synthesize biomass are presumably active as well (Rittmann and McCarty 2001; Dale et al. 2006), although it was shown in an earlier paper that the assumption of a steady-state biomass was justified for modeling microbial respiration in most marine sediments (Dale et al. 2006). This eliminates the need for an explicit calculation of the time and space evolution of the biomass for this case.

The reactions in Table 3 represent the catabolism between electron donors and acceptors written in each case as the transfer of one electron. The rate of uptake of an electron donor by a particular catabolic pathway, therefore, follows the stoichiometries in Table 3 and is modulated by both a kinetic term, $F_{K}$, and a thermodynamic term, $F_{T}$, following the pioneering work of Jin and Bethke (2005). According to their approach as implemented in the Skagerrak study, the rate is given by

$$
R_{D}=v_{\max } F_{K} F_{T},
$$

where $v_{\max }$ is the maximum rate of electron donor (ED) utilization, with the biomass implicit in the rate constant. The kinetic factor is given by a standard dual Monod expression

$$
F_{K}=\left(\frac{\left[E_{D}\right]}{K_{E_{D}}+\left[E_{D}\right]}\right)\left(\frac{\left[E_{A}\right]}{K_{E_{A}}+\left[E_{A}\right]}\right),
$$

where $\left[\mathrm{E}_{\mathrm{D}}\right]$ and $\left[\mathrm{E}_{\mathrm{A}}\right]$ refer to the activities of the electron donor and acceptor respectively and $K_{E_{D}}$ and $K_{E_{A}}$ are the half-saturation constants for the electron donor and acceptor respectively. The thermodynamic driving force, which is assumed to drive the reaction in only one direction, is given by (Jin and Bethke 2005)

$$
F_{T}=\max \left[0,\left(1-\exp \left(\frac{\Delta G_{n e t}}{\chi R T}\right)\right)\right],
$$


where $\triangle G_{N E T}$ is the fraction of the Gibbs energy of catabolism that provides a thermodynamic drive for the reaction (further defined below) and $\chi$ is the average stoichiometric coefficient, $\mathrm{R}$ is the gas constant, and $\mathrm{T}$ is the absolute temperature. The average stoichiometric coefficient, $\chi$, is equivalent to the number of protons translocated across the cell membrane during catabolism and is assumed equal to 1 in anaerobic metabolism (Jin and Bethke 2005). As is apparent from Equation (59) and (60), both $F_{K}$ and $F_{T}$ are dimensionless and vary from 0 to 1 . As pointed out, inclusion of such a thermodynamic term removes the need for kinetic inhibition terms as are often found in microbial rate models (Dale et al. 2008).

In the formulation of Dale et al. (2008) as adapted from Jin and Bethke (2005), the $\Delta G_{N E T}$ term is the sum of two Gibbs energy terms of opposite sign

$$
\Delta G_{N E T}=\Delta G_{I N S I T U}+\Delta G_{B Q},
$$

where $\Delta G_{I N S I T U}$ is the in situ Gibbs energy yield of the catabolic process (Table 3 ) and $\Delta G_{B Q}$ is the bioenergetic energy quantum (Hoehler 2004; Dale et al. 2006)

$$
\Delta G_{\text {INSITU }}=\Delta G^{0^{\prime}}+R T \ln [Q] .
$$

Here $\Delta G^{0^{\prime}}$ is the standard Gibbs energy of catabolism at the in situ temperature and corrected for neutral $\mathrm{pH}$ (implying the same conditions for $\Delta G_{I N S I T U}$ ). This was done to provide an ion activity product, $Q$, defined only in terms of electron donors and acceptors, but one could also define these more generally in terms of a standard Gibbs energy of reaction if the hydrogen ion was included in the expression. The minimum bioenergetic energy, $\Delta G_{B Q}$, is the minimum that can be exploited by living cells to synthesize adenosine tri-phosphate (ATP) and is coupled to the transfer of 3-4 protons across the cellular membrane. Under actively growing conditions, this is usually considered to require $\sim 60 \mathrm{~kJ}$ mol ATP ${ }^{-1}$ (Schink 1997; Jin and Bethke 2005). Hoehler (2004) argued instead that a lower limit of 9-12 $\mathrm{kJ}$ mol ATP ${ }^{-1}$ was more reasonable in energystarved communities, leading to a suggested energy minimum on an electron equivalent basis of

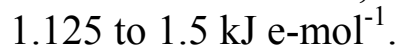

The authors of the Skagerrak study proceeded to calibrate the model on the basis of data collected from the S13 station. The first step was to fit the sulfate data (Figure 19a, g), which was carried out by including a non-local source of sulfate due to bioirrigation (Dale et al. 2008). The measured $\mathrm{CH}_{4}$ profile (Figure 19a) shows the characteristic concave-up shape of AOM. However, the expanded scale in Figure $19 \mathrm{~b}$ also shows that the $\mathrm{CH}_{4}$ exhibits tailing from depth into the sulfate reduction zone, where it persists at a concentration of $10-30 \mu \mathrm{M} \mathrm{CH}_{4}$. To capture this behavior, some tuning of the kinetic and bioenergenetic parameters of the reaction network was required.

The modeling shows that at the depth of the maximum AOM rate, $F_{K}$ and $F_{T}$ for AOM are equal to 0.18 and 0.002 , respectively (Figure 20a, b). The maximum AOM rate, therefore, is strongly reduced by the low bioenergetic drive as a result of thermodynamic conditions very close to the bioenergetic energy minimum $\Delta G_{B Q}$. In contrast, hydrogenotrophic sulfate reduction (hySR), which is considered to consume the $\mathrm{H}_{2}$ and therefore provide the thermodynamic drive for spontaneous methane oxidation (Hoehler 2004), is limited by the kinetic drive, $F_{K}$, rather than by the thermodynamic drive, $F_{T}$ (Figure 20b, f). The modeling clearly demonstrates that the $\mathrm{CH}_{4}$ tail in the sulfate reduction zone is very sensitive to the value of the bioenergetic minimum, $\triangle G_{B Q}$, for AOM (Figure 21). Based on the simulations, the field data suggest a value for 


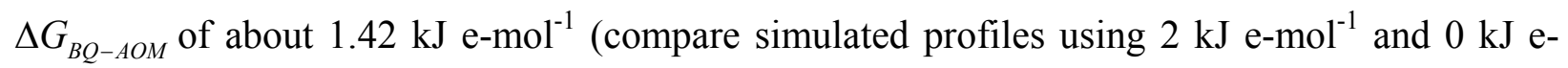
$\left.\mathrm{mol}^{-1}\right)$.

The simulations demonstrate that the $\Delta G_{B Q}$ for $\mathrm{AOM}$ acts as a kind of thermodynamic switch which enables AOM only when $\mathrm{H}_{2}$ levels are maintained at low levels by the sulfate reducing bacteria (Dale et al. 2006; Dale et al. 2008). Furthermore, it is clear that the pore water concentrations in a natural setting of this kind are functions of the kinetic and bioenergetic driving forces of potentially all of the processes affecting reactive intermediates, not just those of the reaction pathway itself. Although kinetically possible, a particular reaction pathway may be limited bioenergetically by other reactions taking place within the microbial network (Dale et al. 2008).

\section{Rates of chemical weathering}

The second example involves the use of reactive transport modeling to estimate the rates of chemical weathering at the Santa Cruz chronosequence (soils of different ages) and relies primarily on the study by Maher et al. (2009). The chronosequence is defined by a series of five marine terraces at different elevations within and northwest of the city of Santa Cruz, California. The local climate is Mediterranean, with cool wet winters and dry hot summers. Precipitation averages $727 \mathrm{~mm}$ annually. The ages of Terraces 1-5 are estimated to be $65 \mathrm{kyr}, 90 \mathrm{kyr}, 137$ kyr, $199 \mathrm{kyr}$, and $226 \mathrm{kyr}$, respectively (White et al. 2009). The local bedrock is covered by 1-10 $\mathrm{m}$ of sediment, principally sands, derived from long shore marine transport of local fluvial sediment from the Santa Cruz Mountains. The spatial distribution of moisture varies seasonally in the upper terrace soils. However, beneath an argillic horizon at about $1 \mathrm{~m}$ depth, moisture contents remain essentially constant throughout the course of the year. Pump tests suggested minimal lateral flow through the argillic horizon, so the deeper portions of the weathering profile behave essentially as a one-dimensional column characterized by steady unsaturated flow at $0.088 \mathrm{~m} / \mathrm{yr}$ as suggested by chloride mass balance (White et al. 2009). The sediments making up the soils are uncemented, so the estimate of a specific surface area of $1.94 \mathrm{~m}^{2} / \mathrm{g}$ for the primary minerals based on grain size and a surface roughness factor is likely a maximum value (Maher et al. 2009). The volume fractions of the primary minerals K-feldspar and plagioclase along with the secondary mineral kaolinite are shown in Figure 22 for the youngest terrace (SCT 1) and the oldest terrace (SCT 5).

Present-day and long-term weathering rates were estimated using the code CrunchFlow. Unsaturated flow was assumed to be steady-state at $0.088 \mathrm{~m} / \mathrm{yr}$. Molecular diffusion was calculated with the diffusion coefficients given in Table 2. Electrochemical migration was also calculated using the approach outlined above and more thoroughly described in Giambalvo et al. (2002). K-feldspar and plagioclase dissolution rates were calculated with a variety of rate laws, but we will focus here on the two providing a good fit to the data while also minimizing the discrepancy between experimental and field weathering rates. The first rate law considered was proposed by Hellmann and Tisserand (2006) based on their extensive experimental studies of albite feldspar as a function of Gibbs energy. They proposed a composite rate law very similar in form to that suggested by Burch et al. (1993) that consists of two individual parallel rate laws: 1) a far from equilibrium rate law, $R_{1}$, with a strongly nonlinear dependence on the Gibbs energy, $\Delta G$, and 2) a close to equilibrium rate law, $\mathrm{R}_{2}$, with a nearly linear dependence on the Gibbs energy 


$$
\begin{gathered}
R_{1}\left(\mathrm{~mol} / \mathrm{m}^{2} / \mathrm{s}\right)=1.02 \times 10^{-12}\left\{1-\exp \left[-0.0000798\left(\frac{|\Delta G|}{R T}\right)^{3.81}\right]\right\} \\
R_{2}\left(\mathrm{~mol} / \mathrm{m}^{2} / \mathrm{s}\right)=1.81 \times 10^{-14}\left[1-\exp \left(-\frac{|\Delta G|}{R T}\right)\right]^{1.17}
\end{gathered}
$$

A second rate law that is considered is referred to as the Al-inhibition model (AIM) and is based on the principle that aluminosilicate dissolution rates are controlled by the formation and destruction of an Al-deficient and Si-rich precursor complex (Gautier et al. 1994; Oelkers et al. 1994; Carroll and Knauss 2005). The rate law considered has the form:

$$
R=A \cdot k_{1} \frac{K_{f}^{\prime}}{K_{f}^{\prime}+a_{A l(\mathrm{OH})_{3}}^{1 / 3}}\left[1-\exp \left(-\frac{|\Delta G|}{3 R T}\right)\right]
$$

where $K_{f}^{\prime}$ is the equilibrium constant for the reaction describing the precursor complex and is calculated from the experimental data of Carroll and Knauss (2005) and described in Maher et al. (2006). The factor of 3 in the denominator of the exponential expression is the Temkin coefficient (Oelkers et al. 1994). For kaolinite precipitation, a linear TST model is used (Aagaard and Helgeson 1982).

Focusing on the mineral volume fractions in Terrace 5, Figure 23 shows that the reactive transport modeling integrated out to $226 \mathrm{kyr}$ captures the geometry of the steep K-feldspar and relatively broad plagioclase fronts very accurately. It is noteworthy that these fits were obtained using virtually the same rate constant and rate law for K-feldspar and albite - the difference in the profiles, in fact, reflects the differences in the solubilities of the two minerals. The model also captures the kaolinite profile fairly well, which indicates that most of the clay developed in the argillic horizon is the result of the early coincidence of the plagioclase and K-feldspar dissolution fronts and does not involve significant quantities of translocated clays (Maher et al. 2009). It should be noted that experimentally-determined rate laws from either the parallel rate law of Hellmann and Tisserand (2006) or the aluminum inhibition model of (Oelkers et al. 1994) can used to match the mineral profiles with virtually no adjustment from experimentally determined values. The rate constants determined in this study are summarized in Table 4. Thus, the oft-cited discrepancy between laboratory and field rates (White and Brantley 2003) does not exist when the nonlinear approach to equilibrium is accounted for, although the supersaturation of secondary phases is an important aspect and also needs to be considered, as discussed below.

To use either of the experimentally-determined rate laws described above and to have them succeed in matching the field weathering data, it is also necessary to allow for significant supersaturation with respect to kaolinite. The effect of the kaolinite supersaturation, either due to very slow kaolinite growth or to formation of a more soluble precursor phase (Steefel and Van Cappellen 1990), is to allow the pore water fluid to approach closer to equilibrium where the rates of dissolution are slower, particularly in the case where a nonlinear dependence on Gibbs energy prevails. The role of slow kaolinite precipitation was hypothesized in an earlier study of 
mineral dissolution in marine sediments (Maher et al. 2006), but pore water data to constrain the saturation state of kaolinite was lacking. In the study of the Santa Cruz Chronosequences, however, pore water data provide an independent, present-day constraint on the kaolinite saturation state. The data indicate that if the kaolinite equilibrium constant determined by Yang and Steefel(2007) at $22^{\circ} \mathrm{C}$ and $\mathrm{pH} 4$ is used, the pore waters are $3-4$ orders of magnitude supersaturated with respect to this phase. Pore waters that were closer to equilibrium with respect to kaolinite would have the effect of making the system more undersaturated with respect to the feldspars, since clay precipitation modulates their saturation state by uptake of aluminum and silica (Steefel and Van Cappellen 1990; Maher et al. 2009). As is apparent from Figure 24, the same model used to closely reproduce mineral profiles in Figure 23 (a result that involves integrating over $226 \mathrm{kyr}$ ) succeeds in capturing the present-day pore water chemistry and the resulting mineral saturation states.

\section{Relative mineral solubilities from reaction front separation}

Reactive transport modeling of the separation of mineral fronts can be used to estimate their relative solubilities with a fair degree of accuracy. This was pointed out as a possibility indirectly by Lichtner (1993), but appears not to have been pursued in the context of a real field system until the study of chemical weathering at the Santa Cruz chronosequences by Maher et al. (2009). In the study at Santa Cruz, the reactive transport modeling showed that the use of equilibrium constants for the specific compositions of feldspar reported, namely a plagioclase with 30\% anorthite $\left(\mathrm{An}_{30}\right)$ and pure K-feldspar (Arnorsson and Stefansson 1999), could not match the observed separation of the K-feldspar and plagioclase weathering fronts. A significantly better match (see Figure 23) was achieved by using end-member compositions of pure K-feldspar and sodic plagioclase $\left(\mathrm{An}_{0}\right)$. As it turns out, the front positions are quite sensitive to the equilibrium constants used, since in the local equilibrium limit the front separation should be a function only of the thermodynamics (Lichtner 1993). Maher et al. (2009) reached the same conclusion using numerical modeling with the reactive transport software CrunchFlow. These results, which are considered to be robust, suggested a model in which the $\mathrm{An}_{30}$ plagioclase was better described as an intergrowth of fine scale lamellae of albite and anorthite such that the anorthitic component dissolved first, leaving the albite as the surviving reactant controlling the front positions once weathering had proceeded to a sufficient extent (Maher et al. 2009).

\section{Rates of biogeochemical reactions in heterogeneous media}

A third example involves simulations of rates in the subsurface to predict the effectiveness and longevity of a remediation treatment for acid mine drainage. This is a topic of interest to researchers and engineers interested in contaminant transport and remediation, in addition to geochemists, and we now see these groups exploring the topic of fluid-rock interaction with much greater depth and focus than was the case previously. The study area is a permeable reactive barrier for treatment of mine drainage high in iron and sulfate and low in $\mathrm{pH}$ at the Nickel Rim mine site in Ontario, Canada (Mayer et al. 2006). The permeable barrier consists of an organic carbon mixture designed to promote microbial reduction of sulfate so as to precipitate sparingly soluble iron sulfide (FeS). The aquifer is bounded by bedrock and is well constrained hydrologically, with a known flux across the domain. The water chemistry monitoring network, the most important of the data used to constrain the rates of reaction and thus the performance of the barrier, consists of 12 well nests aligned parallel to the direction of groundwater flow (Figure 25). Solid phase data (Herbert Jr. et al. 2000) was also used to constrain the reaction network. 
Significant spatial variations are observed in the amount of sulfate and iron removed within the barrier (Figure 26), with the differences attributed primarily to variations in groundwater flow velocities. The rate of sulfate reduction in the barrier is observed to decline over time as the organic carbon is depleted (Benner et al. 2002).

The modeling of the biogeochemical reaction network at the site is carried out with a simpler approach than was used in Dale et al. (2008). The principal reaction involves the oxidation of organic carbon by sulfate to produce dissolved sulfide according to

$$
\mathrm{CH}_{2} \mathrm{O}_{(\mathrm{s})}+\frac{1}{2} \mathrm{SO}_{4}^{2-} \rightarrow \mathrm{HCO}_{3}^{-}+\frac{1}{2} \mathrm{H}_{2} \mathrm{~S}_{(\mathrm{aq})}+\mathrm{H}_{2} \mathrm{O}
$$

This reaction is modeled using a standard dual Monod kinetic scheme, that is, essentially the formulation given in Equation (58) without the thermodynamic limitation term, $F_{T}$. The sulfide produced in this reaction combines with dissolved $\mathrm{Fe}(\mathrm{II})$ to precipitate mackinawite (FeS). Elemental sulfur is also detected and is modeled as another parallel sulfate reduction reaction that goes to an intermediate redox state.

Combining the groundwater flow field and reaction network developed for the site, Mayer et al. (2006) were able to match the observed solute concentration distribution remarkably well (compare Figure 26 and 27).

In matching the concentration contours at 23 months, Mayer et al. (2006) demonstrated that such data, when interpreted with appropriately mechanistic reactive transport modeling, could provide a reasonable estimate of spatially and temporally variable reaction rates in the subsurface (Figure 28). The analysis thus allows them to further develop estimates for the efficacy and longevity of the permeable reactive barrier. Such analyses, to the extent that they can be fully validated, suggest the possibility that reactive transport modeling can provide significant cost savings over expensive field tests, although there is probably no scenario in which the approach dispenses with field testing altogether.

\section{Isotopic reactive transport approaches for deciphering physical and chemical processes}

Early reactive transport modeling studies involving isotopes tend to use lumped parameter models describing a generic isotopic exchange reaction (Richter and Liang 1993; Johnson and DePaolo 1997; Maher et al. 2003). Other approaches use dimensional analysis to simplify systems in order to quantify key parameters (Fantle and DePaolo 2007). Both approaches generally consider the isotopic variations in isolation from the overall chemical evolution of the system, thus limiting the amount of information that can be extracted from the isotopic data. Most importantly, isotopic variations can provide an additional tracer of reaction pathways within ambiguous reaction networks. An important new development is the rigorous incorporation of isotopes into multicomponent models such that the isotopic variations are considered in conjunction with the major element chemistry and thus provide an additional framework for identifying and quantifying physical and chemical processes. As we view the development of isotopic reactive transport models as an important new frontier in fluid-rock interaction, we provide a few examples to illustrate the variety of questions that can be approached with the coupling. 
With respect to physical processes such as transport and transport pathways, naturally occurring variations in the isotopic composition of waters can be used to determine preferential flow paths (Luo et al. 2000) or to determine net recharge rates throughout an aquifer (Maher et al. 2003; Singleton et al. 2006). Singleton et al. (2006) used Sr isotopic variations in an unconfined basaltic aquifer to calculate the long-term net infiltration flux along a flow path. The approach relied on the isotopic variations imparted to the waters from the lithology, with high ${ }^{87} \mathrm{Sr} /{ }^{86} \mathrm{Sr}$ values $(0.712)$ occurring in the unsaturated zone due to presence of granitic sediments (Maher et al. 2003), and relatively low values (0.707) associated with underlying basalts. By accounting for the basalt-fluid interaction along the flow path, regions of high infiltration rates stemming from human activities could be quantitatively distinguished from natural recharge conditions. This example highlights the ability to use isotopically distinct sources to quantify additional flux terms in the reactive transport equation (e.g. infiltration fluxes), thus obtaining additional information that could not be extracted from a simple mixing model.

Isotopes can also be used to decipher individual reaction rates in systems where a key component (e.g. $\mathrm{Ca}, \mathrm{Na}, \mathrm{Si}, \mathrm{Al}$ ) is derived from multiple reactions, or cycled within a reaction network (Maher et al. 2006). For example, in deep-sea sediments silicate dissolution results in the release of $\mathrm{Ca}$ to the pore water. Some of this $\mathrm{Ca}$ may then be incorporated into newly formed calcite along with the initial seawater $\mathrm{Ca}$. Concurrently, changes in the porewater chemistry and/or Ostwald ripening may result in calcite recrystallization, whereby the porewater $\mathrm{Ca}$ is exchanged with both the initial marine calcite and the newly formed calcite. To constrain the rates of mineral transformation in this system, Maher et al. (2006) incorporated the $\left({ }^{234} \mathrm{U} /{ }^{238} \mathrm{U}\right)$ isotopic system into a reactive transport model (CrunchFlow) in order to use the U isotopic variations in pore fluid, silicate minerals and bulk calcite as an additional mass transfer constraint. In this model, the processes of preferential release of ${ }^{234} \mathrm{U}$ from solids to the fluid due to $\alpha$-recoil (during the decay of ${ }^{238} \mathrm{U}$ ), dissolution of silicate minerals, and the co-precipitation of $\mathrm{U}$ into calcite were considered. Although the primary mineral dissolution rates could also be constrained by the aqueous $\mathrm{Ca}$ and $\mathrm{Si}$ profiles, the measured isotopic data for the fluid and the calcite could only be reconciled with the model if a substantial fraction (ca. 30\%) of the primary calcite was recrystallized (Figure 29). This isochemical process would otherwise be undetectable and the sensitivity of isotopes to mineral-fluid exchange provided a unique means of detecting the substantial recrystallization that took place. Mineral-fluid exchange during early diagenesis has important implications for the integrity of a material such as calcite that is commonly used for paleoceanographic studies and studies of this type can be used to understand more clearly how the isotope systems may be modified.

The previous examples highlight isotopic reactive transport approaches involving relatively heavy isotope pairs where mass dependent fractionation is of minor importance relative to other signatures such as those imposed by variations in lithology and radioactive decay. However, for many isotopic systems of interest in biogeochemical cycles, isotopic variations derive from both kinetic and equilibrium effects. An advantage of the integration of isotopes into reactive transport models is that diffusion coefficients specific to each isotope can be implemented to account for kinetic effects resulting from aqueous or gaseous diffusion. For kinetic isotope effects that occur as a result of biological or enzymatic processes, the fractionation factor can be defined as the ratio of the rate constants for each isotope. Similarly, equilibrium constants can be defined for each isotope system to reflect the equilibrium fractionation factors. This ability to track the systematics of individual isotope pairs in conjunction with major element chemistry offers unique opportunities that are just beginning to be explored. 
A recent study by Dale et al. (2009) provides an interesting example where the coupling of the major element chemistry is used to interpret sulfur isotopic data from organic rich muds of the Namibian Shelf. At this site, the supply of hypoxic water coupled with high primary productivity results in anoxic conditions at the sediment-water interface. The anoxic conditions favor the accumulation of particulate organic carbon, resulting in extremely high rates of sulfate reduction $\left(100 \mathrm{mM} /\right.$ year of $\left.\mathrm{SO}_{4}{ }^{2-}\right)$. The high rates of sulfate reduction coupled with the notable lack of oxidants results in $\mathrm{H}_{2} \mathrm{~S}$ concentrations of approximately $10 \mathrm{mM}$. In this setting, Thiomargarita namibiensis, a non-phototrophic large sulfur bacteria produces $\mathrm{SO}_{4}{ }^{2-}$ and $\mathrm{NH}_{4}{ }^{+}$by catalyzing the reaction between $\mathrm{H}_{2} \mathrm{~S}$ and $\mathrm{NO}_{3}{ }^{-}$(Schulz et al. 1999; Bruchert et al. 2003). The $\mathrm{SO}_{4}{ }^{2-}$ then becomes available to oxidize organic carbon or methane. In order to understand the coupling between the $\mathrm{C}, \mathrm{N}$, and $\mathrm{S}$ cycles, and the role of Thiomargarita in the oxidationreduction cycle of $\mathrm{S}$, a multicomponent reactive transport model was developed that includes an explicit representation of the individual $\mathrm{S}$ isotopes $\left({ }^{34} \mathrm{~S},{ }^{32} \mathrm{~S}\right)$ in addition to the major chemical components (Dale et al. 2009). The measurements used to constrain the 1-D model include pore water concentrations, solid phase analyses of $\mathrm{C}, \mathrm{N}, \mathrm{S}$, reactive Fe and elemental $\mathrm{S}$, and rates of sulfate reduction determined using ${ }^{35} \mathrm{~S}$-sulfate whole-core incubations. The porosity and sedimentation rate over the 5 meter deep core were also constrained to account for the effect of compaction during burial.

The reaction network and major geochemical pathways in relationship to expected isotopic fractionations $(\varepsilon)$ are shown in Figure 30. The particulate organic carbon (POC) is characterized as three reactive fractions according to a multi-G model (Westrich and Berner 1984) and is degraded via sulfate reduction, methanogenesis and dissimilatory Fe reduction. $\mathrm{CH}_{4}$ diffusing upwards was allowed to be consumed by anaerobic oxidation of methane (AOM). The $\mathrm{NO}_{3}{ }^{-}$is assumed to be confined within the Thiomargarita cell and thus denitrification is not considered. The maximum fractionation for dissimilatory sulfate reduction $\left(\varepsilon_{\mathrm{SR}}\right)$ derived from both reactive transport model approaches for marine sediments (Goldhaber and Kaplan 1980; Rudnicki et al. 2001; Wortman et al. 2001) and theoretical approaches suggest $\varepsilon_{\mathrm{SR}}$ values of 70 to $80 \%$ (Farquhar et al. 2003), whereas the maximum value measured under laboratory conditions is on the order of 47\% (Bruchert, 2004). Because sulfide oxidizing bacteria have not been grown in pure cultures, the fractionation of sulfide during sulfide oxidation $\left(\varepsilon_{\mathrm{SOx}}\right)$ is not well known, but is expected to be $\sim 5 \%$. By using the constraints from detailed modeling of the $\mathrm{C}, \mathrm{N}$, $\mathrm{S}$ cycles to balance the $\mathrm{S}$ isotope system, the values for $\varepsilon_{\mathrm{SR}}$ and the value of $\varepsilon_{\mathrm{SOx}}$ due to the activity of Thiomargarita can also be constrained.

To formulate the isotopic system, rate constants are prescribed for each isotope for each reaction pathway so that the overall rate $(\mathrm{Ri})$ is simply the sum of the two reaction rates:

$$
R_{i}={ }^{32} R_{i}+{ }^{34} R_{i}={ }^{32} k_{i}{ }^{32} S+{ }^{34} k_{i}{ }^{34} S
$$

where ${ }^{32} k_{i}$ and ${ }^{34} k_{i}$ are the corresponding rate constants. The individual reaction rates for the isotopic species can then be formulated as:

$$
{ }^{32} R_{i}=R_{i}\left(\frac{\alpha_{i}{ }^{32} S}{{ }^{34} S+\alpha_{i}{ }^{32} S}\right)
$$

using the ratio of the two rate constants to define the fractionation factor $\alpha_{i}$ : 


$$
\alpha_{i}=\frac{{ }^{32} k}{{ }^{34} k}=1+\frac{\varepsilon_{i}}{1000}
$$

Because the fractionation factor associated with sulfate reduction is observed to increase with a decrease in the rates of sulfate reduction, $\varepsilon_{\mathrm{SR}}$ was equated with the rate of sulfate reduction using a linear function:

$$
\varepsilon_{S R}=\left(\varepsilon_{S R}\right)_{\max }-m_{S R} r_{i}
$$

where $m_{S R}$ describes the gradient of change of $\varepsilon_{\mathrm{SR}}$ as a function of rate $\left(r_{i}\right)$ of sulfate reduction or anaerobic methane oxidation (AOM). Figure 32 shows the results of using the major element chemistry alone to constrain the values for $\varepsilon_{\mathrm{SR}}$ and $\varepsilon_{\mathrm{SOx}}$. The $\delta^{34} \mathrm{~S}_{\mathrm{SO} 4}$ increases with depth in the zone of sulfate reduction. The $\delta^{34} \mathrm{~S}_{\mathrm{H} 2 \mathrm{~S}}$ rapidly decreases to a minimum of $-24 \%$ by $10 \mathrm{~cm}$ depth, followed by a progressive increase with depth. The values of $\varepsilon_{\text {SOx }}$ and $\varepsilon_{\text {SR-max }}$ of $25 \%$ and $100 \%$ are the model values required to fit the isotope profiles in Figure 31, and a corresponding sensitivity analysis revealed the uniqueness of these parameters. However, these model-derived fractionations are far greater than previous laboratory based estimates (as summarized in Bruchert (2004)) suggesting that the model for the SOx pathway may be missing an additional process. Dale et al. (2009) suggest that this process may be a stepped disproportionation of $\mathrm{S}$ in the cell from $\mathrm{H}_{2} \mathrm{~S}$ to $\mathrm{S}^{\mathrm{O}}$ to $\mathrm{SO}_{4}{ }^{2-}$. The disproportionation step (e.g. $\mathrm{S}^{\mathrm{o}}$ to $\mathrm{SO}_{4}{ }^{2-}$.) would occur with a large and opposite fractionation between $\mathrm{H}_{2} \mathrm{~S}$ and $\mathrm{SO}_{4}{ }^{2-}$. Including this additional step in the model resulted in model values for $\varepsilon_{\mathrm{SOx}}$ and $\varepsilon_{\mathrm{SR} \text {-max }}$ of $5 \%$ and $78 \%$. These valuesare consistent with the theoretical and laboratory values. While multi-stepped disproportionation by Thiomargarita has not been determined experimentally, this example highlights the utility of the reactive transport approach in using natural isotopic data to infer reaction pathways.

An additional important aspect of the data and model presented by Dale et al. (2009) is shown in Figure 32: the measured $\delta^{34} \mathrm{~S}$ values for the solid phases show greater depletion in $\mathrm{FeS}_{2}$ suggesting fractionation during precipitation, although the fractionation factor that would be predicted is zero. In addition, both the $\mathrm{H}_{2} \mathrm{~S}$ and values of the authigenic phases continue to change with depth beneath the zone of sulfate reduction, suggestive of ongoing exchange between the aqueous $\mathrm{H}_{2} \mathrm{~S}$ pool and the reactive portions of the solids. To consider this possibility, Dale et al. (2009) considered a separate exchange process where discrete fractions of the solids $\left(f_{\text {ex }}\right)$ are allowed to undergo isotopic exchange with the fluid. The model was found to reproduce all of the observed data if $f_{\mathrm{ex}}$ was on the order of 0.6 to 0.8 which means that 60 to $80 \%$ of the solid phase exchanges with the fluid. This result is similar to the isotopic exchange observed in the $U$ isotopic data discussed above and seems to suggest that even during early diagenesis modification of the isotopic and possibly trace element features are likely. In addition, this ongoing exchange during diagenesis may be overlooked in settings where complete profiles are not available.

As the field of isotope geochemistry considers more complex biogeochemical and geochemical systems, the ability to constrain the isotope systematics using major element chemistry offers a number of advantages for determining isotopic fractionations associated with specific processes. Conversely, as in the case of the Maher et al. (2006) and the Dale et al. (2009) studies, inclusion of the isotope variations can reveal intricacies of the reaction network and mechanisms that were not detectable from the major element chemistry alone. The presence of multiple reaction pathways can make the interpretation of measured data difficult, but the 
incorporation of isotopic data into overall framework improves the chances of deciphering the system behavior.

\section{CONCLUDING REMARKS}

A good understanding of the coupling between transport and (bio)geochemical kinetics is essential in the study of fluid-rock interaction. In this chapter, we have shown that in open systems characterized by transport, the characteristic time scales of reaction need to be compared with the characteristic time scales for transport-geologic time is often irrelevant. The transport processes that are relevant for the study of water-rock interaction include advection, due in most cases to Darcy flow through porous media, molecular diffusion modified by electrochemical migration where charged species are present, and hydrodynamic dispersion. An idealized version of the reactive transport (or advection-dispersion-reaction) equation was presented and the important non-dimensional quantities were briefly derived and discussed.

The treatment of fluid-rock interaction systems as well-mixed reactors was challenged and it was shown how an analysis of macrodispersion, which has been widely discussed in the hydrologic literature, can be used to produce a residence time probability density function that predicts the ensemble of reaction times for flow paths through heterogeneous media. Real waterrock systems are typically characterized by physical, chemical, and microbiological heterogeneities that can give rise to concentration gradients, and thus to spatially variable reaction rates. It was shown that it is necessary to upscale reaction rates in fluid-rock systems that are not perfectly mixed-simple averaging that does not take into account the multi-scale character of most porous media will inevitably result in rates that are scale dependent.

The remainder of the chapter examined the potential of modern numerical reactive transport modeling for solving important problems in fluid-rock interaction. Three different types of models were proposed to describe reactive transport in porous media, with the choice depending to some extent on the scale of interest and the architecture of the porous medium: 1) continuum models, 2) pore scale models, and 3) multiple continua or hybrid models involving a combination of scales. It was shown that various data, ranging from pore water chemistry to mineral volume fractions, may be used to constrain reactive transport models for fluid-rock interaction. Case studies are presented that demonstrate that reactive transport modeling can be used to estimate rates in 1) marine sediments characterized by anaerobic oxidation of methane, 2) chemical weathering, and 3) a permeable reactive barrier used to remediate groundwater contamination. Finally, the power of integrating isotopic systematics into mechanistic reactive transport modeling was briefly explored and the case was made that incorporation of isotopic data into overall framework of multicomponent reactive transport models improves our chances of deciphering complex biogeochemical systems.

\section{ACKNOWLEDGMENTS}

We are pleased to be able to contribute this chapter to a volume honoring the career of Jacques Schott, who has championed a mechanistic and quantitative understanding of geochemistry now for over 30 years. We thank Sergi Molins-Rafa for his careful review of the manuscript. Funding from the Office of Science at the U.S. Department of Energy through the Geoscience Program in the Office of Basic Energy Sciences (Contract No. DE-AC0205CH11231) is gratefully acknowledged. 


\section{REFERENCES}

Aagaard P and Helgeson HC (1982) Thermodynamic and kinetic constraints on reaction rates among minerals and aqueous solutions, I. Theoretical considerations. American Journal of Science 282:237-285

Aris R (1956) On the dispersion of a solute in a fluid flowing through a tube. Proc. Royal Society London Series A 235:67-77

Arnorsson S and Stefansson A (1999) Assessment of feldspar solublity constants in water in the range 0 degrees to 350 degrees $\mathrm{C}$ at vapor saturation pressures. American Journal of Science 299:173-209

Bahr JM and Rubin J (1987) Direct comparison of kinetic and local equilibrium formulations for solute transport affected by surface reactions. Water Resources Research 23:438-452

Bear J (1972) Dynamics of Fluids in Porous media. Dover, New York

Benner SG, Blowes DW, Ptacek CJ, and Mayer KU (2002) Rates of sulfate reduction and metal sulfide precipitation in a permeable reactive barrier. Applied Geochemistry 17:301-320

Berner RA (1980) Early Diagenesis: A Theoretical Approach. Princeton University Press, Princeton

Bethke CM and Johnson TM (2002) Paradox of groundwater age. Geology 30:107-110

Boudreau BP (1997) Diagenetic Models and their Implementation. Springer-Verlag,

Bruchert V (2004) Physiological and ecological aspects of sulfur isotope fractionation during bacterial sulfate reduction. In Sulfur Biogeochemistry--Past and Present AP Amend, KJ Edwards, and TW Lyons (ed) Geological Society of America, p 1-16

Bruchert V, Joergensen BB, Neumann K, Riechmann D, Schloesser M, and Schulz HN (2003) Regulation of bacterial sulfate reduction and hydrogen sulfide fluxes in the central Namibian coastal upwelling zone. Geochimica Cosmochimica Acta 67:4505-4518

Burch TE, Nagy KL, and Lasaga AC (1993) Free-energy dependence of albite dissolution kinetics at 80 degreees $\mathrm{C}$ and $\mathrm{pH}$ 8.8. Chemical Geology 105:137-162

Carroll SA and Knauss KG (2005) Dependence of labradorite dissolution kinetics on CO2(aq), $\mathrm{Al}(\mathrm{aq})$, and temperature. Chemical Geology 217:213-225

Cirpka OA (2002) Choice of dispersion coefficients in reactive transport calculations on smoothed fields. Journal of Contaminant Hydrology 48:261-282

Cochepin B, Trotignon L, Bildstein O, Steefel CI, Lagneau V, and Van der Lee J (2008) Intercomparison of predictions on a 2-D cementation experiment in porous medium. Advances in Water Resources 31:1540-1551

Dagan G (1988) Time-dependent macrodispersion for solute transport in anisotropic heterogeneous aquifers. Water Resources Research 24:1491-1500

Dagan G (1989) Flow and transport in porous formations. Springer-Verlag, Berlin; New York

Dale AW, Bruchert V, Alperin M, and Regnier P (2009) An integrated sulfur isotope model for Namibian shelf sediments. Geochimica Cosmochimica Acta 73:1923-1944

Dale AW, Regnier P, Knab NJ, Joergensen BB, and Van Cappellen P (2008) Anaerobic oxidation of methane (AOM) in marine sediments from Skagerrak (Denmark): II. Reaction-transport modeling. Geochimica Cosmochimica Acta 72:2880-2894

Dale AW, Regnier P, and Van Cappellen P (2006) Bioenergetic controls on anaerobic oxidation of methane $(\mathrm{AOM})$ in coastal marine sediments: A theoretical analysis. American Journal of Science 306:246-294

Darcy H (1856) Les fontaines publiques de la ville de Dijon. Dalmont, Paris 
Daugherty RL and Franzini JB (1965) Fluid Mechanics with Engineering Applications. McGraw-Hill, New York

Denbigh K (1981) The Principles of Chemical Equilibrium. Cambridge University Press, Cambridge

Dobson PF, Kneafsey TJ, Sonnenthal EL, Spycher NF, and Apps JA (2003) Experimental and numerical simulation of dissolution and precipitation: implications for fracture sealing at Yucca Mountain. Journal of Contaminant Hydrology 62-63:459-476

Fantle MS and DePaolo DJ (2007) Ca isotopes in carbonate sediment and pore fluid from ODP Site 807A: The $\mathrm{Ca} 2+(\mathrm{aq})$-calcite equilibrium fractionation factor and calcite recrystallization rates in Pleistocene sediments. Geochimica Cosmochimica Acta 71:2524-2546

Gautier JM, Oelkers EH, and Schott J (1994) Experimental study of K-feldspar dissolution rates as a function of chemical affinity at $150 \mathrm{C}$ and $\mathrm{pH}$ 9. Geochimica Cosmochimica Acta 58:4549-4560

Gelhar LW (1986) Stochastic subsurface hydrology from theory to applications. Water Resources Research 22:135S-145S

Gelhar LW (1993) Stochastic subsurface hydrology. Prentice-Hall, Englewood Cliffs, N.J.

Gelhar LW and Axness CL (1983) Three-dimensional stochastic analysis of macrodispersion in aquifers. Water Resources Research 19:161-180

Gelhar LW, Welty C, and Rehfeldt KR (1992) A critical-review of data on field-scale dispersion in qquifers. Water Resources Research 28:1955-1974

Giambalvo ER, Steefel CI, Fisher AT, Rosenberg ND, and Wheat CG (2002) Effect of fluidsediment reaction on hydrothermal fluxes of major elements, eastern flank of the Juan de Fuca Ridge. Geochimica Cosmochimica Acta 66:1739-1757

Goldhaber MB and Kaplan IR (1980) Mechanisms of sulfur incorporation and isotope fractionation during early diagenesis in sediments of the Gulf of California. Marine Chemistry 9:95-143

Haggerty R, Schroth MH, and Istok JD (1998) Simplified method of "Push-Pull" test data analysis for determining in situ reaction rate coefficients. Groun Water 36:314-324

Harvey C and Gorelick SM (2000) Rate-limited mass transfer or macrodispersion: Which dominates plume evolution at the Macrodispersion Experiment (MADE) site? Water Resources Research 36:637-650

Helgeson HC (1968) Evaluation of irreversible reactions in geochemical processes involving minerals and aqueous solutions-I. Thermodynamic relations. Geochimica Cosmochimica Acta 32:853-877

Helgeson HC, Garrels RM, and MacKenzie FT (1969) Evaluation of irreversible reactions in geochemical processes involving minerals and aqueous solutions-II. Applications. Geochimica Cosmochimica Acta 33:455-482

Hellmann R and Tisserand D (2006) Dissolution kinetics as a function of Gibbs free energy of reaction: an experimental study based on albite feldspar. Geochimica Cosmochimica Acta 70:364-383

Herbert Jr. RB, Benner SG, and Blowes DW (2000) Solid phase iron-sulfur geochemistry of a reactive barrier for treatment of mine drainage. Applied Geochemistry 15:1331-1343

Hoehler TM (2004) Biological energy requirements as quantitative boundary conditions for life in the subsurface. Geobiology 2:205-215 
Jin QA and Bethke CM (2005) Predicting the rate of microbial respiration in geochemical environments. Geochimica Cosmochimica Acta 69:1133-1143

Johnson TM and DePaolo DJ (1997) Rapid exchange effects on isotope ratios in groundwater systems, 1. Development of a transport-dissolution-exchange model. Water Resources Research 33:187-195

Kang Q, Lichtner PC, and Zhang D (2007) An improved lattice Boltzmann model for multicomponent reactive transport in porous media at the pore scale. Water Resources Research 43, doi:10.1029/2006WR005551

Knab NJ, Cragg BA, Borowski C, Parkes JR, and Pancost R (2008) Anaerobic oxidation of methane $(\mathrm{AOM})$ in marine sediments from Skagerrak (Denmark): I. Geochemical and micrbiological analyses. Geochimica Cosmochimica Acta 72:2868-2879

Lasaga AC (1981) Rate laws in chemical reactions. In Kinetics of Geochemical Processes. Vol 8 ACLaRJ Kirkpatrick (ed) Mineralogical Society of America, p 135-169

Lasaga AC (1984) Chemical kinetics of water-rock interactions. Journal of Geophysical reserach $89: 4009-4025$

Lasaga AC (1998) Kinetic theory in the earth sciences. Princeton University Press, Princeton

Li L, Peters CA, and Celia MA (2006) Upscaling geochemical reaction rates using pore-scale network modeling. Advances in Water Resources 29:1351-1370

Li L, Peters CA, and Celia MA (2007a) Applicability of averaged concentrations in determining geochemical reaction rates in heterogeneous porous media American Journal of Science 307:1146-1166

Li L, Peters CA, and Celia MA (2007b) Effects of mineral spatial distribution on reaction rates in porous media. Water Resources Research 43, DOI: 10.1029/2005WR004848

Li L, Steefel CI, and Yang L (2008) Scale dependence of mineral dissolution rates within single pores and fractures. Geochimica Cosmochimica Acta 72:99-116.

Lichtner PC (1985) Continuum model for simultaneous chemical reactions and mass transport in hydrothermal systems. Geochimica Cosmochimica Acta 49:779-800

Lichtner PC (1988) The quasi-stationary state approximation to coupled mass transport and fluid-rock interaction in a porous medium. Geochimica Cosmochimica Acta 52:143-165

Lichtner PC (1993) Scaling properties of time-space kinetic mass transport equations and the local equilibrium limit. American Journal of Science 293:257-296

Lichtner PC (1996) Continuum formulation of multicomponent-multiphase reactive transport. In Reactive transport in porous media. Vol 34 PC Lichtner, CI Steefel, and EH Oelkers (ed) Mineralogical society of America, Washington, D. C., p 1-81

Lichtner PC (1998) Modeling reactive flow and transport in natural systems. Proceedings of the Rome Seminar on Environmental Geochemistry, 5-72

Lichtner PC and Kang Q (2007) Upscaling pore-scale reactive transport equations using a multiscale continuum formulation. Water Resources Research 43, doi:10.1029/2006WR005664

Luo SD, Ku TL, Roback R, Murrell MT, and McLing TL (2000) In-situ radionuclide transport and preferential groundwater flows at INEEL (Idaho): Decay-series disequilibrium studies. Geochimica Cosmochimica Acta 64:867-881

Maher K, DePaolo DJ, Conrad ME, and Serne RJ (2003) Vadose zone infiltration rate at Hanford, Washington, inferred from Sr isotope measurements. Water Resources Research 39:1029-1043 
Maher K, Steefel CI, DePaolo DJ, and Viani BE (2006) The mineral dissolution rate conundrum: Insights from reactive transport modeling of $U$ isotopes and pore fluid chemistry in marine sediments. Geochimica et Cosmochimica Acta 70:337-363

Maher K, Steefel CI, White AF, and Stonestrom DA (2009) The role of reaction affinity and secondary minerals in regulating chemical weathering rates at the Santa Cruz Soil Chronosequence, California. Geochimica Cosmochimica Acta 73:2804-2831

Malmström ME, Destouni G, Banwart SA, and Strömberg BHE (2000) Resolving the scaledependence of mineral weathering rates. Environmental Science Technology 34:13751378

Mayer KU, Benner SG, and Blowes DW (2006) Process-based reactive transport modeling of a permeable reactive barrier for the treatment of mine drainage. Journal of Contaminant Hydrology 85:195-211

Meile C and Tuncay K (2006) Scale dependence of reaction rates in porous media. Advances in Water Resources 29:62-71

Murphy WM, Oelkers EH, and Lichtner PC (1989) Surface reaction versus diffusion control of mineral dissolution and growth rates in geochemical processes. Chemical Geology 78:357-380

Navarre-Sitchler A, Steefel CI, Yang L, Tomutsa L, and Brantley SL (2009) Evolution of porosity and diffusivity associated with chemical weathering of a basalt clast. Journal of Geophysical Research--Earth Surface Processes, doi:10.1029/2008JF001060

Newman JS (1991) Electrochemical Systems. Prentice-Hall, Englewood Cliffs, New Jersey

Oelkers EA (1996) Physical and chemical properties of rocks and fluids for chemical mass transport calculations. In Reactive Transport in Porous Media. Vol 34 PC Lichtner, CI Steefel, and EH Oelkers (ed) The Mineralogical Society of America, Washington, D.C., p 131-191

Oelkers EH, Schott J, and Devidal J-L (1994) The effect of aluminum, pH, and chemical affinity on the rates of aluminosilicate dissolution reactions. Geochimica et Cosmochimica Acta 58:2011-2024

Onsager L (1931) Reciprocal relations in irreversible processes II. Physical Review 38:22652279

Ortoleva P, Chadam J, Merino E, and Sen A (1987) Geochemical self-organization II: The reactive-infiltration instability. American Journal of Science 287:1008-1040

Palandri JL and Kharaka YK (2004) A compilation of rate parameters of water-mineral interaction kinetics for application to geochemical modeling. USG Survey. WaterResources Investigations Reports 04-1068

Pharmamenko EI (1967) Electrical Properties of Rock. Plenum Press,

Plummer LN, Busenberg E, Bohlke JK, Nelms DL, Michel RL, and Schlosser P (2001) Groundwater residence times in Shenandoah National Park, Blue Ridge Mountains, Virgina, USA: a multi-tracer approach. Chemical Geology 179:93-111

Pokrovsky OS, Golubev SV, and Schott J (2005) Dissolution kinetics of calcite, dolomite and magnesite at 25 degrees $\mathrm{C}$ and 0 to 50 atm pCO(2). Chemical Geology 217:239-255

Prigogine I (1967) Introduction to the Thermodynamics of Irreversible Processes. Interscience, New York

Pruess K and Narisimhan TN (1985) A practical method for modeling fluid and heat flow in fractured porous media. Society of Petroleum Engineers Journal 25:14-26 
Richter FM and Liang Y (1993) The rate and consequences of Sr diagenesis in deep-sea carbonates. Earth and Planetary Science Letters 117:553-565

Rudnicki MD, Elderfield H, and Spiro B (2001) Fractionation of sulfur isotopes during bacterial sulfate reduction in deep ocean sediments at elevated temperatures. Geochimica Cosmochimica Acta 65:777-789

Schink B (1997) Energetics of syntrophic cooperation in methanogenic degradation. Microbiology and Molecular Biology Reviews 61:262-280

Schnoor JL (1990) Kinetics of chemical weathering: a comparison of laboratory and field weathering rates. In Aquatic Chemical Kinetics: Reaction Rates of Processes in Natural Waters W Stumm and JJ Morgan (ed) Wiley, p 475-504

Schulz HN, Brinkhoff T, Ferdelman TG, Hernandez Marine M, Teske A, and Joergensen BB (1999) Dense populations of a giant sulfur bacterium in Namibian shelf sediments. Science 284:493-495

Singleton MJ, Maher K, DePaolo DJ, Conrad ME, and Dresel PE (2006) Dissolution rates and vadose zone drainage from strontium isotope measurements of groundwater in the Pasco Basin, WA unconfined aquifer. Journal of Hydrology 321:39-58

Skagius K and Neretnieks I (1986) Diffusivity measurements and electrical-resistivity measurements in rock samples under mechanical stress. Water Resources Research 22:570-580.

Snodgrass MF and Kitanidis PK (1998) A method to infer in-situ reaction rates from push-pull experiments. Ground Water 36:645-650

Spiegelman M, Kelemen PB, and Aharonov E (2001) Causes and consequences of flow organization during melt transport: The reaction infiltration instability in compactible media. Journal of Geophysical Research 106:2061-2077

Steefel CI (2007) Geochemical kinetics and transport. In Kinetics of Water-Rock Interaction SL Brantley, J Kubicki, and AF White (ed) Springer, New York, p 545-589

Steefel CI, DePaolo DJ, and Lichtner PC (2005) Reactive transport modeling: An essential tool and a new research approach for the Earth Sciences. Earth and Planetary Science Letters 240:539-558

Steefel CI and Lasaga AC (1990) The evolution of dissolution patterns: Permeability change due to coupled flow and reaction. In Chemical Modeling of Aqueous Systems II. Vol 416 D Melchior and RL Bassett (ed) American Chemical Society, Washington, p 212-225.

Steefel CI and Lasaga AC (1994) A coupled model for transport of multiple chemical species and kinetic precipitation/dissolution reactions with application to reactive flow in single phase hydrothermal systems. Am. J. Sci. 294:529-592

Steefel CI and Lichtner PC (1994) Diffusion and reaction in rock matrix bordering a hyperalkaline fluid-filled fracture. Geochimica et Cosmochimica Acta 58:3595-3612

Steefel CI and Lichtner PC (1998a) Multicomponent reactive transport in discrete fractures: II. Infiltration of hyperalkaline groundwater at Maqarin, Jordan, a natural analogue site. Journal of Hydrology 209:200-224

Steefel CI and Lichtner PC (1998b) Multicomponent reactive transport in discrete fractures: I. Controls on reaction front geometry. Journal of Hydrology 209:186-199

Steefel CI and MacQuarrie KTB (1996) Approaches to modeling of reactive transport in porous media. In Reactive Transport in Porous Media. Vol 34 PC Lichtner, CI Steefel, and EH Oelkers (ed) The Mineralogical Society of America, Washington, D.C., p 83-130 
Steefel CI and Van Cappellen P (1990) A new kinetic approach to modeling water-rock interaction: the role of nucleation, precursors, and Ostwald ripening. Geochimica et Cosmochimica Acta 54:2657-2677

Taylor GI (1953) The dispersion of soluble matter in a solvent flowing through a tube. Proc. Royal Society London Series A 219:196-203

Thompson JB (1959) Local equilibrium in metasomatic processes. Researches in Geochemistry 1:427-457

Tompson AFB, Carle SF, Rosenberg ND, and Maxwell RM (1999) Analysis of groundwater migration from artificial recharge in a large urban aquifer: A simulation perspective. Water Resources Research 35:2981-2998

Varni M and Carrera J (1998) Simulation of groundwater age distributions. Water Resources Research 34

Weare JH, Stephens JR, and Eugster HP (1976) Diffusion metasomatism and mineral reaction zones; general principles and application to feldspar alteration. American Journal of Science 276:767-816

Weissmann GS, Zhang Y, LaBolle EM, and Fogg GE (2002) Dispersion of groundwater age in an alluvial aquifer system. Water Resources Research 38:1198

Westrich JT and Berner RA (1984) The role of sedimentary organic matter in bacterial sulfate reduction--the G model tested. Limnology and Oceanography 29:236-249

White AF and Brantley SL (2003) The effect of time on the weathering of silicate minerals: why do weathering rates differ in the laboratory and field? Chem. Geol. 202:479-506

White AF, Schulz MS, Stonestrom DA, Vivit DV, Fitzpatrick V, Bullen TD, Maher K, and Blum $\mathrm{AE}$ (2009) Chemical weathering of a marine terrace chronosequence, Santa Cruz, California: Controls on solute fluxes and comparisons of long-term and contemporary mineral weathering rates. Geochimica Cosmochimica Acta 73:2769-2803

Wortman UG, Bernasconi SM, and Boettcher ME (2001) Hypersulfidic deep biosphere indicates extreme sulfur isotope fractionation during single-step microbial sulfate reduction. Geology 29:647-650

Yang L and Steefel CI (2007) Kaolinite dissolution and precipitation kinetics at $22^{\circ} \mathrm{C}$ and $\mathrm{pH} 4$. Geochimica Cosmochimica Acta 72:99-116

Yeh GT and Tripathi VS (1989) A critical evaluation of recent developments in hydrogeochemical transport models of reactive multichemical components. Water Resources Research 25:93-108

Zhu C (2005) In situ feldspar dissolution rates in an aquifer. Geochimica Cosmochimica Acta 69:1435-1453 


\section{FIGURE CAPTIONS}

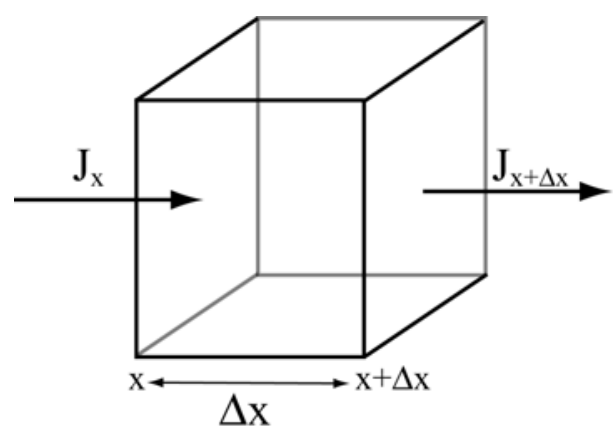

Figure 1. Derivation of a continuity equation (Fick's Second Law).

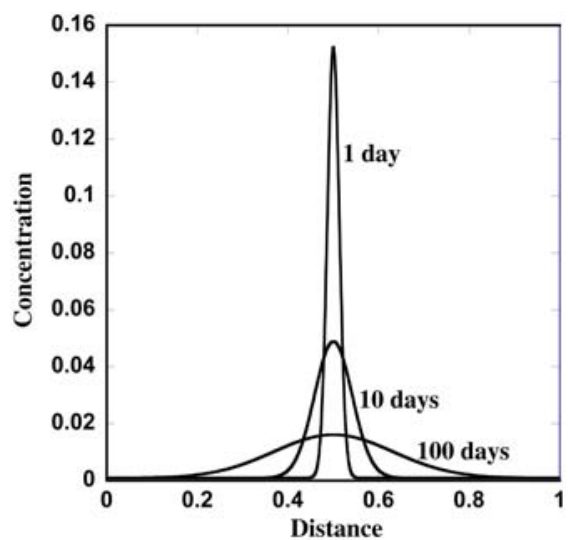

Figure 2. Spreading of an initially sharp solute plume as a result of molecular diffusion. 

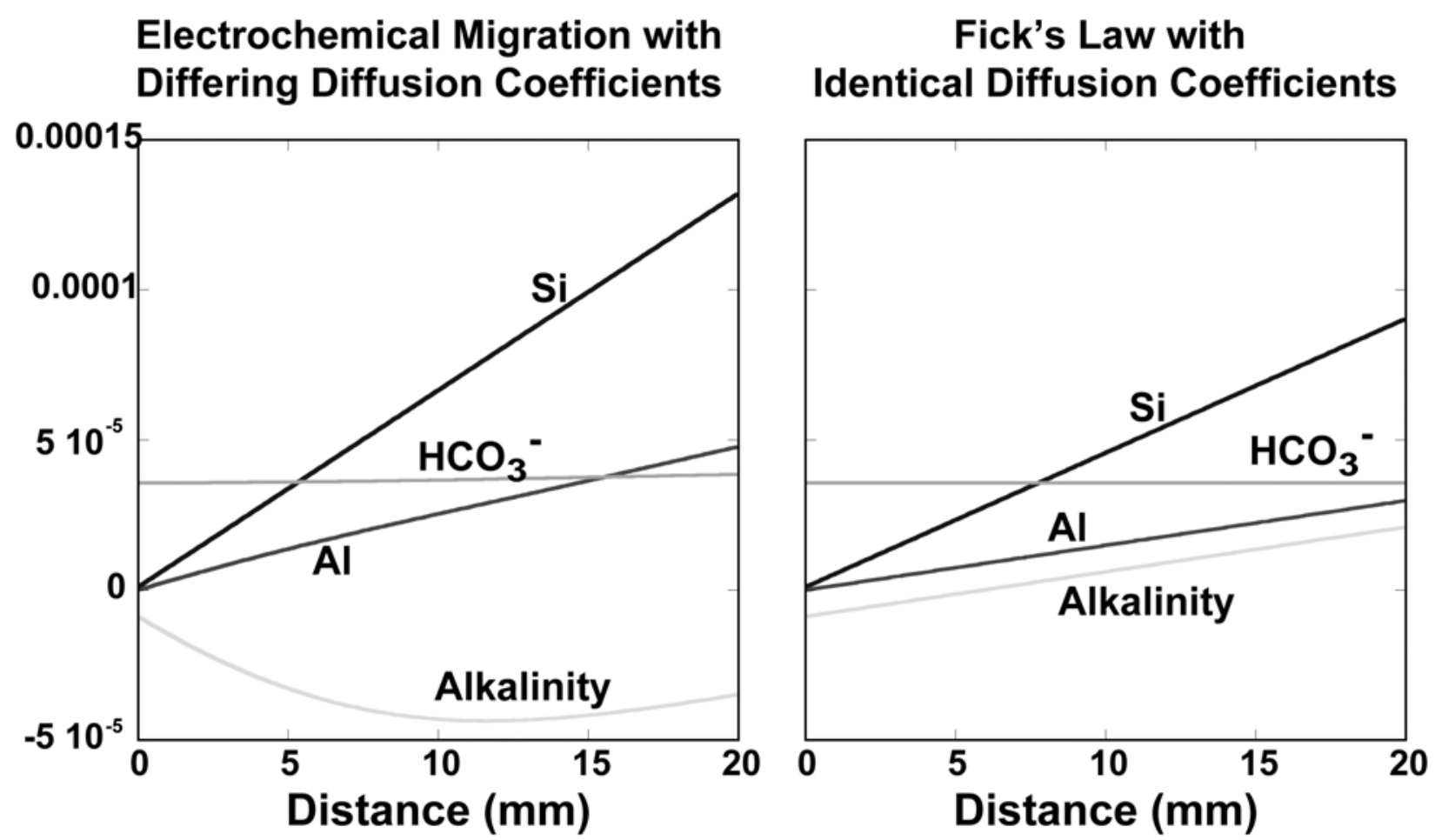

Figure 3. Comparison of diffusion profiles in the case of a dilute, mildly acidic solution (pH 4) on the left reacting with an albite grain located $2 \mathrm{~cm}$ to the right. The left panel shows a calculation using differing diffusion coefficients for the ions (see Table 2) and includes electrochemical migration. The right panel shows a calculation in which identical diffusion coefficients for all species are used-in this case, electrochemical migration vanishes and diffusion occurs according to Fick's Law. From Steefel (2007).

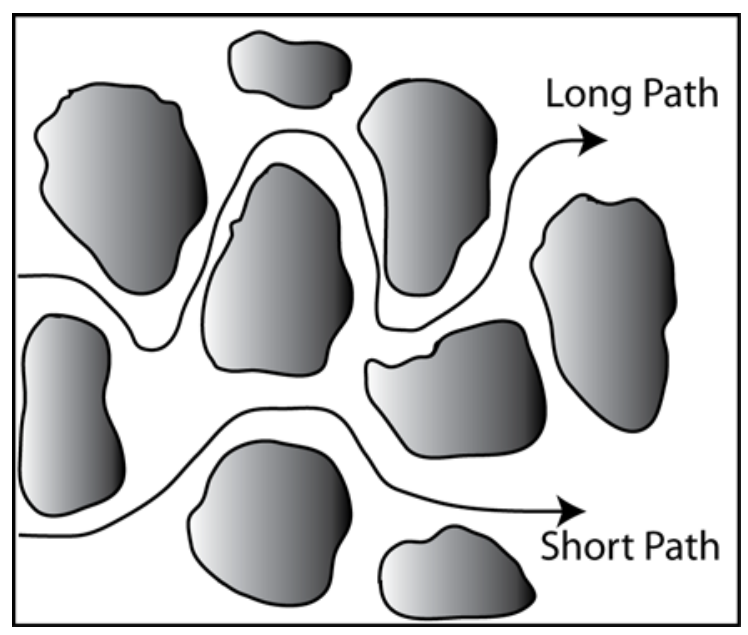

Figure 4. Tortuous diffusion paths in porous material. 

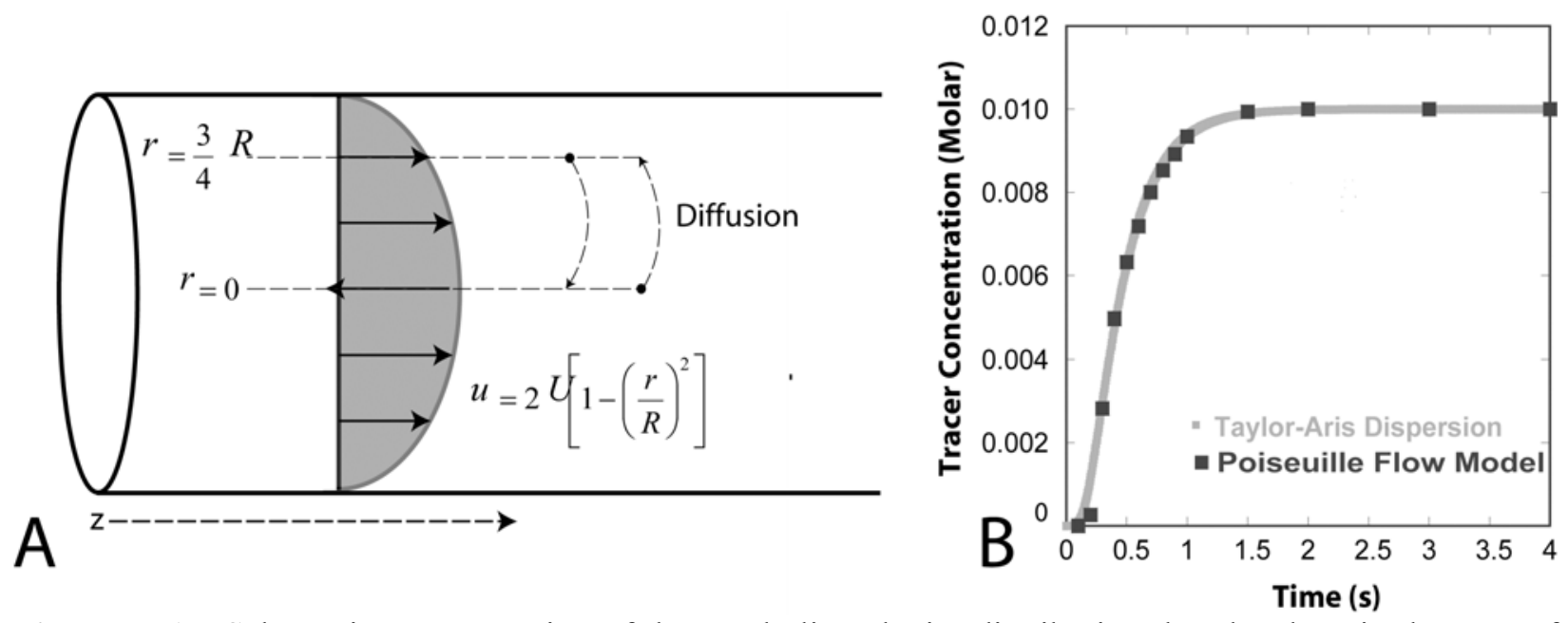

Figure 5. A. Schematic representation of the parabolic velocity distribution that develops in the case of Poiseuille flow. B: Comparison of non-reactive tracer breakthrough profile using a Taylor-Aris dispersion coefficient (Taylor 1953) and a full two-dimensional calculation of transport in a cylindrical tube using the analytical solution for Poiseuille flow.
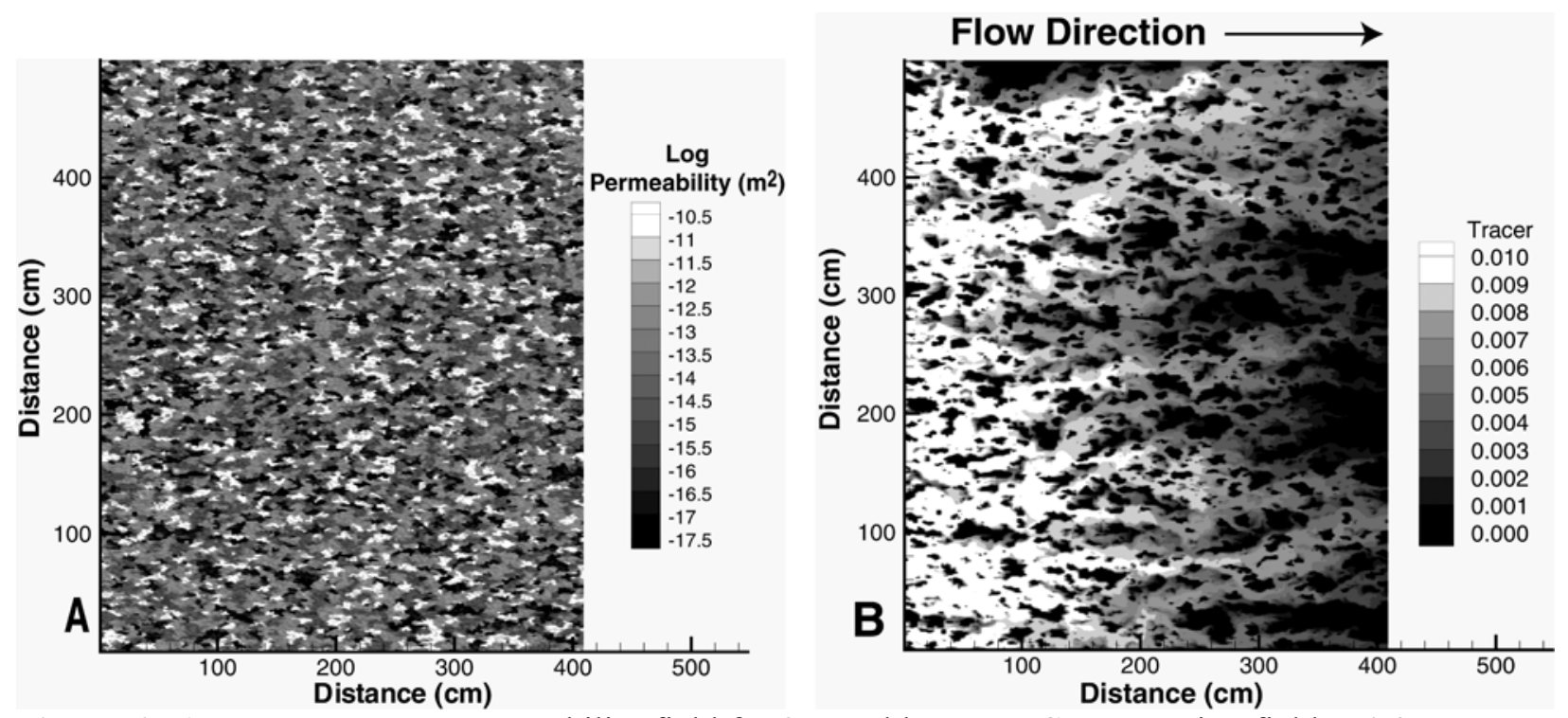

Figure 6. A. Heterogeneous permeability field for $2 \mathrm{D}$ problem. B. Concentration field at 0.25 years as a result of flow from left to right across the heterogeneous domain. After Steefel (2007). 


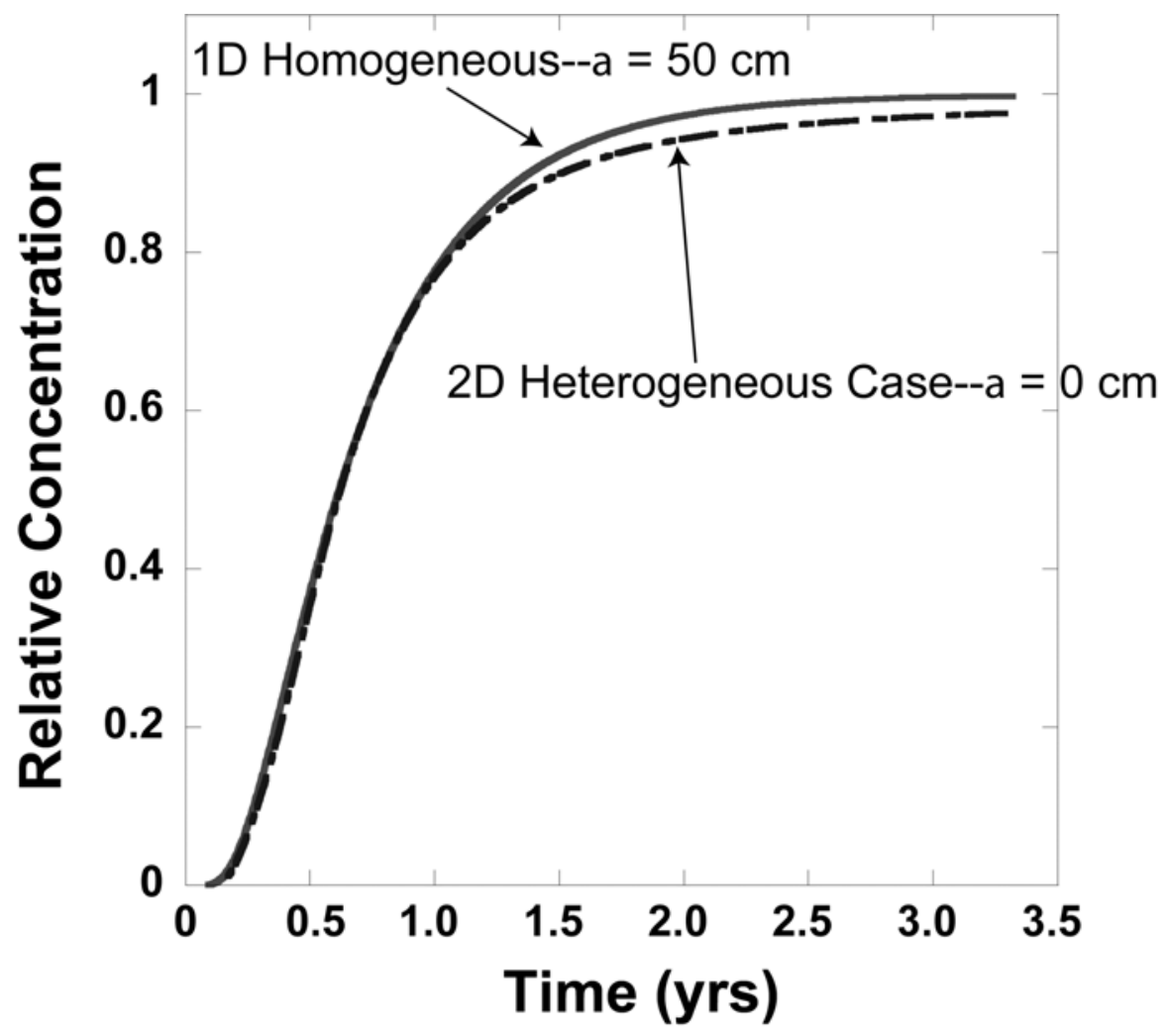

Figure 7. Comparison of solute breakthrough curves for the case of the heterogeneous permeability field shown in Figure 6A, calculated with a dispersivity, $\alpha,=0$, and a 1D homogeneous permeability field calculated with $\alpha=50$ centimeters. After Steefel (2007).

A. Unweathered Basalt

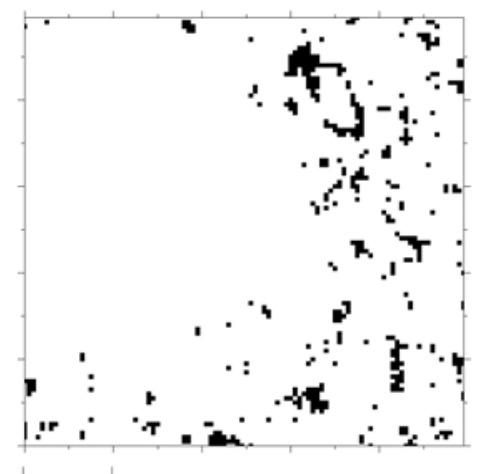

88 microns

\section{B. Weathered Basalt}

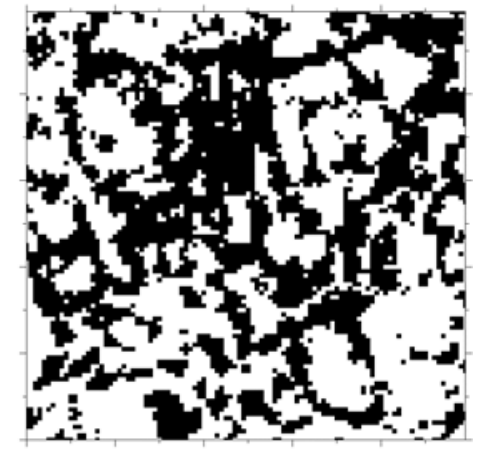

88 microns

Figure 8. Microtomographic images of porosity (dark voxels) in unweathered (Panel A) and weathered (Panel B) basalt. Note the increase in pore connectivity in the weathered sample, which has the effect of increasing the diffusivity of the material. From Navarre-Sitchler et al. (2009). 

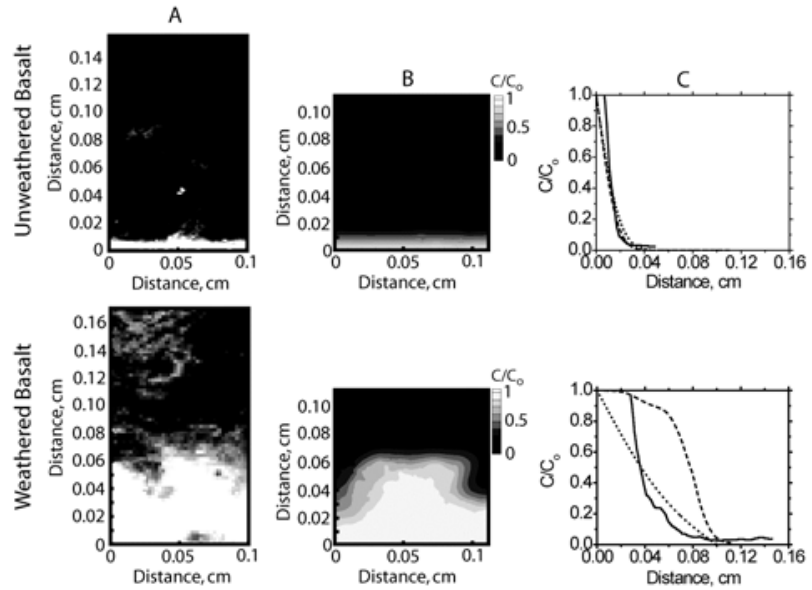

Figure 9. Comparison of results from diffusion experiments and models for unweathered (top) and weathered (bottom) basalt. A) $\mu \mathrm{XRF}$ image of Br concentrations in physical diffusion experiments after 7 days. Higher concentrations of $\mathrm{Br}$ appear whiter. B) Contour plot of $\mathrm{Br}$ concentrations from 3D pore network simulation at same scale as $\mu \mathrm{XRF}$ images for comparison. C) Concentration profiles of $\mathrm{Br}$ in physical diffusion experiments (solid line), 1D model results (dotted line) and 3D model results (dashed line). From Navarre-Sitchler et al. (2009).

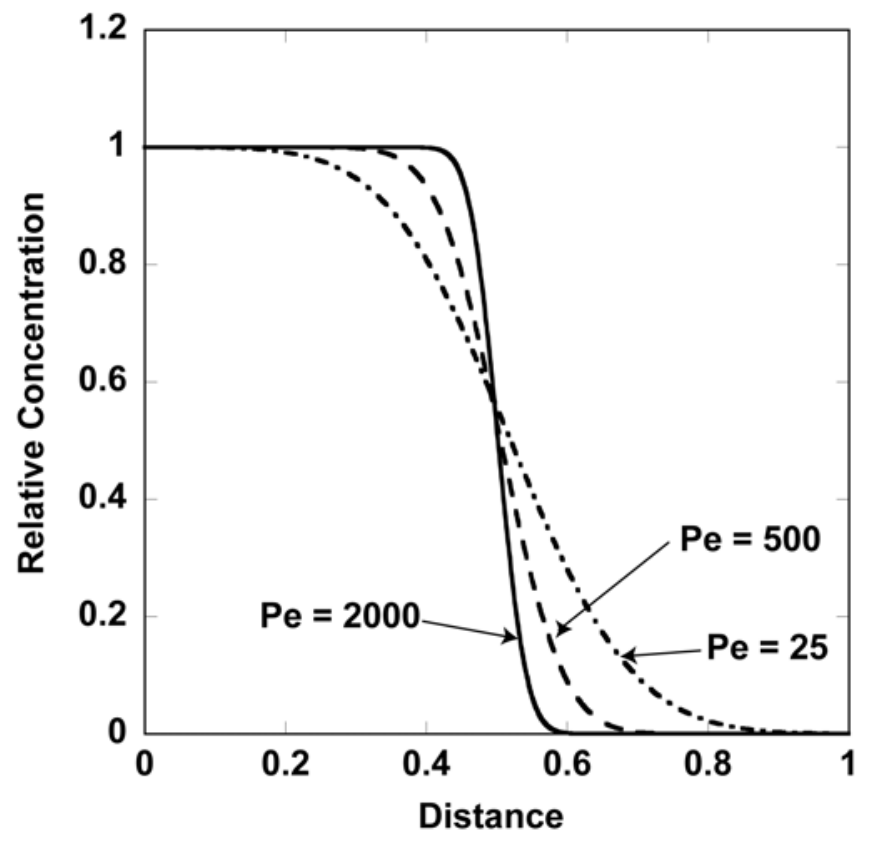

Figure 10. Effect of the non-dimensional Péclet number on the shape of a concentration profile. The length scale is given by the flow distance, with flow from left to right. 


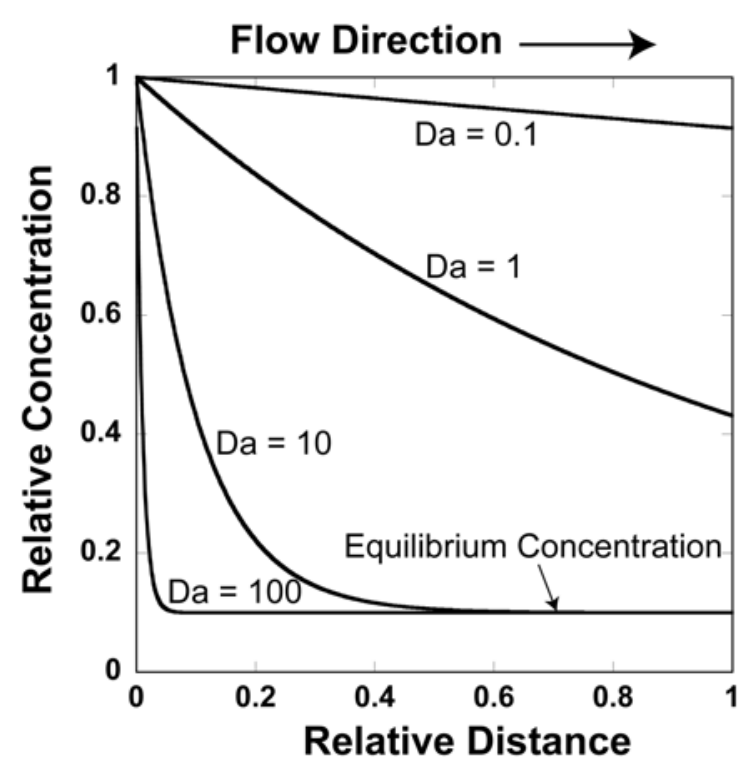

Figure 11. Effect of the non-dimensional Damköhler number on the shape of a concentration profile at steady-state. A large Damköhler number indicates that the reaction kinetics are rapid compared to transport rates over the length scale considered, or equivalently, that the characteristic time for transport is significantly less than the characteristic time for reaction. The local equilibrium approximation is justified in such cases. 


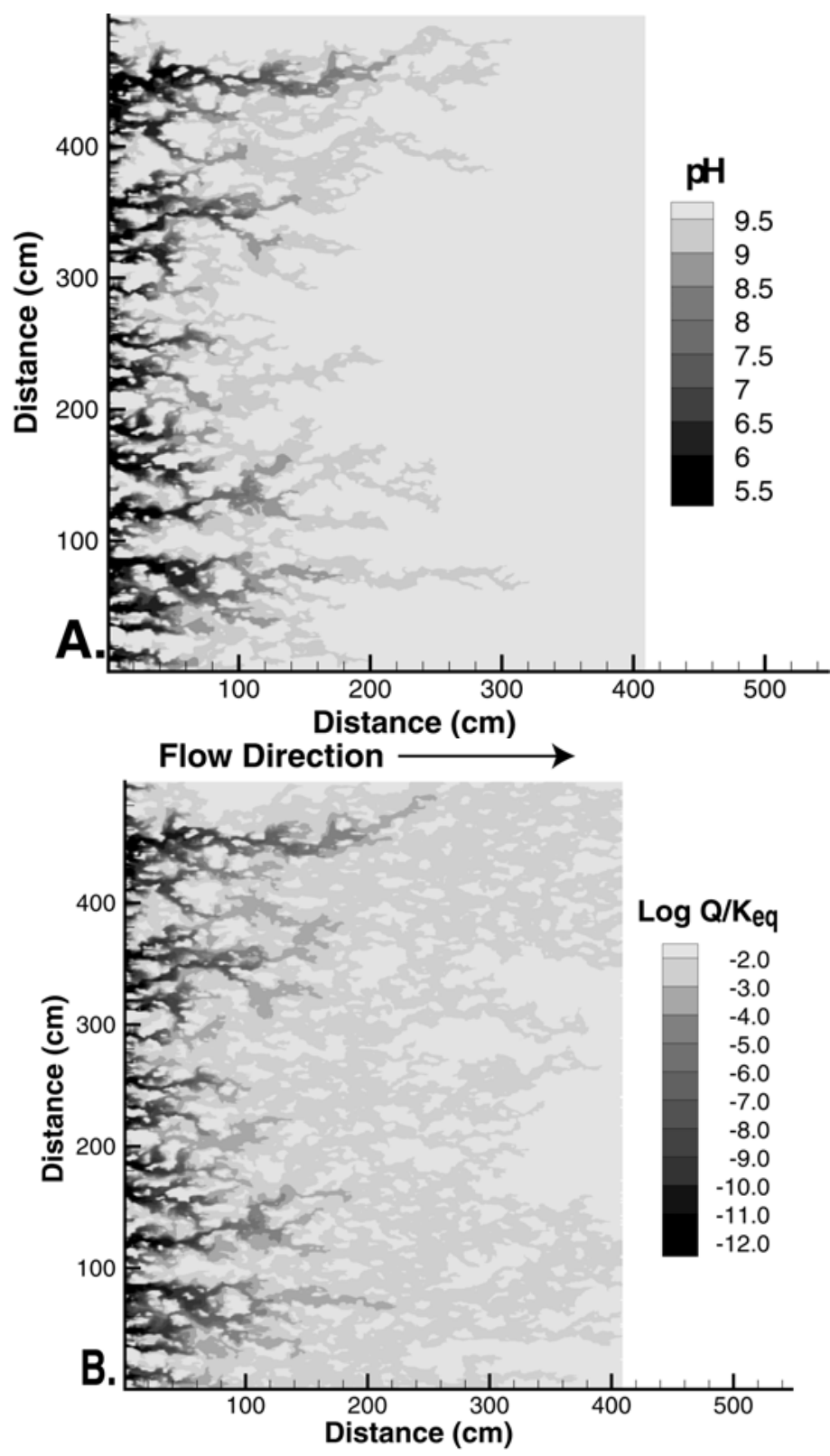

Figure 12. A: $\mathrm{pH}$ distribution for the $2 \mathrm{D}$ heterogeneous flow field shown in Figure 6. $\mathrm{pH}$ at the left side of the flow domain is fixed at 5. The principal reaction is the dissolution of plagioclase with a rate law that includes dissolved aluminum inhibition (Oelkers et al. 1994). B. The saturation state of the pore fluid with respect to plagioclase $\left(\log \mathrm{Q} / \mathrm{K}_{\mathrm{eq}}\right)$ varies spatially, resulting in a heterogeneous distribution of surface reaction versus transport control of the rate. From Steefel (2007). 


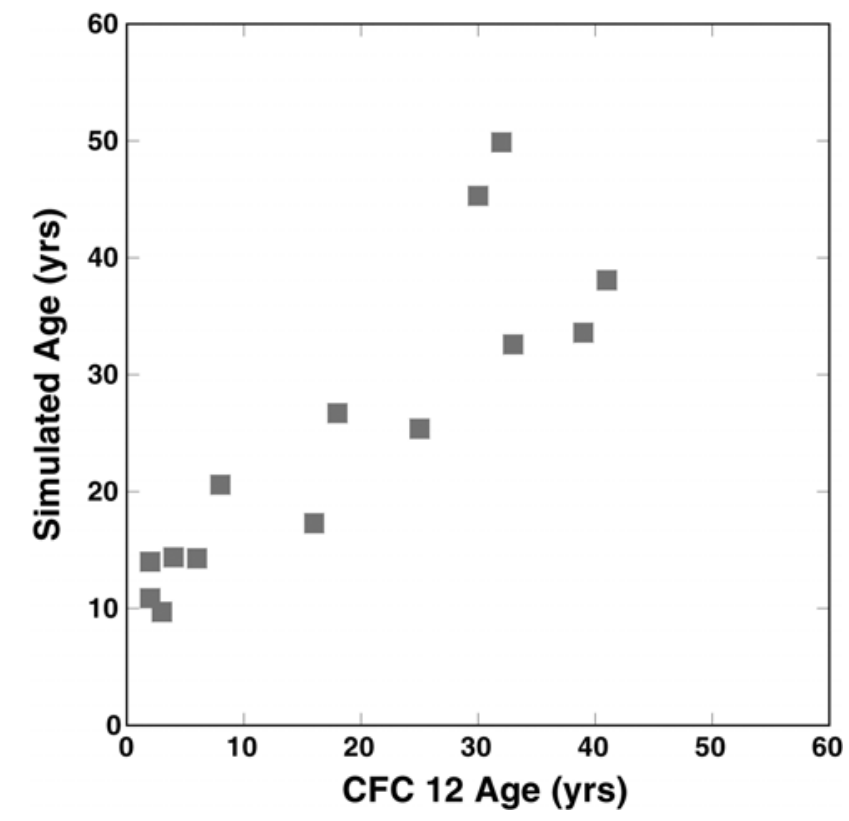

Figure 13. Chlorofluorocarbon (CFC) ages compared to simulated CFC ages based on high resolution groundwater flow modeling from a heterogeneous alluvial fan aquifer in California (Weissmann et al. 2002).

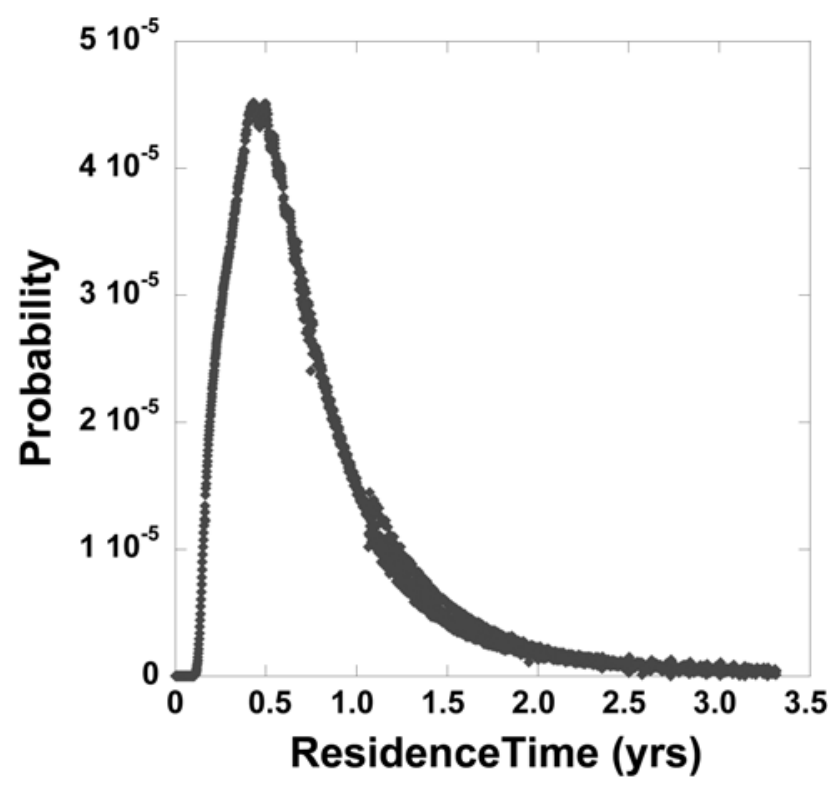

Figure 14. Residence time distribution for the two-dimensional flow case presented in Figure 9. Residence times are presented in terms of probabilities and are calculated recursively based on the breakthrough curve shown in Figure 7. From Steefel (2007). 


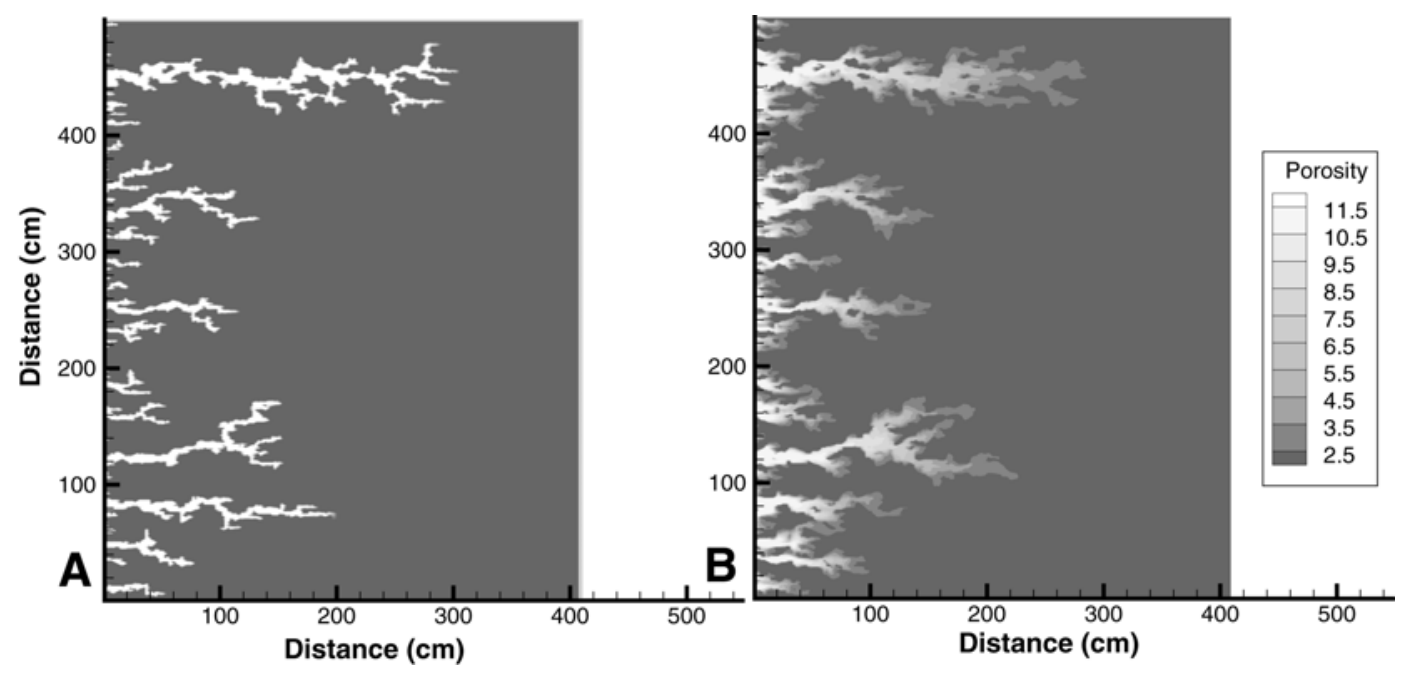

Figure 15. The reactive-infiltration instability results in "wormholing", as regions experiencing an increase in porosity and permeability as a result of mineral dissolution accelerate their growth at the expense of adjacent regions. The wormholing rate is at a maximum under transport-controlled conditions (Panel A) - at lower Damköhler numbers (Panel B), fingers are more diffuse and the difference between the growth rates of individual fingers is less. From Steefel (2007).
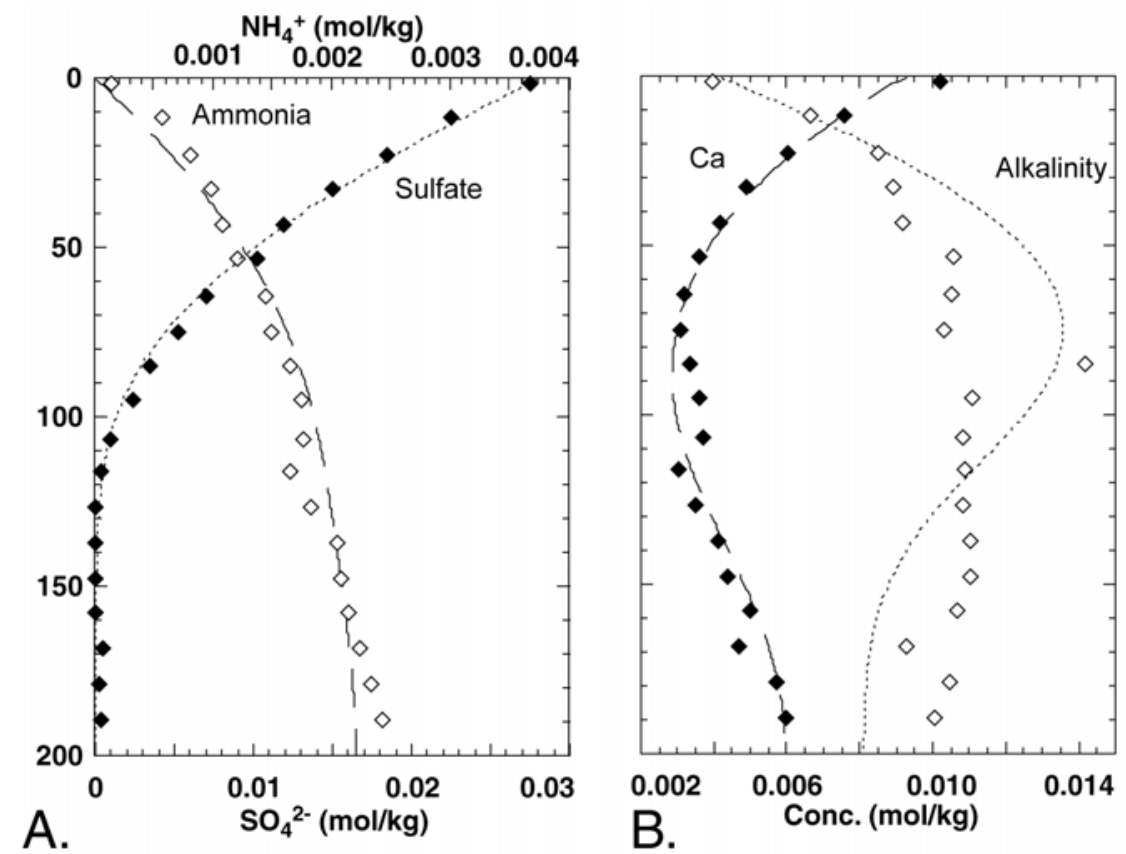

Figure 16. A. Fit of the sulfate and ammonia profiles at Site 984 in the North Atlantic with the reactive transport code CrunchFlow allows the determination of the rate of microbially-mediated sulfate reduction. B. Fit of the calcium and alkalinity profiles provides the rates of both plagioclase dissolution and calcite precipitation (Maher et al. 2006). 


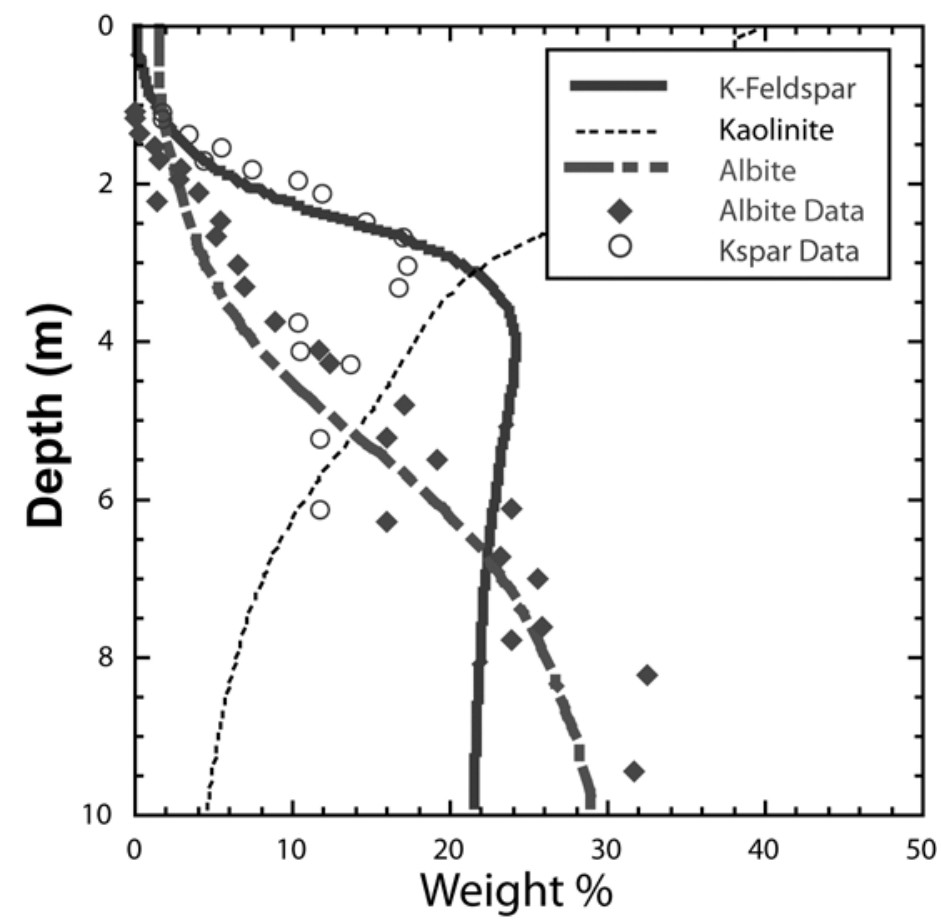

Figure 17. Fitting of the profiles of plagioclase and potassium feldspar from Terrace 5 (226,000 years) at the Santa Cruz Chronosequence (Maher et al. 2009) using the reactive transport code CrunchFlow.

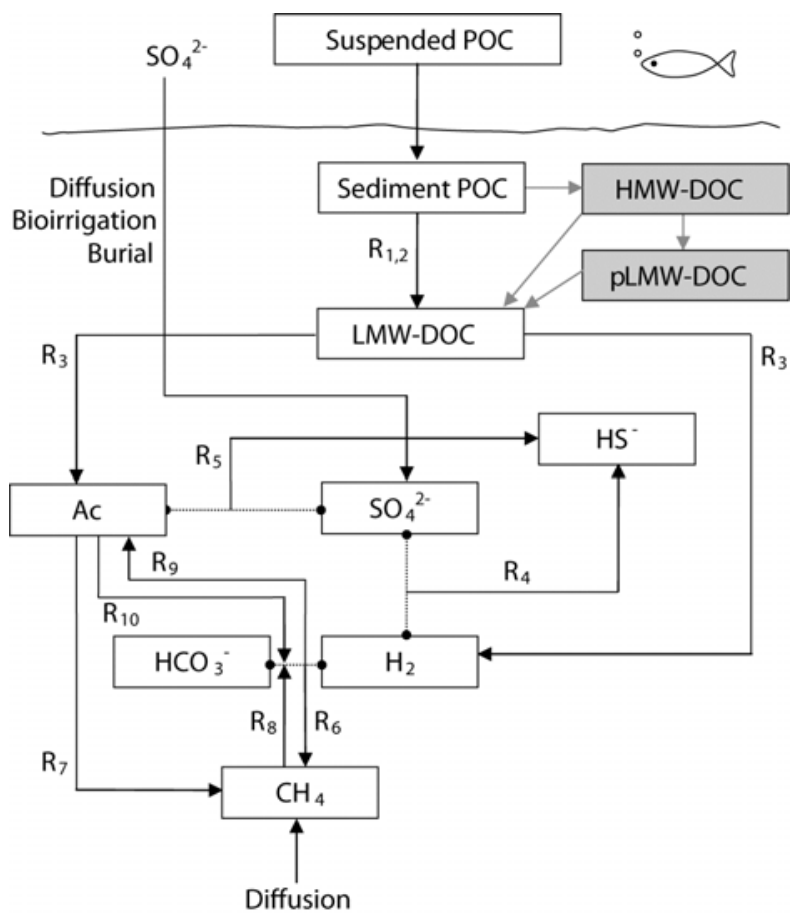

Figure 18. Schematic representation of the reaction network in which particulate organic carbon (POC) undergoes hydrolysis to LMW-DOC, which is then fermented to $\mathrm{H}_{2}$ and acetate. From (Dale et al. 2008). 

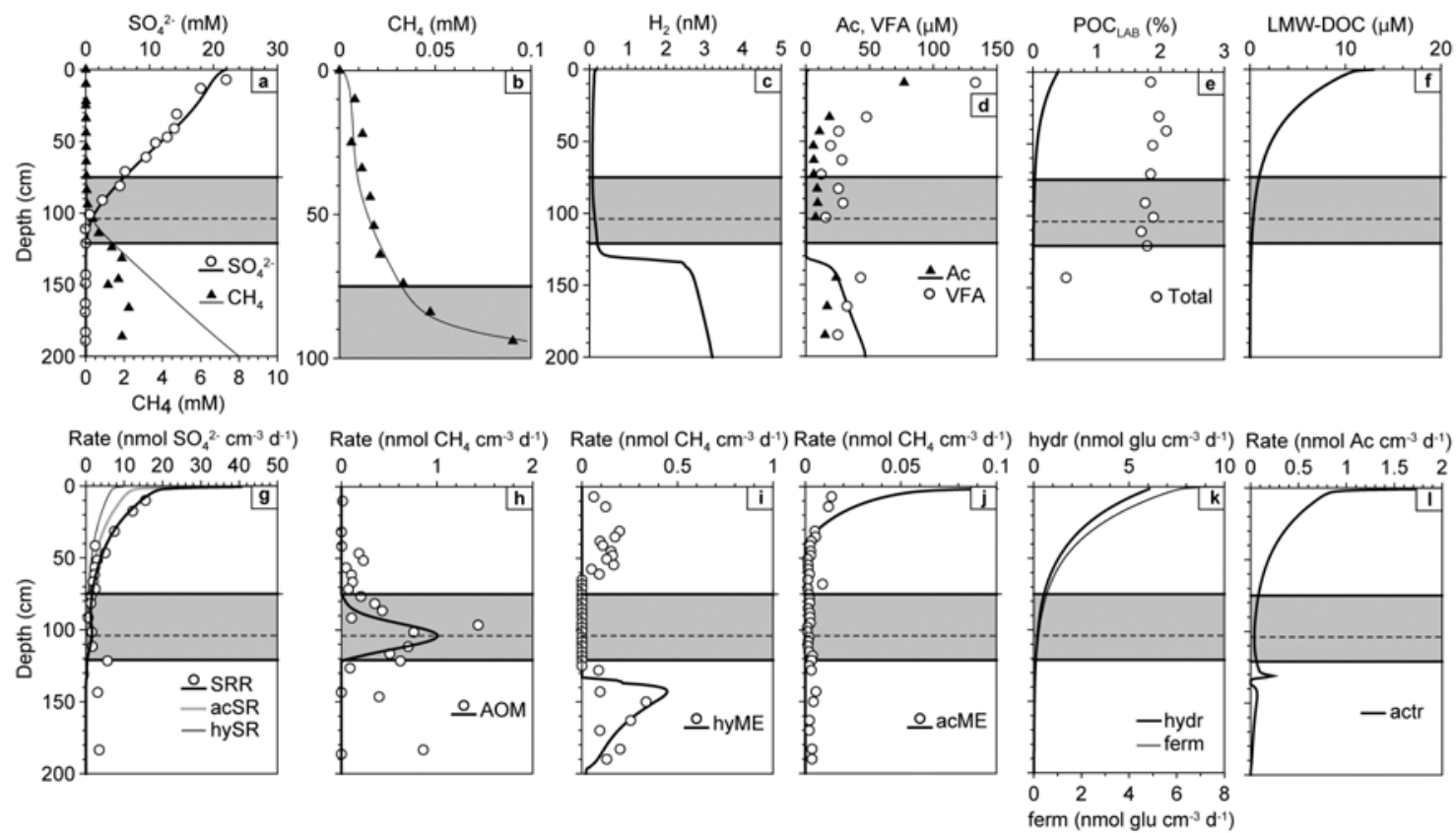

Figure 19. Measured (symbols) and modeled (lines) concentrations (top row) and rates (bottom row) for station S13 at Skagerrak. All rates are in production or consumption of solutes per unit volume of pore water. The shaded band indicates the sulfate-methane transition zone and the horizontal dashed line shows the depth of maximum AOM rate. See Table 3 for definition of individual reaction pathways. From (Dale et al. 2008).

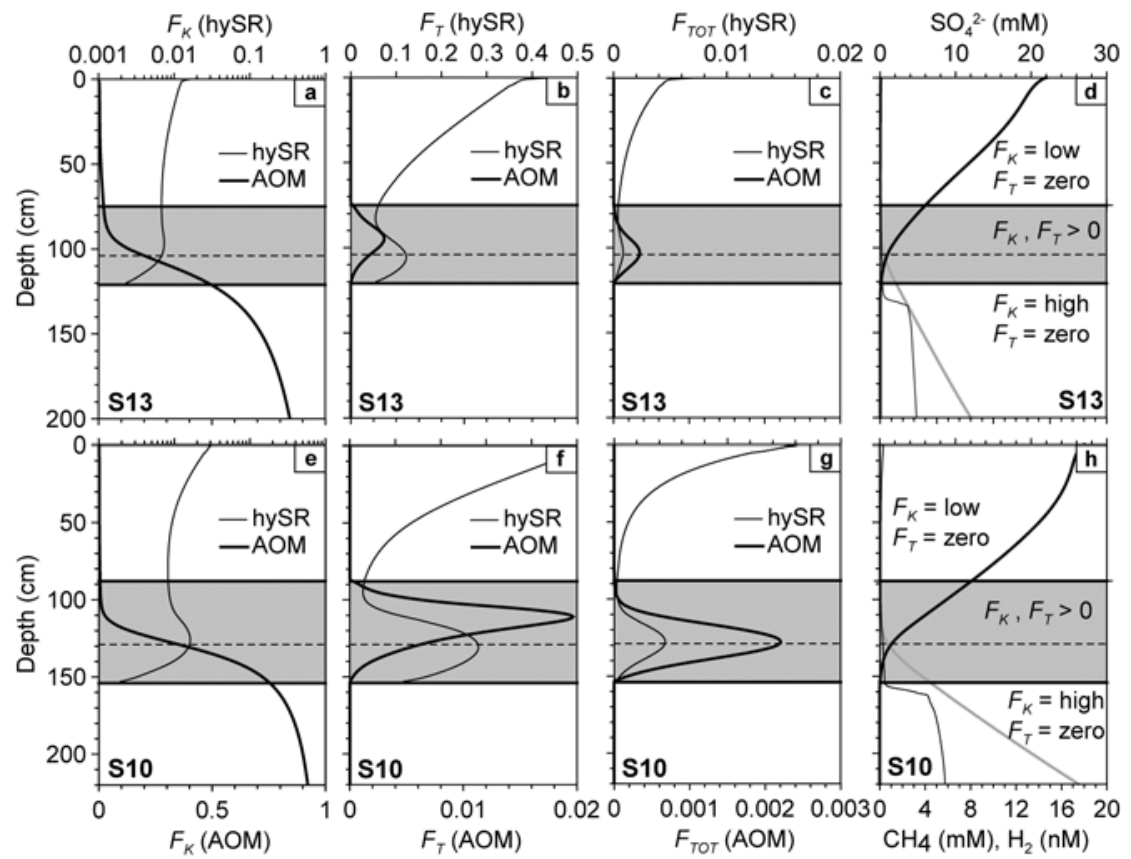

Figure 20. Model results for kinetic driving forces, $F_{K}$, and thermodynamic forces, $F_{T}$, and total driving forces, $F_{T O T}$ for various reaction pathways for stations S13 and S10 at Skagerrak. From Dale et al. (2008). 


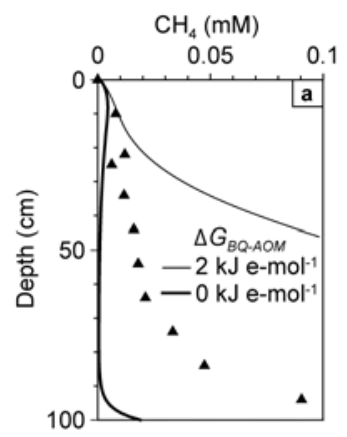

Figure 21. The effect of changes in $\Delta G_{B Q-A O M}$ on the $\mathrm{CH}_{4}$ tail in the sulfate reduction zone. The measured data is shown as symbols. From Dale et al. (2008).
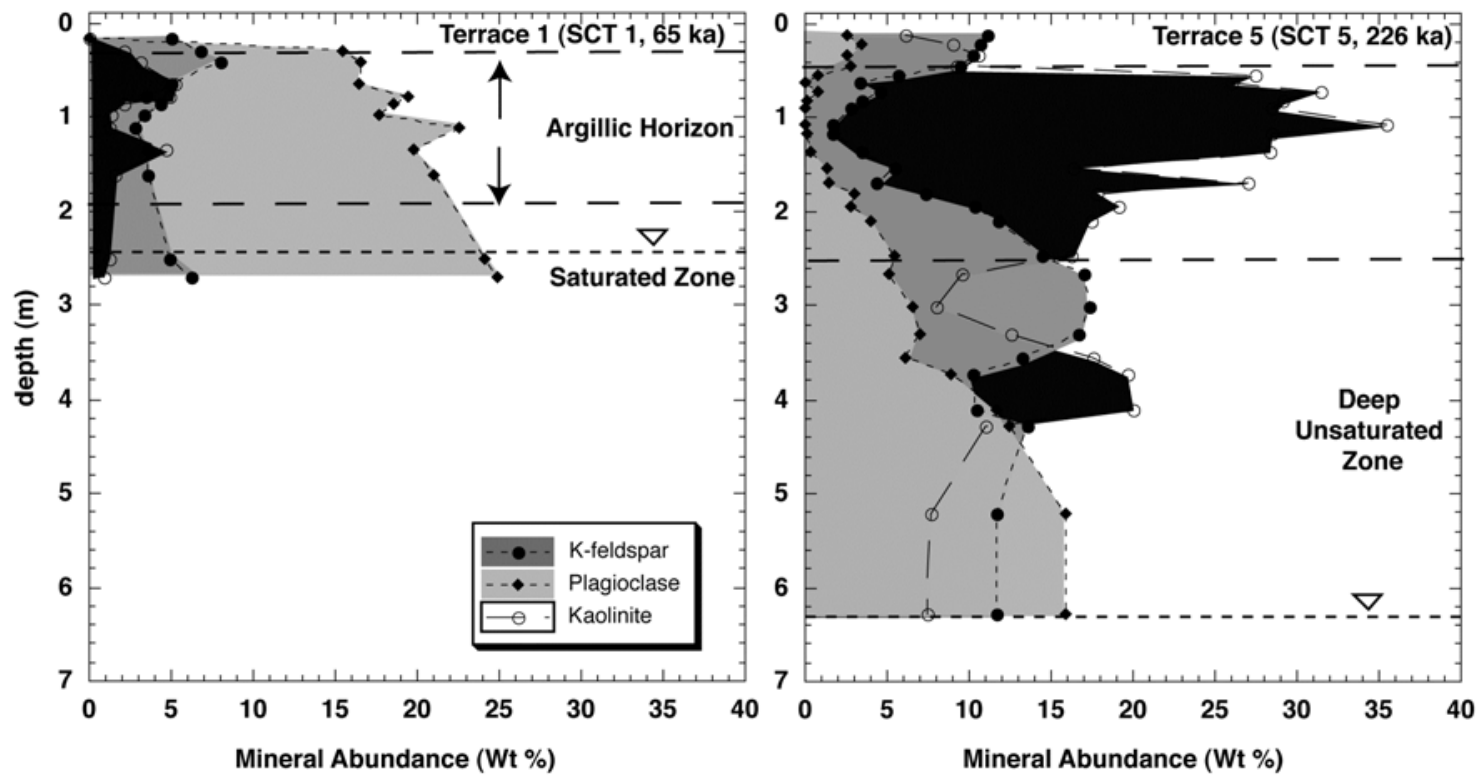

Figure 22. Profile evolution between SCT 1 (65 ka) and SCT 5 (226 ka). The zone of peak kaolinite accumulation referred to as the argillic horizon is shown as thick dashed lines, and the average water table depth is shown as a light stippled line. Data summarized from White et al. (2009). 

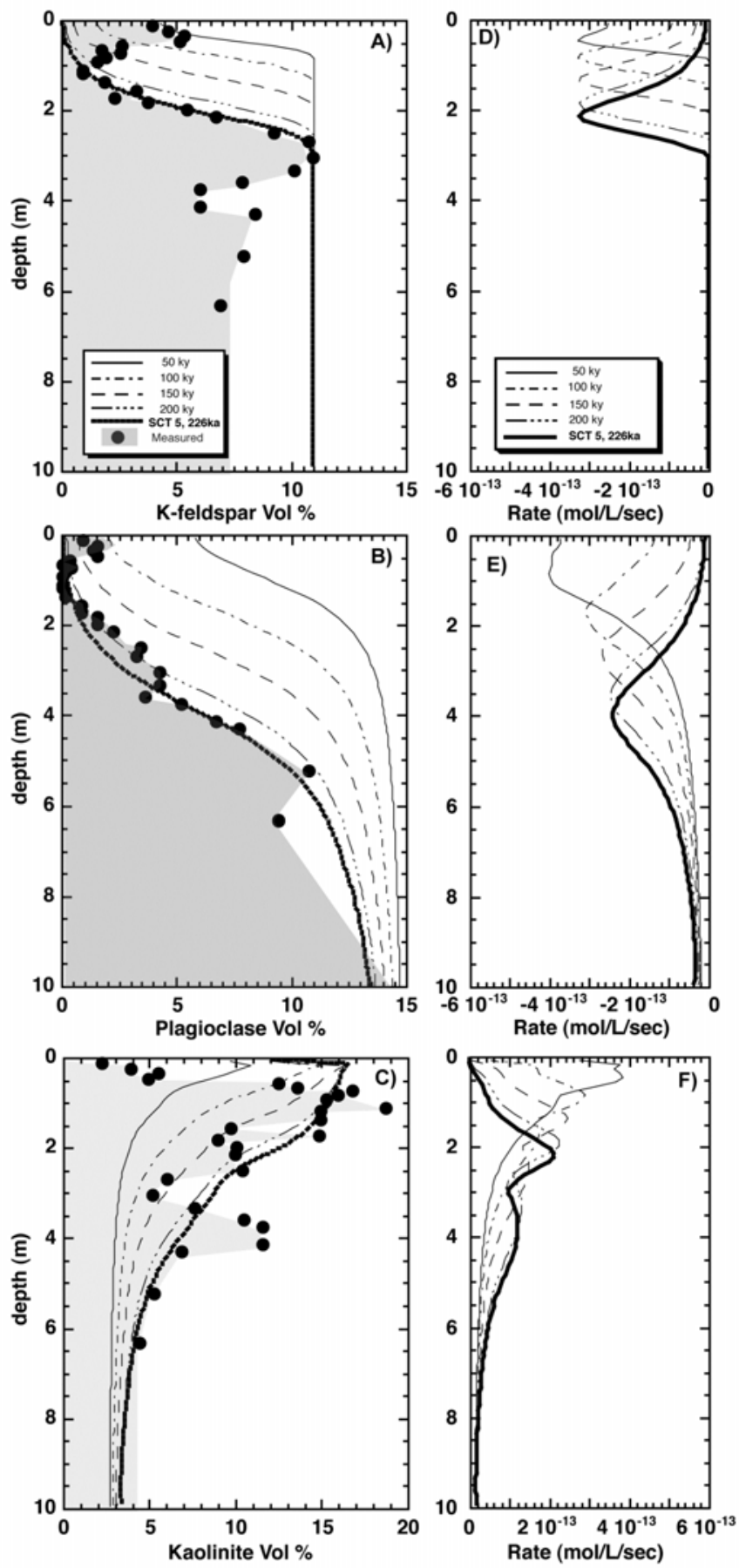

Figure 23. Model profiles corresponding to the SCT 5 (226 ka). Model Profiles corresponding to the ages of the younger terraces are shown for reference and the SCT 5 profile is shown in bold. A-C: Profile evolution for K-feldspar and albite dissolution and kaolinite precipitation. D-E: overall reaction rates (mol/L(porous media)/sec) as a function of depth for individual minerals. From Maher et al (2009). 

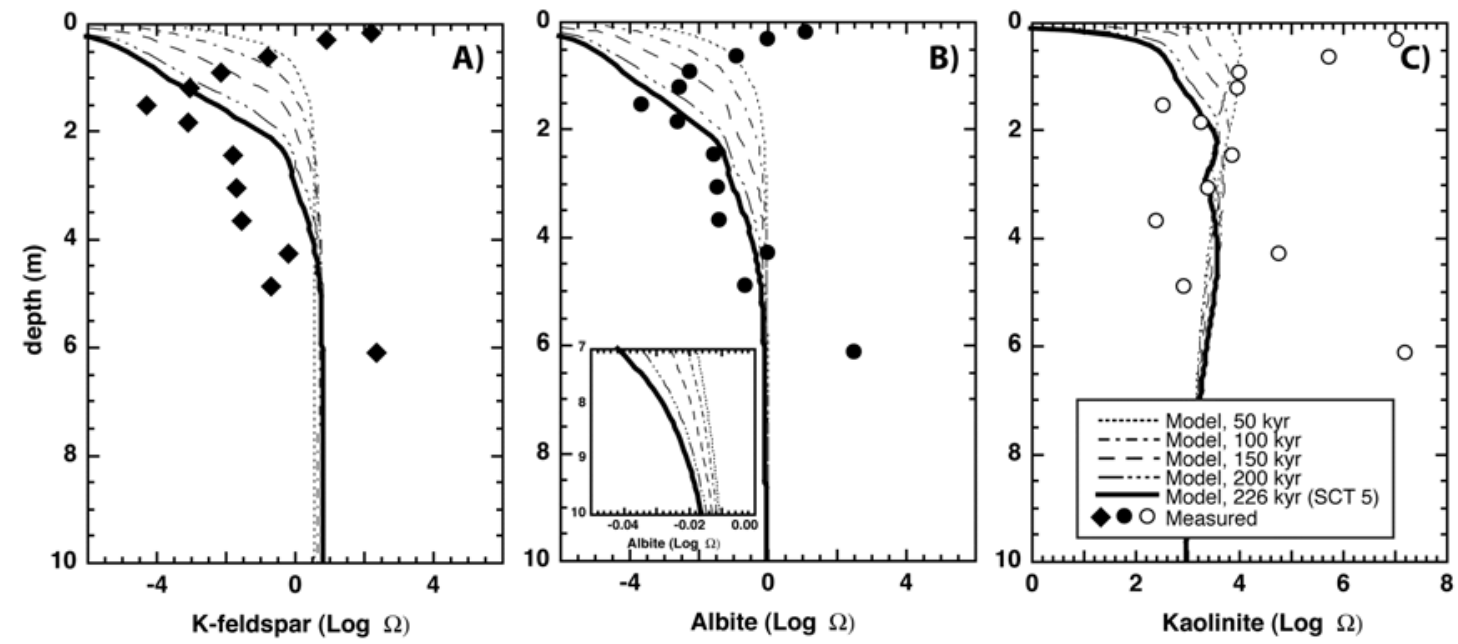

Figure 24. Saturation state profiles from model simulations compared to values calculated from aqueous concentrations. From Maher et al (2009).

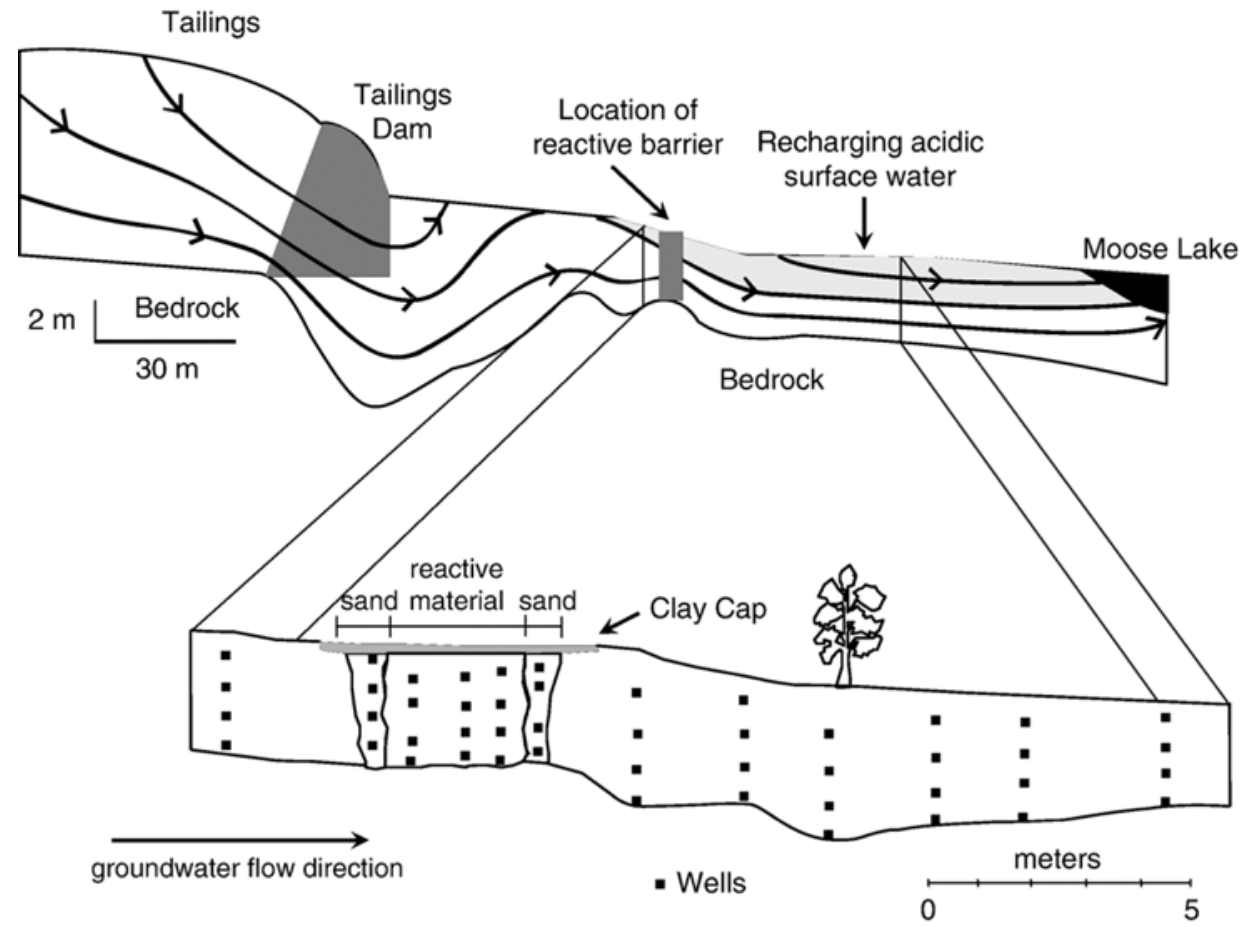

Figure 25. Schematic description of Nickel Rim mine tailings site and the investigation area for permeable reactive barrier (Mayer et al. 2006). 


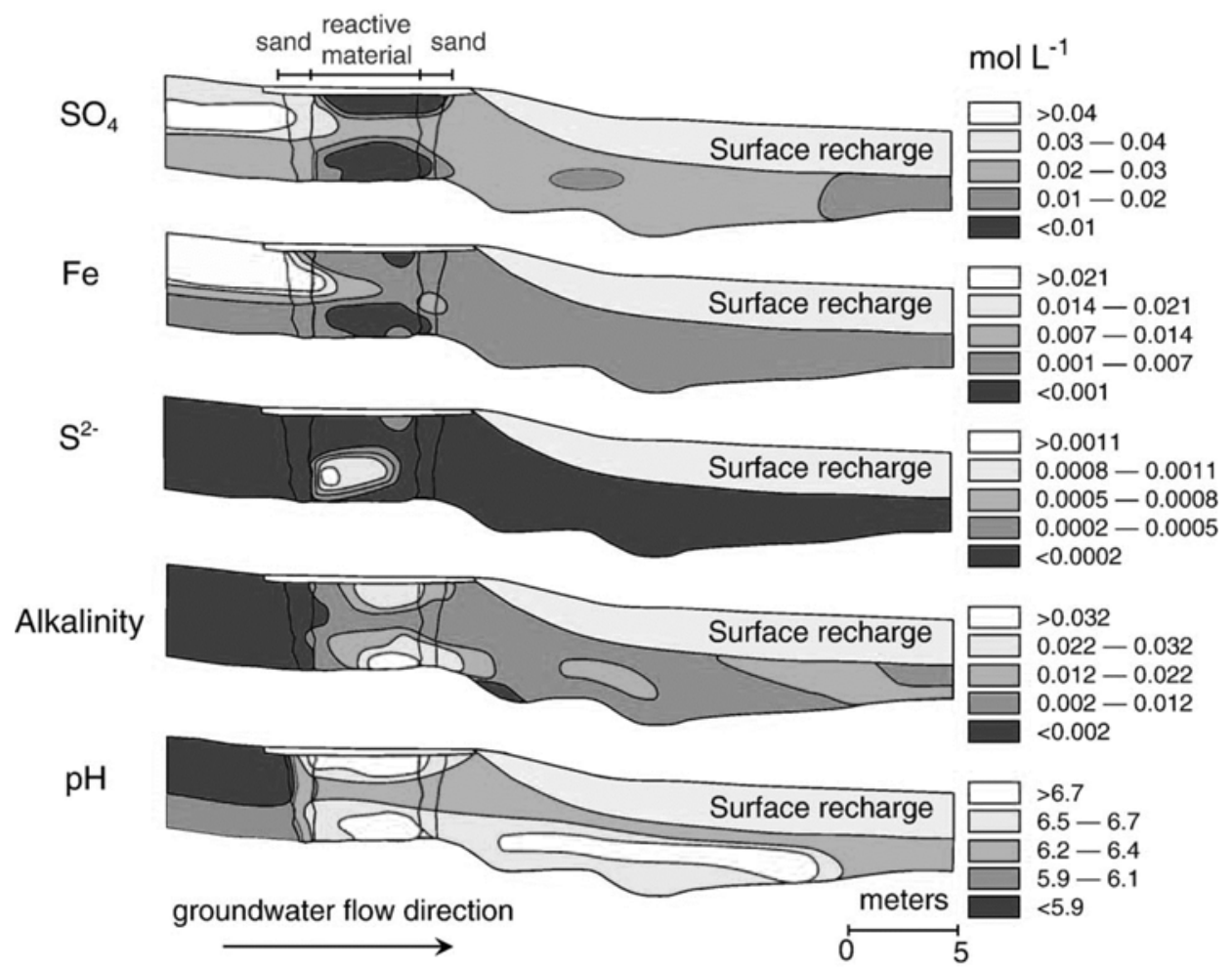

Figure 26. Concentration contours of dissolved sulfate, iron, sulfide, alkalinity and $\mathrm{pH}$ in the Nickel Rim permeable reactive barrier (Mayer et al. 2006).
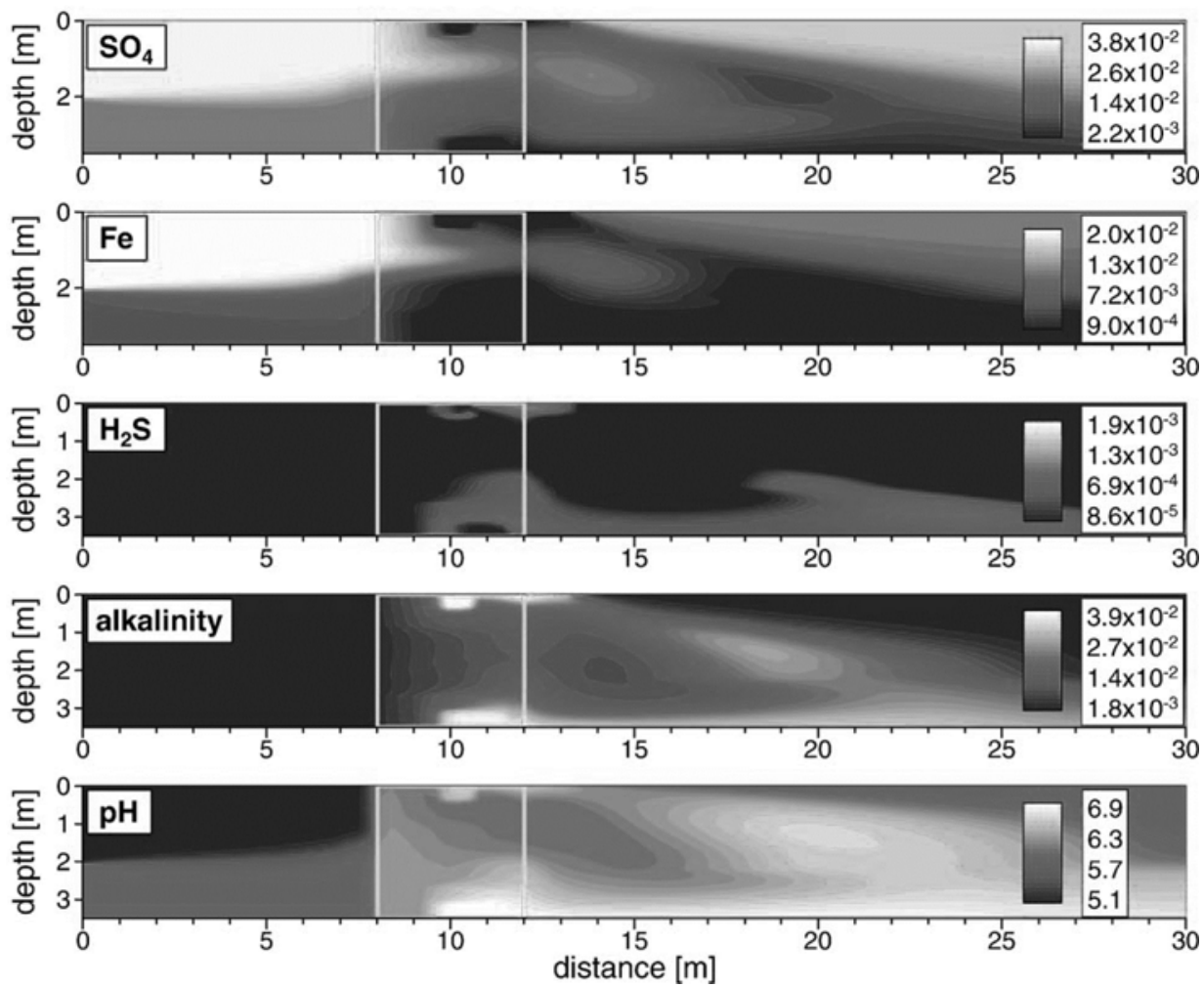

Figure 27. Simulated concentration contours for $\mathrm{SO}_{4}, \mathrm{Fe}, \mathrm{H}_{2} \mathrm{~S}$, alkalinity, and $\mathrm{pH}$ after 23 months of operation of the PRB (Mayer et al. 2006). 

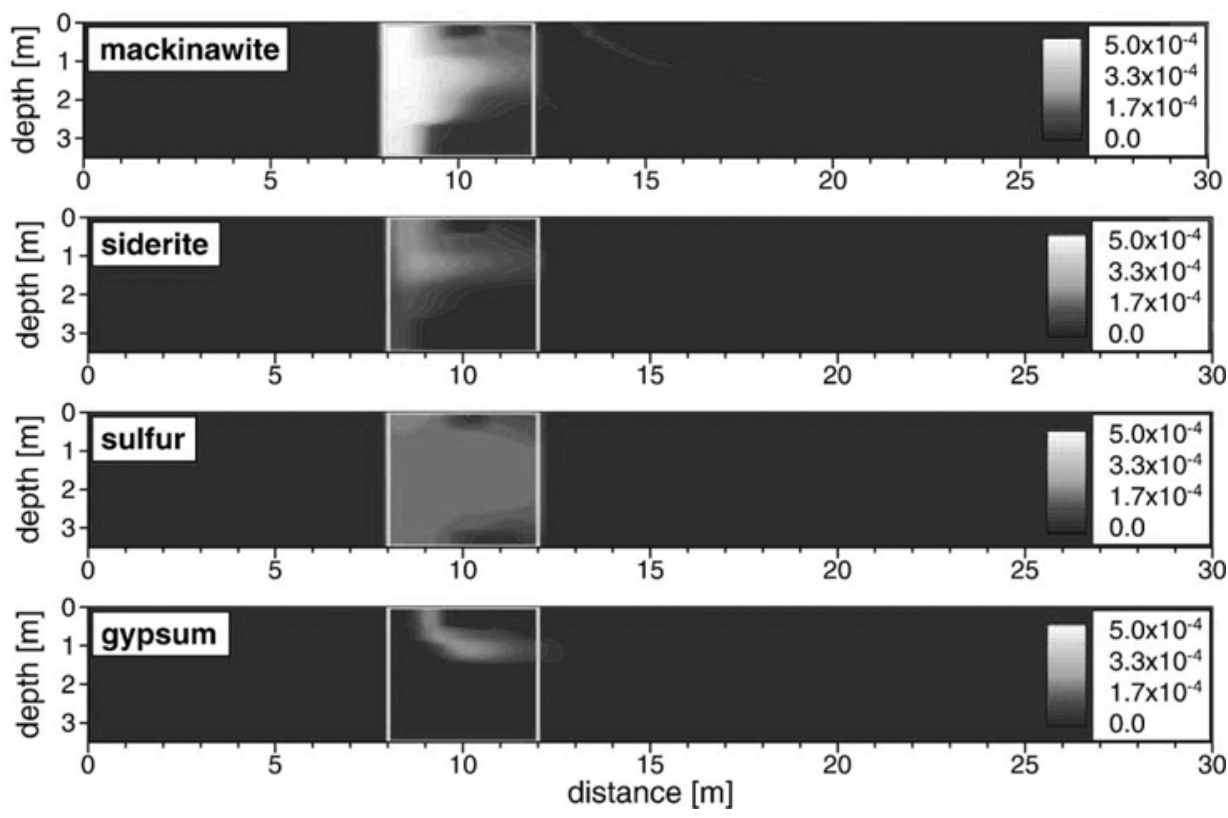

Figure 28. Simulated contours of mineral volume fractions for mackinawite, siderite, elemental sulfur, and gypsum after 23 months of operation of the PRB (Mayer et al. 2006).
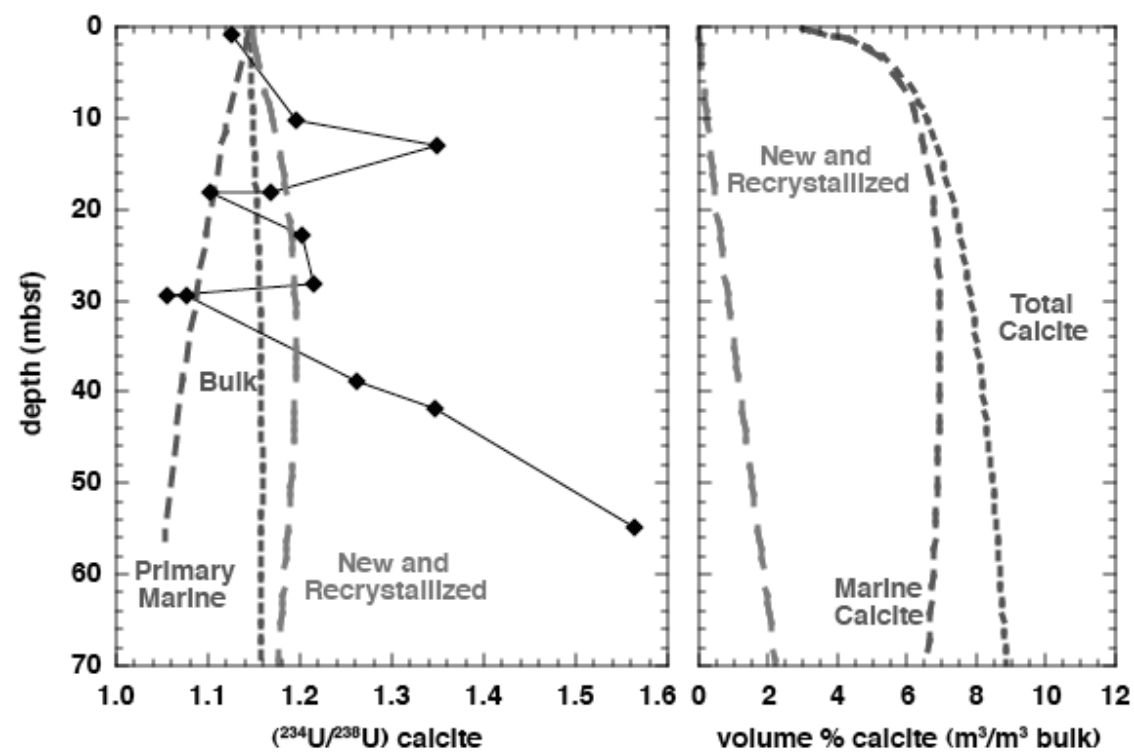

Figure 29. Summarized from Maher et al. (2006). (A) Measured bulk (symbols) and model $\left({ }^{234} U /{ }^{238} U\right.$ ) of the calcite fractions. The $\left({ }^{234} \mathrm{U} /{ }^{238} \mathrm{U}\right)$ of the new and recystallized calcite is greater than the bulk calcite or primary marine due to the $\alpha$-recoil enrichment of the pore fluid. The recrystallization process not only enriches the calcite $\left({ }^{234} \mathrm{U} /{ }^{238} \mathrm{U}\right)$ but also lowers the pore fluid $\left({ }^{234} \mathrm{U} /{ }^{238} \mathrm{U}\right)$ at depth (not shown) due to exchange of $U$. The primary marine calcite reflects the $\left({ }^{234} U /{ }^{238} U\right)$ for closed system decay of $U$ in calcite. B) The resulting distribution of different calcite pools showing the increase in new and recrystallized calcite components. 


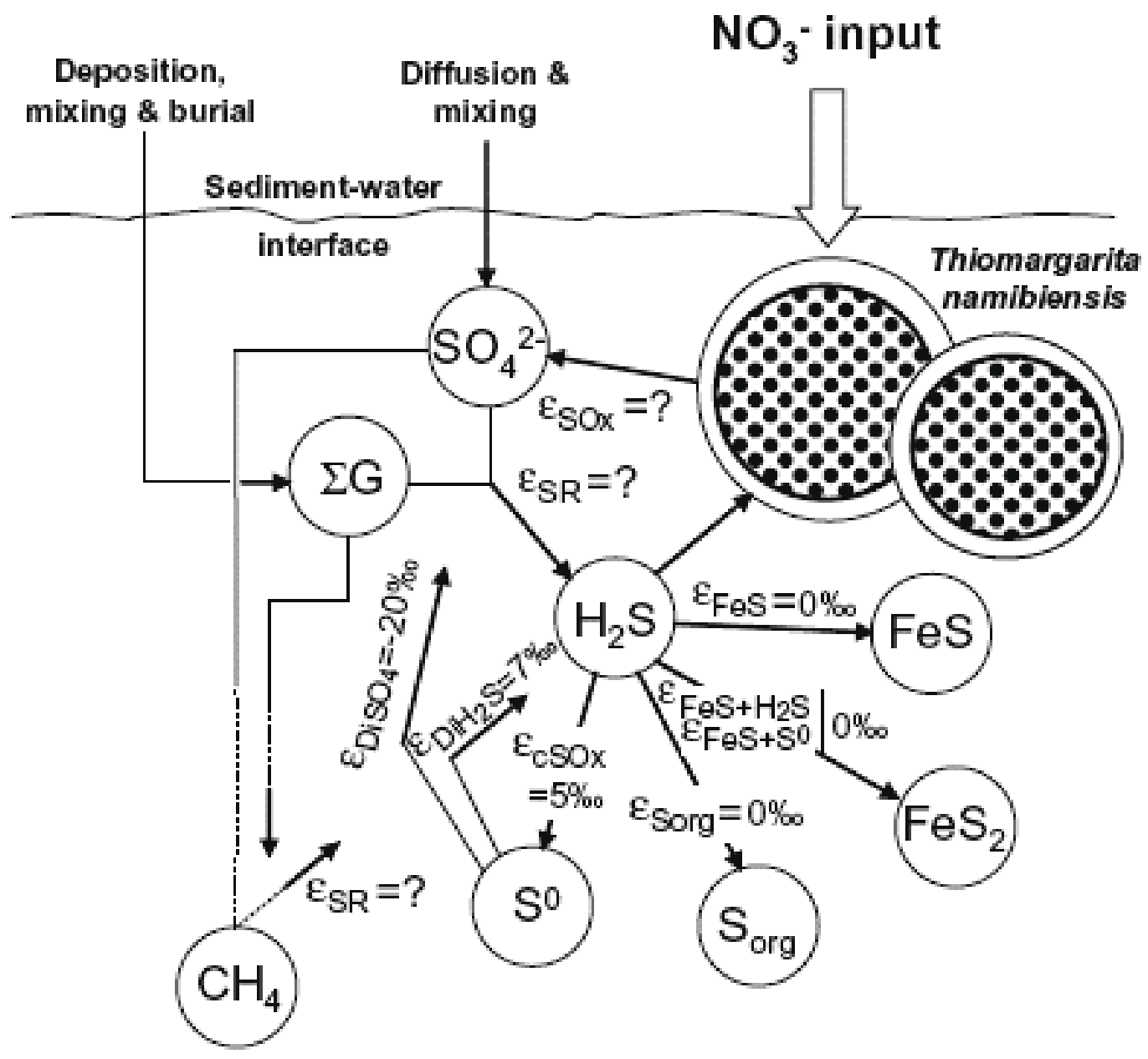

Figure 30. Conceptual model of the $\mathrm{S}$ isotope fractionations at the Namibia site from Dale et al. (2009). The $\varepsilon_{\text {SOx }}$ and $\varepsilon_{\text {SR }}$ fractionation factors that were constrained with the model are indicated by "?". The parameters used in the model accompanied with a detailed description of the reaction network can be found in Table 3 of Dale et al (2009). 


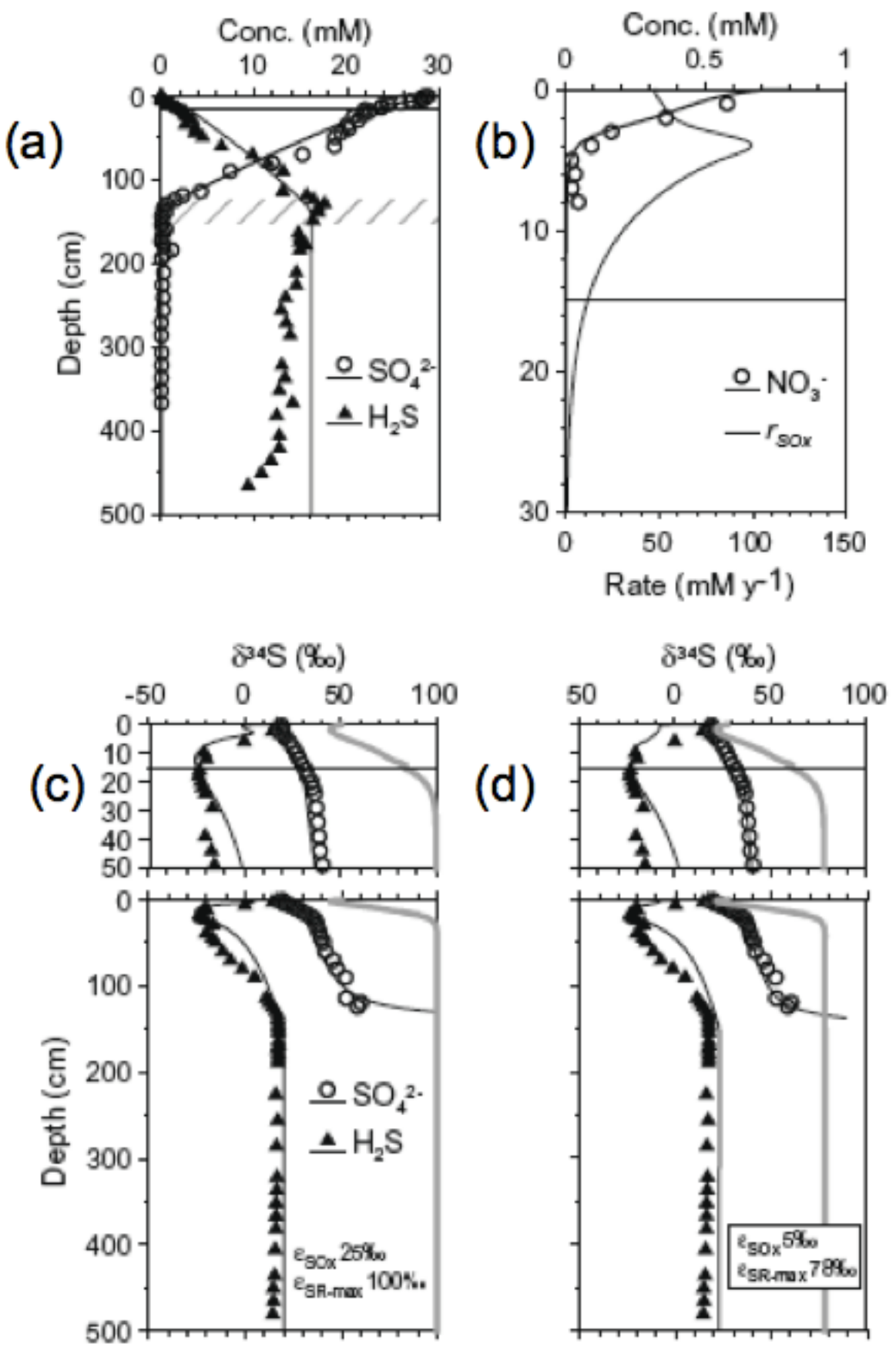

Figure 31. Summarized from Dale et al. (2009). (a) measured (symbols) and modeled lines (lines) for $\mathrm{SO}_{4}{ }^{2-}$ and $\mathrm{H}_{2} \mathrm{~S}(\mathrm{aq})$ profiles, (b) measured and model pore water $\mathrm{NO}_{3}{ }^{-}$profiles and the rate of microbial sulfide oxidation $\left(r_{S O x}\right)$ for the top $30 \mathrm{~cm}$; ( c) baseline model simulations using rates determined from elemental chemistry and values $\varepsilon_{\mathrm{SOx}}$ and $\varepsilon_{\mathrm{SR} \text {-max }}$ of 25 and $100 \%$ determined by best fit to the data ; (d) case with sulfide oxidation occurring with an additional disproportionation step and $\varepsilon_{\mathrm{SOx}}$ and $\varepsilon_{\mathrm{SR}-\max }$ of 5 and $78 \%$. Thick grey line shows the rate-dependent fractionation for sulfate reduction. 

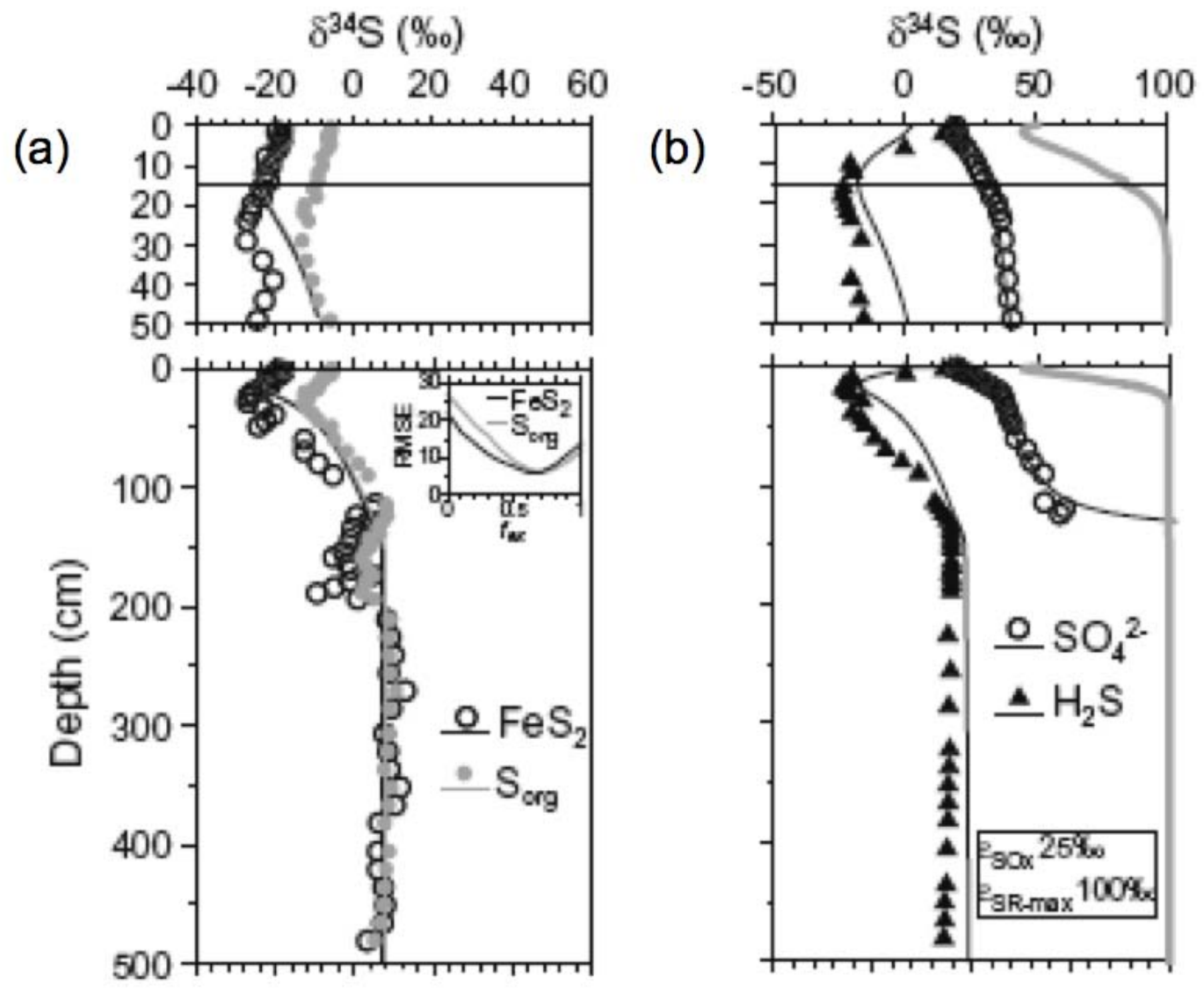

Figure 32. Summarized from Dale et al. (2009). (a) Model and measured $\delta^{34} \mathrm{~S}$ profiles for solid phases showing the model for the downhole decrease in $\delta^{34} \mathrm{~S}$ due to exchange between solids and the aqueous $\mathrm{H}_{2} \mathrm{~S}$; (b) measured (symbols) and modeled lines (lines) for $\mathrm{SO}_{4}{ }^{2-}$ and $\mathrm{H}_{2} \mathrm{~S}(\mathrm{aq}$ ) profiles. Thick grey line shows the rate-dependent fractionation for sulfate reduction. 
Table 1. Range of values of hydraulic conductivity and permeability (Bear 1972).

\begin{tabular}{|c|c|c|c|c|c|c|c|c|c|c|c|c|c|}
\hline $\mathrm{K}(\mathrm{cm} / \mathrm{s})$ & $10^{2}$ & $10^{1}$ & $10^{0}$ & $10^{-1}$ & $10^{-2}$ & $10^{-3}$ & $10^{-4}$ & $10^{-5}$ & $10^{-6}$ & $10^{-7}$ & $10^{-8}$ & $10^{-9}$ & $10^{-10}$ \\
\hline$\kappa\left(\mathrm{cm}^{2}\right)$ & $10^{-3}$ & $10^{-4}$ & $10^{-5}$ & $10^{-6}$ & $10^{-7}$ & $10^{-8}$ & $10^{-9}$ & $10^{-10}$ & $10^{-11}$ & $10^{-12}$ & $10^{-13}$ & $10^{-14}$ & $10^{-15}$ \\
\hline $\begin{array}{l}\text { Unconsolidated } \\
\text { Sand \& Gravel }\end{array}$ & \multicolumn{2}{|c|}{$\begin{array}{l}\text { Clean } \\
\text { Gravel }\end{array}$} & \multicolumn{3}{|c|}{$\begin{array}{l}\text { Clean Sand or } \\
\text { Sand \& Gravel }\end{array}$} & \multicolumn{5}{|c|}{ Very Fine Sand, Silt, Loess, Loam } & & & \\
\hline $\begin{array}{l}\text { Unconsolidated } \\
\text { Clay \& Organic }\end{array}$ & & & & & \multicolumn{2}{|l|}{ Peat } & \multicolumn{3}{|c|}{ Stratified Clay } & \multicolumn{4}{|c|}{ Unweathered Clay } \\
\hline $\begin{array}{l}\text { Consolidated } \\
\text { Rocks }\end{array}$ & \multicolumn{4}{|c|}{ Highly Fractured Rocks } & \multicolumn{3}{|c|}{ Oil Reservoir Rocks } & \multicolumn{2}{|c|}{ Sandstone } & \multicolumn{2}{|c|}{ Limestone } & \multicolumn{2}{|c|}{ Granite } \\
\hline
\end{tabular}


Table 2. Tracer diffusion coefficients of ions at infinite dilution in water at $25^{\circ} \mathrm{C}$. Modified from Lasaga (1998).

\begin{tabular}{|c|c|c|c|}
\hline Cation & $\begin{array}{l}D_{i} \times 10^{5} \\
\mathrm{~cm}^{2} / \mathrm{s}\end{array}$ & Anion & $\begin{array}{l}D_{i} \times 10^{5} \\
\mathrm{~cm}^{2} / \mathrm{s}\end{array}$ \\
\hline $\mathrm{H}^{+}$ & 9.31 & $\mathrm{OH}^{-}$ & 5.27 \\
\hline$\overline{\mathrm{Li}^{+}}$ & 1.03 & $\mathrm{~F}^{-}$ & 1.46 \\
\hline $\mathrm{Na}^{+}$ & 1.33 & $\mathrm{Cl}^{-}$ & 2.03 \\
\hline $\mathrm{K}^{+}$ & 1.96 & $\mathrm{Br}^{-}$ & 2.01 \\
\hline $\mathrm{Rb}^{+}$ & 2.06 & $\mathrm{I}^{-}$ & 2.00 \\
\hline $\mathrm{Cs}^{+}$ & 2.07 & $\mathrm{IO}_{3}^{-}$ & 1.06 \\
\hline $\mathrm{NH}_{4}^{+}$ & 1.98 & $\mathrm{HS}^{-}$ & 1.73 \\
\hline $\mathrm{Ag}^{+}$ & 1.66 & $\mathrm{HSO}_{4}^{-}$ & 1.33 \\
\hline $\mathrm{Mg}^{2+}$ & 0.705 & $\mathrm{NO}_{2}^{-}$ & 1.91 \\
\hline $\mathrm{Ca}^{2+}$ & 0.793 & $\mathrm{NO}_{3}^{-}$ & 1.90 \\
\hline $\mathrm{Sr}^{2+}$ & 0.794 & $\mathrm{HCO}_{3}^{-}$ & 1.18 \\
\hline $\mathrm{Ba}^{2+}$ & 0.848 & $\mathrm{H}_{2} \mathrm{PO}_{4}^{-}$ & 0.846 \\
\hline $\mathrm{Mn}^{2+}$ & 0.688 & $\mathrm{H}_{2} \mathrm{AsO}_{4}{ }^{-}$ & 0.905 \\
\hline $\mathrm{Fe}^{2+}$ & 0.719 & $\mathrm{H}_{2} \mathrm{SbO}_{4}^{-}$ & 0.825 \\
\hline $\mathrm{Co}^{2+}$ & 0.699 & $\mathrm{SO}_{4}^{2-}$ & 1.07 \\
\hline $\mathrm{Ni}^{2+}$ & 0.679 & $\mathrm{SeO}_{4}{ }^{2-}$ & 0.946 \\
\hline $\mathrm{Cu}^{2+}$ & 0.733 & $\mathrm{CO}_{3}{ }^{2-}$ & 0.955 \\
\hline $\mathrm{Zn}^{2+}$ & 0.715 & $\mathrm{HPO}_{4}{ }^{2-}$ & 0.734 \\
\hline $\mathrm{Cd}^{2+}$ & 0.717 & $\mathrm{CrO}_{4}{ }^{2-}$ & 1.12 \\
\hline$\overline{\mathrm{Pb}^{2+}}$ & 0.945 & $\mathrm{MoO}_{4}^{2-}$ & 0.991 \\
\hline $\mathrm{UO}_{2}{ }^{2+}$ & 0.426 & $\mathrm{PO}_{4}{ }^{3-}$ & 0.612 \\
\hline $\mathrm{Cr}^{3+}$ & 0.594 & & \\
\hline $\mathrm{Fe}^{3+}$ & 0.607 & & \\
\hline $\mathrm{Al}^{3+}$ & 0.559 & & \\
\hline
\end{tabular}


Table 3. Reaction network implemented in reactive transport modeling of Skagerrak sediments undergoing anaerobic oxidation of methane (Dale et al. 2008).

\begin{tabular}{|c|c|c|}
\hline Rate & Type & Reaction Stoichiometry \\
\hline $\mathrm{R}_{1}$ & hydr & $\mathrm{CH}_{2} \mathrm{O}_{\text {LAB }} \rightarrow 1 / 6 \mathrm{C}_{6} \mathrm{H}_{12} \mathrm{O}_{6(\mathrm{aq})}$ \\
\hline $\mathrm{R}_{2}$ & hydr & $\mathrm{CH}_{2} \mathrm{O}_{\mathrm{REF}} \rightarrow 1 / 6 \mathrm{C}_{6} \mathrm{H}_{12} \mathrm{O}_{6 \text { (aq) }}$ \\
\hline $\mathrm{R}_{3}$ & ferm & $1 / 24 \mathrm{C}_{6} \mathrm{H}_{12} \mathrm{O}_{6(\mathrm{aq})}+1 / 6 \mathrm{H}_{2} \mathrm{O} \rightarrow 1 / 12 \mathrm{CH}_{3} \mathrm{COO}^{-}+1 / 6 \mathrm{H}_{2(\mathrm{aq})}+1 / 6 \mathrm{H}^{+}+1 / 12 \mathrm{HCO}_{3}^{-}$ \\
\hline $\mathrm{R}_{4}$ & hySR & $1 / 2 \mathrm{H}_{2(\mathrm{aq})}+1 / 8 \mathrm{SO}_{4}^{2-}+1 / 8 \mathrm{H}^{+} \rightarrow 1 / 8 \mathrm{HS}^{-}+1 / 2 \mathrm{H}_{2} \mathrm{O}$ \\
\hline $\mathrm{R}_{5}$ & acSR & $1 / 8 \mathrm{CH}_{3} \mathrm{COO}^{-}+1 / 8 \mathrm{SO}_{4}^{2-} \rightarrow 1 / 8 \mathrm{HS}^{-}+1 / 4 \mathrm{HCO}_{3}^{-}$ \\
\hline $\mathrm{R}_{6}$ & hyME & $1 / 2 \mathrm{H}_{2(\mathrm{aq})}+1 / 8 \mathrm{HCO}_{3}^{-}+1 / 8 \mathrm{H}^{+} \rightarrow 1 / 8 \mathrm{CH}_{4}+3 / 8 \mathrm{H}_{2} \mathrm{O}$ \\
\hline $\mathrm{R}_{7}$ & acME & $1 / 8 \mathrm{CH}_{3} \mathrm{COO}^{-}+1 / 8 \mathrm{H}_{2} \mathrm{O} \rightarrow 1 / 8 \mathrm{CH}_{4}+1 / 8 \mathrm{HCO}_{3}^{-}$ \\
\hline $\mathrm{R}_{8}$ & $\mathrm{AOM}$ & $1 / 8 \mathrm{CH}_{4}+3 / 8 \mathrm{H} 2 \mathrm{O} \rightarrow 1 / 2 \mathrm{H}_{2}+1 / 8 \mathrm{HCO}_{3}^{-}+1 / 8 \mathrm{H}^{+}$ \\
\hline $\mathrm{R}_{9}$ & acet & $1 / 2 \mathrm{H}_{2(\mathrm{aq})}+1 / 4 \mathrm{HCO}_{3}^{-}+1 / 8 \mathrm{H}^{+} \rightarrow 1 / 8 \mathrm{CH}_{3} \mathrm{COO}^{-}+1 / 2 \mathrm{H}_{2} \mathrm{O}$ \\
\hline $\mathrm{R}_{10}$ & actr & $1 / 8 \mathrm{CH}_{3} \mathrm{COO}^{-}+1 / 2 \mathrm{H}_{2} \mathrm{O} \rightarrow 1 / 2 \mathrm{H}_{2}+1 / 4 \mathrm{HCO}_{3}^{-}+1 / 8 \mathrm{H}^{+}$ \\
\hline
\end{tabular}


Table 4: Summary of rate constants for Santa Cruz, terrace 5 (SCT 5)

\begin{tabular}{|c|c|c|c|c|}
\hline & & Albite $^{a}$ & K-feldspar ${ }^{b}$ & Kaolinite $^{c}$ \\
\hline & & $\begin{array}{c}\log \text { rate constant } \\
\left(\mathrm{mol} / \mathrm{m}^{2} / \mathrm{sec}\right)\end{array}$ & $\begin{array}{c}\log \text { rate constant } \\
\left(\mathrm{mol} / \mathrm{m}^{2} / \mathrm{sec}\right)\end{array}$ & $\begin{array}{c}\log \text { rate constant } \\
\left(\mathrm{mol} / \mathrm{m}^{2} / \mathrm{sec}\right)\end{array}$ \\
\hline Maher et al. (2009) & & $25^{\circ} \mathrm{C}$ & $25^{\circ} \mathrm{C}$ & $25^{\circ} \mathrm{C}$ \\
\hline TST Rate Law & & $-14.3 \pm 0.3$ & $-14.7 \pm 0.2$ & $-19.6 \pm 3$ \\
\hline Al-Inhibition Rate Law & & $-12.1 \pm 0.3$ & $-12.4 \pm 0.2$ & $-19.4 \pm 3$ \\
\hline Close-to-Equilibrium & Rate & & & \\
\hline Law & $\mathrm{k}_{1}$ & $-12.5 \pm 0.3$ & $-13.6 \pm 0.2$ & $-19.7 \pm 3$ \\
\hline & $\mathrm{k}_{2}$ & $-14.3 \pm 0.3$ & $-14.8 \pm 0.2$ & \\
\hline White et al. (2009) & & & & \\
\hline Weathering Gradient M & $\mathrm{del}^{\mathrm{d}}$ & -15.3 & -15.3 & n.d. \\
\hline
\end{tabular}

a: surface area of $1.94 \mathrm{~m}^{2} / \mathrm{g}$ (White et al. 2009), activation energy of $69.8 \mathrm{~kJ} / \mathrm{mol}$ (Hellmann and Tisserand, 2006).

b: surface area of $1.94 \mathrm{~m}^{2} / \mathrm{g}$ (White et al. 2009), activation energy of $38 \mathrm{~kJ} / \mathrm{mol}$ (Palandri and Kharaka 2004).

c: surface area of $10 \mathrm{~m}^{2} / \mathrm{g}$ (White et al. 2009), activation energy of $22.2 \mathrm{~kJ} / \mathrm{mol}$ (Palandri and Kharaka 2004).

$\mathrm{d}::$ at a flow rate of $0.058 \mathrm{~m} / \mathrm{yr}$ determined from fit to solid data using spreadsheet model.

n.d.: not determined 